\title{
Studies at the interface between anxiety and depression
}

Citation for published version (APA):

Overbeek, D. T. (2003). Studies at the interface between anxiety and depression. [Doctoral Thesis, Maastricht University]. Universiteit Maastricht. https://doi.org/10.26481/dis.20040616do

Document status and date:

Published: 01/01/2003

DOI:

10.26481/dis.20040616do

Document Version:

Publisher's PDF, also known as Version of record

\section{Please check the document version of this publication:}

- A submitted manuscript is the version of the article upon submission and before peer-review. There can be important differences between the submitted version and the official published version of record.

People interested in the research are advised to contact the author for the final version of the publication, or visit the DOI to the publisher's website.

- The final author version and the galley proof are versions of the publication after peer review.

- The final published version features the final layout of the paper including the volume, issue and page numbers.

Link to publication

\footnotetext{
General rights rights.

- You may freely distribute the URL identifying the publication in the public portal. please follow below link for the End User Agreement:

www.umlib.nl/taverne-license

Take down policy

If you believe that this document breaches copyright please contact us at:

repository@maastrichtuniversity.nl

providing details and we will investigate your claim.
}

Copyright and moral rights for the publications made accessible in the public portal are retained by the authors and/or other copyright owners and it is a condition of accessing publications that users recognise and abide by the legal requirements associated with these

- Users may download and print one copy of any publication from the public portal for the purpose of private study or research.

- You may not further distribute the material or use it for any profit-making activity or commercial gain

If the publication is distributed under the terms of Article $25 \mathrm{fa}$ of the Dutch Copyright Act, indicated by the "Taverne" license above, 
STUDIES AT THE INTERFACE BETWEEN

ANXIETY AND DEPRESSION 
$15 \mathrm{BN} 90-90-182-594$

Mot dank ant PMS Vijuadal, Smith Kline Beecham, El Lilly, Pfizer en lundbeck

Productic: Datawyse I Universinire Pess Maasticht 


\section{STUDIES AT THE INTERFACE BETWEEN ANXIETY AND DEPRESSION}

\section{PROEFSCHRIFT}

ter verkrijging van de graad van doctor aan de Universiteit Maastricht, op gezag van de Rector Magnificus, Prof mr GPMF Mols,

vollgens het beshuit van het College van Decanen, in het openbat te verdedigen

op woensdag 16 juni 2004 om 12.00 uur

door

Dina Theodora Overbeck 


\section{Promotor:}

Professor dr EJL Gricz

\section{COPROMOTOR:}

Dr KRJ Schruers

\section{BEOORDELINGSCOMMISSIE:}

Professor dr J van Os (voorzitter)

Professor dr C Faravelli, Florence University, Iraly

Dr F Pecters

Professor dr HM van Pragg

Professor: dr M de Vries 


\section{CONTENTS}

Intraductory section

1 Foreword

2 Epidemiology of anxiery disorders

Setion I. Prevalence of depression in panic disorder and absessive-compulane disorder

3 Comorbidity of depression and panic clisorder

4 Comorbidity of OCD and depression: prevallence, symptom severity and treatment effect

Section II. Panic disorder and associaled pbenomena

5 Suicidal ideation in panic disorder patients

6 Sleep complaints in panic disorder patients

7 Blood-injury related phobic avoidance as predictor of nonresponse to pharmacotherapy in panic disorder with agoraphobia

Settion III. The afferive spectrum in panta: an expeninnental approach

8 Experimental affective symptoms in panic disorder patients

Section IV. The imterface: another apprach

9 The interface between anxicty and depression: comorbidity and concepts

Stmmary and coniluding remarks

Samenwatting encondtrste

Dankwoon

Carricalum vitae

Ptibliations 



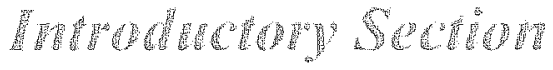





\section{FOREWORD}

The subject of this thesis is situated at the interface betwoen anxicty and depression. The term 'interface' has multiple meanings in different domains. 'Interface' commonly refers to a boundary betwecn two things, but can also refer to the overlap, and interaction between two theories or phenomena. Anxicty and depression can be viewed as separate entitics, but also as overlapping or interacting concepts. An interface serves a dual purpose: it separates as well as it connects. This is the central theme of this thesis.

Fear and sadness can be considered mormal counterparts of palbologial anxiety and depression. "They both describe normal human affects that can turn into pathology, or formal psychiatric disorders. Anxiety disorders and depressive disorders are the most prevalent psychiatric disorders, not only as discrete psychiatric disorders, but also in combined conditions, in which symptoms of both disorders coexist. These 'comorbid' conditions are usually characterized by higher severity, treatment resistance, and worse prognosis (Rapaport, 2001; Lecrubier, 2001). Because of their high prevalence, and impact on treatment and quality of life, these disorders are of major clinical importance. However, psychiatric comorbidity has received little attention in clinical practice or research.

The term to describe co-occurrence of psychiatric disotders in several forms is 'comorbidity'. It is frequently used, but inconsistently defined. Comorbidity is a complex and heterogencous construct, with several monings. It is originally derived from general medicine and refers to the existence of two (or more) separate disorders with their own etiology and pathophysiology, in the same patient. In psychiatry, the use of this construct is cause of serious concen (Bogenschutz and Numberg, 2000, Vella et al., 2000), which is partially explained by the nature of the current nosology in psychiatry. Classification systems used in psychiatry are generally not based on ctiopathogenests, but on a-theoretical, historically developed consensus agrecments, and have been argued to largely lack cmpirical foundation (van Ptaag, 2000). The prevailing diagnostic systems in modern western psychiarry, DSM-TV and ICD-10, provide operational criteria to make psychiaric diagnoses from a surfacedescriptive point of view, thereby cnabling the exchange of knowledge in corresponding terms. These systems, however, have clear shortcomings felated to the nature of their design. Diagnoses ate assigned when a certain number out of a discrete list of symptoms is present. The list is rather arbitrary, and 
many combinations of various symptoms can lad to similar diagnoses. Somerimes core symptoms between two disorders overtap ${ }^{2}$. Moreover, subsequent versions of DSM and ICD provide modified criteria and skip Hicrarchical rules from earlier vetsions, which has lead to large variations in prevalence rates of indwidual disorders and of comorbidity figures. To complicate matters even further, comorbidity has been defined differently in several studics. For example, comorbidity sometimes tefers to concurrent diagnoses (cross-sedional, or to lifetime diagnoses (co-sydromab), or to syndromal conditions in combination with symptoms of another disorder (swarnal-

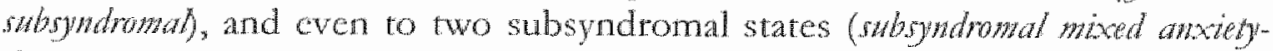
deprestion). Therefore, it is not sumprising that these issues have led to much confusion around the concept of comorbidity (Barbee, 1998). In every single study, albeit a clinical naturalistic study or a large scale population survey, a strict definition of the rem comorbidity as is applied, is required for a proper understanding of the study findings.

However, no science can do without classification; psychiatry needs systems like DSM of ICD. It is cleat that the current classifications also had a positive influence on psychiatry. The value lies in their use as a descriptive and classificatory tool, although their scientific basis should not be overated.

The studies on which this thesis is based were performed at the Academic Anxiety Center in Mastricht, an outpatient clinic for diagnosis and rearment of: anxiety disonders. The majority of the presented studies are clinical pidemiologic by nature, and describe prevalence data and namulistic treatment effect for anxiety disorders.

The introducrory chapter of this thesis provides a review of epidemiological stanfics on DSM-TV defined anxiety disorders. This chapter describes the backgtound for the subsequent chapters, which ate centered on the theme of comotbidity of anxicty and deprossion. The focus of the rwo chapters in Secion I is the prevalonce of comotbid depression in clincal samples of panic disoter pationts, and pationts suffering from obsessive compulsive disoter. These studics also empirically assess the implications of comorbid depression

1. Ahymosis af Major Depression can be made by the presence of depressed mood, weight

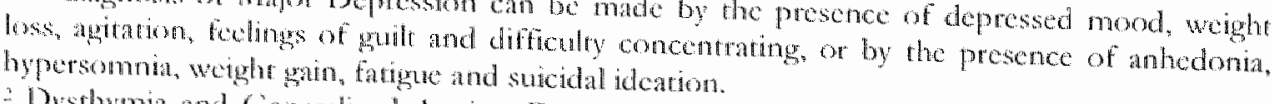

Dyshyma and Generalized Ansiey Disomder both share syptoms of poor concentration,

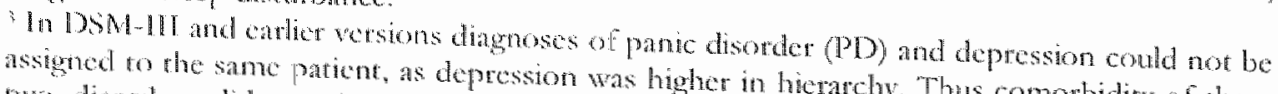

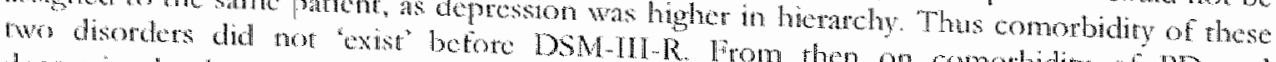
depression thas ben repoted in ange number of studies. 
for treatment outcome. This section is followed by the presentation of three clinical studies concerning associated features in panic disorder patients. The subject of the first of these studies is the occurrence of surcidal ideation in panic disorder patients, as previous studies have reported an clevated suicide risk in panic disorder. The second study focuses on subjective slep complaints in panic disorder patients. The hypothesis that noctumal panic attacks and comorbid depression are responsible for sleep difficulties is tested. The third chapter of Section II is a replication study, testing the predictive value of a high score on blood-injury phobia (-avoidance) for treatment outcome of panic disorder. Section III is an excursion into the laboratory, to test in an experimental condition the observation that panic disorder paticnts often report aggressive symptoms and mood changes during panic attacks. The $\mathrm{CO}_{2}$ challenge paradigm, which originally was developed in our own laboratory (Verburg et al., 2001), has been frequently used as an experimental model for panic disorder. This paradigm has been effective in selectively provoking symptoms of a panic attack in predisposed subjects. The study uses this provocation method to assess aggressive and depressive feelings in addition to anxiety. Section IV of this thesis goes beyond DSM terms and its disputed validiry. This chapter offers a conceptual approach to fear and sadness and discusses the relationship between anxiety and depression with reference to the evolutionary theories in psychiatry and a philosophical reflection.

\section{REFERENGES}

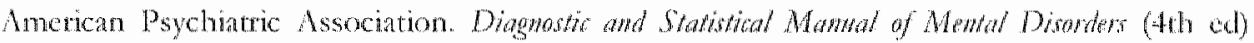
1994, Washington DC, American Psychiatric Press

Barbee JG. Mixed symptoms and syndromes of anxicty and depression: diagnostic, prognosic,

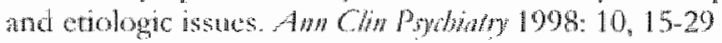

Bogenschutz MP and Nurnberg HC. Theoretical and methodological issues in paychiatric comorbidity. Han Rei Pydrawy 2000: 8, 18-24.

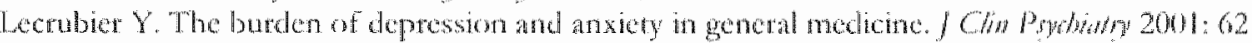
Suppl $8,4.9$

Rapaport, M. H. Prevalence, recognition, and trament of comorbid depression and anxicty. I Clu Pydratry 2001: 62 Suppl 24, 6-10

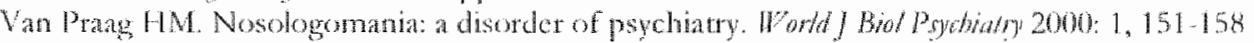

Volla G, Angona M and Nhan D. The complexity of psychiate comobidity: a onceptual and merhodological discussion. Pyolopalorology $2000: 33,25-30$

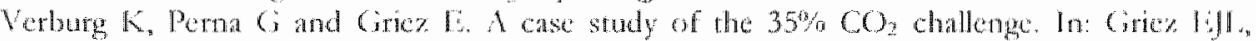

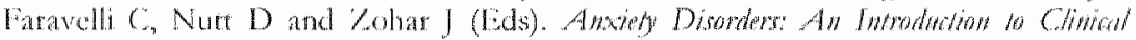

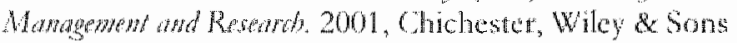

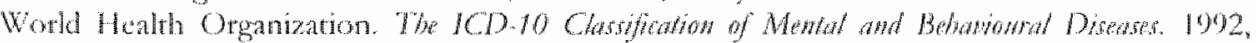
Genew, WHO 



\section{EPIDEMIOLOGY OF ANXIETY DISORDERS}

T. Overbeek, E. Vermetten and E. Griez

In: Griez EJL, Faravelli C, Nutt D and Zohar I (Eds). Amater) Disorders: An Introdaction to Chnical Management and Reseamd. Wiley \& Sons, Chichester, 2001 pp 3-23 

Anxiety disorders have a high impact on daily life (illness intrusiveness) and cause a great deal of suffering for the individual paticnt (Antony et al., 1998). They also have a substantial impacr economically and incur a great deal of expenditure by society as a whole. Greenberg et al. (1999) report a total of $\$ 42.3$ billion per year as direct and indirect expenses in the USA and there are no obvious reasons to assume that the picture for furopean countrics would be very different (Costa e Silva, 1998; Martin, 1998).

In the last decades some large epidemiological studies have provided much information about the occurrence of psychiatric disotders in general and anxiery disorders in particular. The Epidemiologic Catchment Area (IBCA) study and the National Comorbidity Survey (NCS) in the USA (both coordinated by the National Institute of Mental Health NIMH) and the Munich Follow-up study in Europe are examples of landmark studies in this field (Regier er al., 1990b; Kessler et al., 1994; Wittchen ct al., 1992). The World Health Organization (WHO) Study on Psychological Problems in General Health Care can be considered as an intermediate stage between epidemiological and clinical studies, and provides information on prevalence rates of mental disorders in primary care in 14 different countries world-wide (Sartorius et al., 1996). Many other clinical studies of specific target populations have yielded much information. Clinical studies often reveal different prevalence rates and comorbidity figures from population-based surveys and this is partly due to selection bias and severity of symptoms, and diagnostic criteria and instruments used. Therefore, Angst et al. (1997) advocate using subthreshold syndromes to enhance further the validity of dingnostic systems. They state that if subthreshold syndromes (especially concening depression and anxicty) were included in diagnostic systems, the coverage of treated cases would be improved by nearly a third.

All excellent existing studies notwithstanding, there are still many reasons to be careful in making clear statements about the prevalence of mental disorders. We are facing different studics conducted in different countries in various settings: findings cannor be easily compared or generalized. Epidemiological studies have often used different diagnostic instruments, different sampling procedures, different case definitions, different time frames for the diagnoses (e.g. lifetime, six-inonth prewalence or current diagnoses) and difictent severity ratings for diagnostic decisions (W/ttchen et al., 1992). The teservations above show the need for caurion when interpreting the results.

Knowledge about prevalence rates of mental disorder does not automatically imply what needs to be done. There is a diserepancy between the real occurtence of disorders and the need for treatment, of the possibility of finding 
the most adequate trearment for a diagnosed condition. Some filters can be taken into considetation. The first filter is recognition and correct diagnosis by the gencral practitioner. It is estimated that about $50 \%$ of cases do not pass this filter. The second filter is the most adcquate treatment of the diagnosed discase. Again, only half of the patients pass. When these two fulters are taken together, only roughly about $25 \%$ of disordered subjects finally receive adequatc treatment. In addition, for some disorders patients do not really need treatment, e.g. most specific phobias can be adequately dealt with by means of avoidance. This means that although specific phobias are much more prevalent than, for example, obsessive-compulsive disorder (11\% and $2-3 \%$ respectively), obscssive-compulsive disorder (OCD) should have preponderance.

Anxicty disorders are by far the most common psychiatric disorders (25\%), followed by major depression (17\%) (Kessler et al., 1994). Lifetime prevalence tatcs for all anxiety disorders lumped together as found in the NCS are $19.2 \%$ for men, 30.5\% for women (Kessler et al., 1994). There is a strong correlation between socio-economic status and anxiery disorders. The one year prevalence as based on ECA data is $12.6 \%$ for all types of anxiery disonders, compared to 14.6\% lifetime (Regier et al,, 1998).

A final important introductory cavcat is the issue of comorbidity. Comorbidity between disorders quite dramatically complicates the interpretation of many studies. Exen apart from the considerable comorbidity figures between the anxiety disorders themselves, comonbidity tates between anxiery disorders and depressive disorders are very high (especially panic disorder with agotaphobia, social phobia and OCD), ranging from $30 \%$ for co-existing in time to $60 \%$ lifetime. Comorbidiry tates between, for example, generalized anxiety disorder (GAD) or post-traumatic stress disorder (PTSD), and other psychiatric disorders are even higher, about $80 \%$ for GAD and $90 \%$ for PTSD lifetime figures.

The comorbidiry of anxicty disorders and depressive disorders in general practice is common, with the happy consequence that the chance of recognition and the likclihood of receiving treatment are increased (Sartorius et al, 1996). However, for the epidemiologist this is complicated further because there is also a substantial comorbidity between several medical conditions (e.g. cardiac, pulmonary, cerebrovascular, gastrointestinal, diabetes and dermatologic discases) and anxicty disorders (especially panic disorder, GAD and agoraphobia) (Stoudemire, 1996).

In this chapter the epidemiologic findings from some large population-based surveys and some smaller but relevant clinical studies will be reviewed. In doing so, DSM-IV anxiety disorders are artanged by diagnostic category (APA, 1994). 


\section{PANC DISORDER AND AGORAPHOBIA}

According to DSM-IV panic attacks are defined as sudden spells of unidentifed feelings consisting of at least four out of 13 symptoms as palpitations, chest strains, sweating, shottness of breath, feclings of choking, trembling, nausea, dizziness, paresthesias, chills or hot flushes, depersonalization or derealization, fear of dying or losing control. Although having panic atracks does not imply that the diagnosis of panic disorder (PD) can be male and isolated panic artacks are not diagnosed as a disorder, they are ofren associated with substantial morbidity and do have some clinical significance (Klerman et al., 1991).

In order to make a diagnosis of PD, additional criteria are that these atracks at least once have been unexpected, followed by at least one month of feaful expectation or concem about the consequences of an attack. In the DSM-TV criteria as to the frequency of the attacks (in DSM-III-R, APA 1984, threc attacks in a period of three weeks) are abandoned.

PD is frequently followed (or accompanied) by agoraphobia. Agoraphobia in DSM-IV is defined as (a) fear of being in places or situations from which escape might be difficult or help might not be available, (b) these situarions are avoided or endured with matked distress or the patient needs a companion, and (c) the fear is not better explained by another mental disorder.

As such, isolated panic attacks (as defined above) are quire frequent, estimated at $7-9 \%$ for lifetime prevalence rates, although rather heterogencous figures come from different countries (Pélissolo and Lépine, 1998). The ECA study on panic by Eaton reports $15 \%$ of all respondents have had a panic altack in lifetime, $3 \%$ in the past month, while $1 \%$ of the subjects meet criteria for PD in the past month (Eaton et al., 1994). In a survey among 1035 adolescents in Bremen, Germany, $18 \%$ of participants repotted having had at leat one panic attack (in a lifetme), with $0.5^{\%} \%$ of them moting DSM-IV criteria for PD (Essau et al., 1999).

\section{Pretalence}

The prevalence of PD, assessed with diagnostic criteria and structured interviews, has been found in the majority of surveys to have lifetime rates between $1.5 \%$ and $2.5 \%$. Twelve-month prevalence rates are gencrally about 1\% (Pélissolo \& Tépine, 1998).

Although PD can be diagnosed apart from agoraphobia, in clinical practice it is rare to find a parient suffering from PD who did not develop agoraphobia to a certain extent. This however is in contrast with the results from the NCS study, where it was found that $50 \%$ of PD patients report no agoraphobia (Iaton et al., 1994). Either way, it is infrequent to find an agoraphobic without a history of a panic attack. Horwath er al. (1993) have shown that epidemiologic studics that used the Diagnostic Interview Schedule and lay intcrvicwers, such as the 
BCA study, may have over-estimated the prevalence of agotaphobia without panic. The investigators took a sample of 22 ECA subjects diagnosed as having agoraphobia without panic attacks, and had them blindly reinterviewed. Reanalysis showed that only one of these subjects was left with the original diagnosis, one was assigned to having PD with agoraphobia, one had agoraphobia with limited symptom attacks, and the vast majority were reappraised as specific phobias (Horwath et al., 1993).

In addition, a recent study by Wittchen et al. (1998) in a community sample of 3021 young subjects (14 to 24 years) in Munich, Germany, addresses the relationship between PD and agoraphobia. They found that liferime prevalence of PD with agoraphobia was as high as for PD without agoraphobia, both being $8 \%$. Post hoc clinical review of the CIDI-positive agoraphobics revealed that many respondents did not have agoraphobia, but actually suffered from specific phobia, e.g. situational phobias. This resulted in a corrected agoraphobia prevalence of $3.5 \%$ instead of the original $8.5 \%$. However, even after this correction, the majority of respondents with confirmed agoraphobia were found not ro have a prior history of panic. However, in the NCS where agoraphobia was a separate diagnosis, it was found to have a lifetime prevalence rate of $6.7 \%$, and a one-month prevalence of $2.3 \%$ (Magee et al, $1990)$

\section{Denograpbics and rise factors}

Most studics reporting on PD or panic attacks consistently show higher rates for women than for men. Panic attacks are almost twice as common in women, whereas PD ranges from 1.5 to twice as much. The age at onset of PD in general lies in the mid-twenties, with hazard rates for women ranging from 25 to 35 years, for men between 30 and 45 years (Wittchen and Essau, 1993). Marital status is a significant risk factor for PD: the highest lifetime prevalence pares are found in widowed, separated or divorced subjects Wittehen and Lssau, 1993). On cducational level and risk for developing PD there are no consistent findings, Caron et al. (1994) report from the NCS data a tenfold higher risk for persons with less than twelve yeats of education. Several sndies have suggested that life events such as carly parental loss or childhood abuse may cnlance the tisk of PD, but there appears to be no speciffeity since this also applies to other psychiatric disorders as post-traumatic stress disorder and
affective disorders.

Other supposed risk factors ate smoking habits, although there is no consensus about causality or just corrclation because all psychatric patients smoke more that the general population. Breslau and Klein (1999) find evidence for smoking leading to PD. Others also indicate a role for smoking in developing PD (Pohl et al., 1992; Biber and Alkin, 1999; Amering et al., 1999). Another 
that have symptoms of shotness of breath can lead to anxiety in general and PD in particular (Smoller et al., 1999). It is shown that respiratory discase in childhood (especially bronchitis and asthma) predisposes to PD in later life (Zandbergen et al., 1991; Verburg et al, 1995; Pemat at., 1997). Aso, chronic obstructive pulmonary disorders can lead to PD in primarly lung patients (Wingate and Hansen-Flaschen, 1997), although the role of psychological factors, such as cognitive misinterpretation of bodily symptoms (e.g. shortness of breath) must be taken into account (Moore and Zebb, 1999).

\section{Natural conrie}

PD and agoraphobia seem to be a chronic condition, (Pollack and Smoller, 1995; Hirschfeld, 1996; Liebowitz, 1997) mostly with a fluctuating course with periods of waxing and waning (Liebowitz, 1997; Pollack and Otto, 1997). In some studies longitudinal aspects have been addressed, eg. in a three-year follow-up only $10 \%$ were shown to be symptom free (Noyes et al., 1990). Fatavelli et al. (1995) found that only $12 \%$ of PD patients after free years were in full remission. PD can be a very disabling disorder with high impact on daily life and social, personal and professional functioning and put a great burden on quality of life, (Candilis and Pollack, 1997; Candilis et al., 1999).

\section{Comorbidity}

Comotbidity of PD and agoraphobia is very common, as the panic attacks are often viewed as the precipitating cause for agoraphobia to develop ( $K$ lein and Klein, 1989). From this perspective, it is unnecessary to speak of true comorbidity, because the PD with agoraphobia can be considered one disease entity. The comorbidity of PD with agoraphobia is reported ranging from $29.5 \%$ to $58.2 \%$. In the NCS (Eaton et al., 1994) $50 \%$ of the PD patients had comorbid agoraphobia. Also, findings from the study of Wittchen et al. (1998), cited above, indicate that half of patients with PD also developed agoraphobic avoidance. There is also a high degree of comorbiclity with other anxicty disorders, such as social phobia (20-75\%, see Pélissolo and Iépine, 1998) and GAD $(20 \%), 14 \%$ for obsessive-compulsive disonder and $6 \%$ for post. traumatic stress disorder (Goisman et al., 1994).

The Munich Follow-up Study (Wittchen and Essau, 1993) also stresses the risk for PD patients of developing comorbid other psychiatric disorders. In more than half of the cases some comorbid disorder will develop over time. Maior depression (Merikangas er al. 1996) is the most frequent comorbid diagnosis, $30-60 \%$ of PD patients suffer from a depressive disorder Weissman er al. 1997). Most studies report a concurrent prevalence rate of about $30 \%$, with liferime prevalence of depression occurring in about $60 \%$ (Wetaler and Sanderson, 1995). Also, the NCS data have shown a lifetime prevalence of depression in PD patients of $55.6 \%$ (Kessler et al., 1998a). There are divergent 
vicws about the order of onset in comorbid PD and depression. In the ECA analysis it is shown that onset of panic is first in about $30 \%$ of cases, onset of depression precedes in another $30 \%$, and simultancous onset occurs in $40 \%$ (Regier et al., 1998). Also, some clinical studies have shown similar figures about the order of onset in comorbid PD and depression (Stein et al., 1990; Lydiard, 1991). Other clinical studies report that the onset of PD was first in about wo-third of comorbid cases (Hunt and Andrews, 1995). The clinical significance of comorbidity lies in the severity of symptoms at the outset (Andrade er al., 1994).

Substance abuse (alcohol, drugs and medication) is also a common comorbid disorder, in 36\% of cases, according to ECA data (Regier et al., 1990a). Most frequently, these abuse disorders are supposed to be secondary to the PD, and can be interpreted as self-medication (Marshall, 1997; Merikangas et al., 1998; Swendsen et al., 1998). Some authors, however, dispute this; Katerndahl and Realini (1999) for example found that the majority of drug and alcohol abusers report that the abuse started before the onset of the panic attacks.

The comorbidity of PD with other general medical conditions is described in a review by Zaubler and Katon (1998). It is shown that PD is common in cardiac, gastrointestinal, tespiratory and neurological disorders.

\section{SPICHECPHOBHA}

Specific phobias are the second most common anxiety disorder, after social phobia. They are, however, less impressive because they are mostly less incapacitating than other anxiety disorders. A specific phobia is defined as a circumscribed, persistent, and unreasonable fear of a particular object or situation. Exposure to this phobic stimulus is associated with an acute and severe anxicty reaction. Athough individuals with specific phobias recognize their fear is unrealistic, most adjust their lifestyle so that they can completely avoid ot at least minimize this contact (Eyer, 1998). Within the specific phobia category there is considetable heterogenciry. In the DSM-IV, four subtypes are defincd: animal phobias, situational phobias, blood-injury phobia, and naturecnvironment phobia. The first three have been differentiated on the basis of a combination of factors including age at onset, symptom response, heritability and biological challenges (Iyer, 1998; Verburg et al., 1994). On the separate position of the nature-covironment phobin there is less consensus (Fyer, 1998).

\section{Prowlence}

The NCS rates for one-month and lifetime specific phobia are $5.5 \%$ and $11.3 \%$ respectively (Magee et al., 1996). Among women, fear of animals is most frequent; fear of heights is most prevalent in men (Curtis et al., 1998). In a study addressing blood-injury phobia a lifetime prevalence of $3.5 \%$ was found, and a 
men age at onset of 5.5 years. Aso noteworthy is that none of the subjects had ever sought professional theatment (Bienvenu and Eaton, 1998).

\section{Demographics and risk factoms}

Female to male ratio for specific phobia is $23: 1$. In the NCS females had a lifetime prevalence of $15.7 \%$ and men $6.7 \%$ (Kesslet et a1. 1.994).

\section{Natural cowrse}

Simple phobia appeared in a study by Goisman et al. (1998) to be a chronic ilness of moderate sevetity for which behavioral treatment methods of recognized efficacy were infrequently being used. The number of cars, independent of type, ptedicts impaiment and professional help-secking (Chapman et al., 1993; Curtis et al., 1998).

\section{Comorbidity}

Simple phobia is highly comorbid with other disorders; $83.4 \%$ of persons with simple phobia teported at least one lifetime comorbid disorder (Magee er al., 1996). The other anxiery disorders and major deptession are most frequent. Also, specific phobia is frequently diagnosed as a comorbid disorder in other anxiety disorders (Goisman et al., 1998).

\section{SOCHL PHOBIAS}

In recent years social phobia has gained mote professional and public interest and increasingly is being recognized as a real anxiety disorder for which treatment can offer an improvement of the patients' quality of life (Kasper, 1998). Social phobia (social anxiety disorder) usually is rather disabling, characterized by matked fear of performance, excessive teat of scrutiny, and fear of acting in a way that may be embarrassing. Most patients are oversensitive to the assumed opinion of others and have a low self-estech, although they feel their fears are exaggetated and out of proportion. Going through the feared situations, or even anticipating them, most people suffer from physical symptoms like sweating, trembling or blushing, and these symptoms can become a trigger on their own to worry about soctal consequences. This all can lead to avoidance of many social struations, or they endure these situations with extreme anxiety or distress (Jiebowitz, 1999). As in all cases of phobias, the individual recognizes that his or her fears are unreasonable.

Social phobia can be divided in two subtypes. The first is gencralized social phobia (or complex social phobia), patients being anxious in most situations, concerning performance and interactional situations. The parient with nongeneralized social anxiety disorder being scared of only one or two (ustual 
performance-related) social situations, such as public speaking, or other public performance, such as writing or eating in front of others (Stein and Chavira, 1998; Mouticr and Stein, 1999). Both types, however, tend to be underdiagnosed and undertreated (Stein and Chavira, 1998). There are some differences berween the stbgroups; the generalized type has even less chance of spontancous tecovery than the non-generalized. In the generalized subtype there is a stronger genetic factor (Kessler et al., 1998b). The generalized subtype is usually more invalidating and carries a higher risk of comorbidity. Age of onset does not differ between the subtypes.

Differential diagnoses for social anxiety disorder are: major depression with social withdrawal, PD with social avoidance, agoraphobia, GAD, OCD, and body dysmorphic disorder. Another important disorder to differentiate from social phobia is the DSM-TV axis II avoidant personality disorder. Although often seen as comorbid disorder, it is becoming increasingly clear that much avoidant personality disorder as defined by DSM-IV merely denotes a subgroup of patients with axis I generalized social phobia (Moutier and Stein, 1999),

\section{Prepalence}

Among the anxiety disorders social phobia nowadays is consideted the thind most common psychiatric disorder $(13.3 \%)$, exceeded in lifetime prevalence only by major depression (17.1\%) and alcohol dependence (14.1\%) (Kessler et al., 1994), at least in the United States according to the NCS data. Prevalence rates for social phobia have increased in last decades. Earlier surveys, based on DIS and DSM-III criteria gave figures ranging from $2 \%$ to $4 \%$ (Pélissolo and lépine, 1998). The ECA survey, for example, found one-month prevalence of $1.3 \%$, a six-month prevalence of $1.5 \%$ and a lifetme prevalence of $2.8 \%$ (Schneice et al., 1992). Subsequent studies, based on DSM-III-R criteria and CIDI-intervicus which explore more abundant and diversified social situations, reveal more elevared lifetime prevalenecs for social phobia, between $4.1 \%$ and $16 \%$. The NCS study found a one-month prevalence of $4.5 \%$ and a lifetime prevalence of $13.3 \%$ (Magee et al., 1996).

A study by Woller and others (1996) conducted in a general health care setting tercaled a one-month prevalence of $4.9 \%$, and a liferime prevalence of $14.4 \%$. They also stress that social phobia is underdiagnosed by general practitioners, in only $24.2 \%$ of the social phobics a diagnosis of anxiety disorder was made. When occurring with a comorbid depression even fewer patients were diagnosed as having a social phobia, although the presence of a comorbid depression increased the chance of diagnosing a psychological disorder. Nevertheless, it should be noted that in some epidemiologic studies conducted in the Tar East much lower liferime prevalences are found, about $0.5 \%$ (Lepine and Lellouch, 1995). It is uncleat whether this occurs on account of a cultural 
bias of response or because of true psychopathological cross-culnual differences.

\section{Domagrablics ond risk factors}

Most surveys mention a slight preponderance of women in social phobia (1.5 times as many as men). The NCS reports lifetime prevalence for women of $15.5 \%$ and tor men 11.1\% (Magee et al. 1996). In a sudy specincally addessing gender differences in social anxiery disonder (Weinstock, 1999) the authors state that although women ate more dikely to have social phobia, men are more likely to seek treatment, possibly explained by difterences in gendet roles and social expectations. There seems to be a difference in foared items between men and women: concems about eating in testaurants and writing in public were more common in men, problems with using public restrooms and speaking in public were more common in women.

Social phobia is more frequenty found at a younger age (18 to 29 years), anong the less educated, the single, and the lower socio-economic chas Schneier et al., 1992). The Weiller et al. (1996) study showed an unemployment rate of $9.3 \%$, compared with $1.3 \%$ for the control group. Employment status was also poor in the ECA study; social phobics changed their jobs more often and showed more absentecism (Davidson et al., 1993).

\section{Natmal contre}

Typically social phobia has an onset in puberty and is often preceded by a general shyness in eatly youth (1iebowitz, 1999). The natural course tends to be chronic, untemitring and in course of time increasingly complicated by comorbid disorders. Because of the early age of onset, the disorder stongly influerces further psychological developmont, formation of rolationships, cducational choices and cateer perspectives (Davidson er al., 1993).

\section{Comorbidity}

As it is the case for PD, in social phobia as well, the comorbidity rate is high. Around $80^{\circ} \%$ of social phobia co-exists with other disorders (1.cpine and Pelissolo, 1996; Mongomery, 1998). In particulat, lifecime depression is high, about $70 \%$, as well as other anxiety disonders. PD was diagnosed in 49\%, G AD in $32 \%$ and OCD in 11\% of social phobics (Van Ameringen et al., 1991). However, this study only comptised 57 subjects. Analysis of a part of liCA dara with 123 social phobics revealed that $11.6 \%$ of them had lifetime $P D, 45 \%$ had comorbid agomphobia, $60.8 \%$ had specific phobia, and 26.9\%, had (3) D (Davidson et al, 1993). The data from the NCS showed comorbidity with PD in $10.9 \%$ of cascs, with agoraphobia in $23.3 \%$, GMD in $13.3 \%$ and specific phobia in $37.6 \%$ (Magee et al., 1996). 
Because of the eatly onset of social phobia, most often (in $70 \%$ of cases) the comorbid disorders appear secondary to the social phobia (Schneier et al., 1992).

The relationship between social phobia and alcoholism is a complex one. Reported prevalence rates vary widely, due to differing definitions, and methodological differences (Lepine and Pelissolo, 1998). Most studies on socia! phobia in patients with alcohol problems, abuse or dependence, report prevalences about 10 to $20 \%$. Studies addressing social phobic patients teport alcoholism in about 14 to $40 \%$ of cases. The social phobia most often predates the onser of alcohol problems. Although many social phobia sufferers use alcohol in an attempt to self-medicate their distressing anxiety symptoms, it appears that alcohol can actually increase anxiety, and at cycle may develop in which the sufferer drinks in order to relieve increasing levels of anxiety (Lepine and Pelissolo, 1998).

\section{OIBSTSSEVICOMPUISIVE DISORDER}

Obsessive Compulsive Disorder (OCD) is defined as the presence of tecurrent obsessions (persistent thoughts, impulses, or images) or compulsions (repetitive behavior or thought patterns induced in an attempt to prevent anxiety) that are excessively time-consuming (taking more than an hour a day) or cause marked distress or significant impairment. The subject rocognizes that these patterns are excessive.

Differential diagnosis of OCD includes GAD, PD, phobias, compulsive personality disorder, and hypochondriasis. Whille many of these syndromes are characterized by intrusive thoughts, few have associated rituals. The complex tics seen in some patients with "Tourette's syndrome may be difficult to distinguish from the compulsions seen in OCD, and, in fact, there is significant overlap in symptoms between whe two disorders (Rasmussen and Eisen, 1992). Although the phenomenology of OCD appears to be quite diverse, with many. distinct kinds of obsessions and compulsions, there ate three important core fearurcs: abnormal risk assessment, parhologic doubt, and incomplereness. These features cut across phenomcnological subtypes and may be useful in defining homogeneotis subgroups with distinct treatment outcomes (Rasmussen and Eisen, 1992). Pigot (1998) also describes core features of $O C D$ and subdivides them in two categories: altered risk appraisal versus need
for complete-ness/symmemy.

\section{Prevalence}

for OCD prevalence figures have been gradually growing over the years, as is the case for social phobia. Formerly OCD was rhought to be quite rare, as people did not easily request treatment due to fear or shame Rasmussen and 
Eisen, 1992). Recent epidemiological studies have shown a six-month prevalence rate of OCD of approximately 1\% (Bebbington, 1998), to a lifetime prevalence tate of 2-3\% (Hollander, 1997; Sasson et al. 1997), which means that OCD is much more common than previously suggested. Hollander (1997) calls OCD 'the hidden epidemic', where socinl phobia has been called 'the neglected anxiety disorder' (Liebowitz, 1999). An carliet cross-national study by Weissman et al. (1997), using DSM-III criteria, reports annual prevalence rates ranging from $1.1 \%$ in Korea and New Zealand to $1.8 \%$ in Puerto Rico. The only exception was Tawan $(0.4 \%)$, which has the lowest prevalence ates for all psychiatric disorders (Weissman et al., 1994).

Unfortunately one of the best epidemiological studies in the U.S.A. the NCS did not address OCD because the diagnostic instrument used (the CUDI) excluded these cases (Bebbington, 1998).

\section{Demographics and riste factors}

The cross-national collaborative study examined $O C D$ in seven different countries and found rather consistent figures. Age of onset was mid-tomate rwenties. Female to male ratio ranged from 1.2 to 3.8 (Weissman et al., 1994), but earlier studies (among which was the ECA) reported an equal sexdistribution.

In a study that specifically addressed gender differences in a clinical sample of OCD patients Castle et al. (1995) found a male to female ratio of 1:1.35. Mcan age of onset for men was 22 years, for women 26 years. Mean age at assessment did not differ significantly, 32.8 years for men and 34.6 years for women.

\section{Nahurat course}

OCD has a chronic course, and few patients achieve true remission. Although symptoms may fluctuate over time, the disorder rarely is resolved spontaneously without approprate treatment (Goodman, 1999). Full remission of OCD symptoms is rare, but episodic improvement in OCD symptoms is not uncommon (Pigot, 1998). In a 40-ycar follow-up of 122 OCD patients, Skoog and Skoog (1999) substantiated these generalities: $20^{6 \%}$ achieved complete recovery, $28 \%$ recovery with subclinical symptoms, another $35^{\text {th }} \%$ still had clinical symptoms but did improve. Some $4.8 \%$ had OCD for more than thirty years.

\section{Comorbidity}

Depression is the most frequent complication of OCD, as reported in several studies (Black and Noyes, 1990). Comotbidiry tares in repotted studies vary widely, from $19 \%$ to $90 \%$ (Milanfranchi et al., 1995). Within this wide range, however, most epidemiological studies show that about one thitd of OCD 
patients suffer from a lifetime depressive episode. In chicical populations, comorbidity rates are increasing to about two-thirds (Crino and Andrews, 1996). Rasmussen found that one third of OCD patients suffer from concurrent depression at referral, and rwo-thirds suffer from lifetime depression (Rasmussen and Eisen, 1994), a similar finding as in PD. One explanation of the discrepancy berween clinical and nonclinical studies could be that many OCD patienrs only seek help when depressed, as suggested by Black and Noyes (1990). As to chronology, it is found that most often the onset of OCD is before the depression (38\%), transition from depression to OCD occurs in only $11 \%$ of cases (Black and Noyes, 1990).

Personality disorders are frequenty diagnosed in OCD, but may remit with cffective antiobsessional treatment (Pigott, 1998). This questions the validity of the axis II diagnosis at the ourset. Also, a study by Ricciardi et al. (1992) showed that among 17 patients with $O C D$ and concomitant personality disorder, after treatment nine out of ten responders no longer met the personality disorder-criteria (Ricciardi et al., 1992).

$O C D$ also co-exists with a number of other Axis I disorders including PD (54\%, Crino and Andrews, 1996), social phobia (42\%, Crino and Andrews, 1996), cating disorders (17\%, Rasmussen and Eisen, 1994), and Tourette's disorder $(5 \%$, Black and Noyes, 1990). Crino and Andrews (1996) remark that the high comorbidity of $P D$ and social phobia in $O C D$ is in contrast to the low comorbidity of OCD in primary PD or social phobic patients. However, they did not find any different rate of comorbid depression among the anxiety
disorders.

\section{GINERALIZED ANXIETY DISORDER}

The concept of generalized anxicty disorder (GAD) is subject to discussion. Although the disorder is regarded as prevalent in primary care as well as in specialized settings, because of the high comorbidity rates associated with GAD the controversy is about wherher to consider $G A D$ as a independent disonder or as a residual or prodrome of other disorders (Wittchen et al., 1994). The diagnostic category of GAD has changed a lot in the past two decades (Brawman-Mintzer and Lydiard, 1996). The shifung diagnostic criteria, the relative low diagnostic reliability, and questions regarding the diagnostic validity probably contributed to the relative little atrention that has been paid to the investigation of GAD compared with most other anxiety disorders (Brawman-
Muntzer and Lydiatd, 1996).

\section{Prevaline}

The most wecent epidemiologic study using DSM-III-R criteria is the NCS in the United States. The prevalence rate for current GAD was $1.6 \%, 12$-month 
prevalence was $3.1 \%$ and liferime prevalence for GAD was $5.1 \%$ (Wittchen et al., 1994). These figures make GAD more common than PD in the NCS. It is shown that GAD is more common in primary care, and one of the least common anxiety disorders in mentall health centers (Btawman-Mintert and Lydiard, 1996).

\section{Demographics and risk factors}

GAD is twice as common among women as among men. In the age group berween 25-35 years the prevalence is highest (Wittchen er al., 1994). Risk factors for GAD are being separated, widowed or divorced (the same risk factors as for $\mathrm{PD}$ ), and also unemployment or being a homemaker is a significant correlate of GAD. However, another recent study (Bienvenu et al, 1998) suggests that being widowed is not a risk factor.

\section{Natural conse}

GAD appears to have a chronic course. Woodman et al. (1999) conducted a five-year follow-up study comparing primary GAD patients to PD patients. At baseline the GAD subjects were significantly older, had a higher level of education and occupational class, earlier age of onset and longer illness dutation. At follow-up, significantly more GAD patients continued to meet full criteria for the baseline disorder, and fewer were in partial or complete remission or had fluctuations. Although global severity, measured by clinical global impression (CGI), was less at baseline, at follow-up the improvement on the CGI was significantly less for the GAD patients compared with the PD patients. Findings from this study support the validity of the GAD concept, in view of the diagnostic stability and different natural course (Woodman et al., 1999).

\section{Consorbidity}

Lifetime comorbidity for GAD is very high, $90.4^{\%} \%$ of cases (Witrchen et al., 1994). The strongest comorbidities are with affective disorders (mania 10.5\%, major depression $62.4 \%$, dysthymia $39.5 \%$. Comorbidity figures with other anxiety disorders are $23.5 \%$ for $\mathrm{PD}, 25.7 \%$ for agotaphobia, $35.1 \%$ for simplc phobia and $34.4 \%$ for social phobia. Alcohol abuse and dependence was seen in $37.6 \%$ of cases and drugs in 27.6\%. Another study by Brawman-Mintzer et al. (1993) reports comorbid social phobia in $23 \%$ and simple phobia in $21 \%$ of cases as the most frequent, after excluding lifetime depression. The high comorbidity figures have led to disagreement concerning the existence of GAD as an independent diagnostic entity, and to assumptions that $G A D$ is a prodrome or residual of other disorders (Brawman-Mintzer and Lydiard, 1996). Nlso, at least partly the same genetic factors contribute to major depression and GAD, as shown by Kendler (1996). However, in the NCS it is shown that at 
least $30 \%$ of current GAD patients had neither current nor recent (but only lifetime) comorbid disorders. This is put forward by the authors as supporting the validity of GAD as an independent diagnosis (Wittchen et al., 1994), although this does not preclude GAD from being a prodrome of any other disorder.

GAD is frequently seen in primary health care, and especially in patients with medically unexplained somatic complaints such as chest pain and irritable bowel symptoms (Roy-Byrne, 1996). As such, it is also associated with somatization disorder and chronic fatigue syndrome (Fischler et al., 1997). Comorbidity with axis-II disorders is also high, reported up to $49 \%$ (Sanderson ct al., 1994).

\section{PGSTTRAUMATICSTRISS DISORDTRR}

The DSM-IV definition for post-traumatic stress disorder (PTSD) contains criteria for (a) the raumatic experience; (b) re-experiencing; (c) avoidance of associated stimuli and numbing; (d) increased arousal. Duration of symptoms should be at least one month $(\mathrm{e})$, and $(\mathrm{f})$ distress or impairment in functioning is reguired (APA, 1994). When PTSD was first defined in DSM-III (APA, 1980) the original stressor criterion characterized traumatic experiences as being outside the range of human experience. However, when the prevalence of such events was systematically examined it became apparent that trauma is surprisingly commonplace. Several studies have investigated the overall prevalence of tratumatic events in the general population looking both at community-based populations and populations of indrviduals at high risk for trauma or exposed to events such as natural disasters (Acierno er al., 1999). The nature of the trauma can be very diverse, such as childhood abuse, traffic accidents, fires, violent assault, robberies and floods or earthquakes.

\section{Prwalence}

Prevalence rares have increased from DSM-III to DSM-III-R and DSM-IV. Also, in some relephone interview surveys prevalence is much higher, and in studies among young persons where recall-bias may be minimal. Kessler et al. (1995) reported about the National Comorbidity Surwey of 5877 persons, aged 15 to 54 years. The estimated lifetime prevalence of PTSD was found to be $7.8 \%$ (Kesslet et al, 1995).

In rourine clinical practice, PTSD is often underdiagnosed if the PTSD is not the presenting complaint, but an additional diagnosis (Zimmerman and Mattia, 1999). The same comment, however, can be made for other anxiety disorders, as social phobia (Kessler et al., 1999). Reasons for misdiagnosis of PrTSD include a high tate of comotbidity, patient denial or minimization, overly high diagnostic thresholds set by clinicians, or failure to take a trauma history 
(Davidson and Connor, 1999). In a cohort study of 185 persons involved in a raffic accident and a hotel-fire Maes et al. (1998) found after seven to nine months a prevalence of DSM-III-R PTSD of $23 \%$. Almost $50 \%$ of them had symptoms the first day, about $70 \%$ developed PTSD symptoms during the first week after the event.

In one study, victims of substantiated child abuse and neglect were assessed and compared with a group of matched non-abused and non-neglected children and followed into adulthood. Victims of child abuse (sexual and physical) and neglect were found to be at increased risk of developing PTSD. More than a third of the childhood victims of sexual abuse $(37.5 \%), 32.7 \%$ of those physically abused, and $30.6 \%$ of victims of childhood neglect, met DSMIII-R criteria for lifetime PTSD. Childhood victimization, however, is not a sufficient condition for developing PTSD, also family, individual, and lifestyle variables place individuals at risk and contributed to the symptoms of PTSD (Widom, 1999).

North et all. (1999) report on a follow-up on the terrorist Ofilahoma City bombing in 1995 where a bomb blast killed 168 people. In their sample of 182 participating adults, $45 \%$ had a post-disaster psychiatric disorder and $34.3 \%$ had PTSD. The onset of PTSD was swift, with $76 \%$ reporting same-day onset. The relatively uncommon avoidance and numbing symptoms virtually dictated the diagnosis of PTSD (94\% meeting avoidance and numbing criteria had full PTSD diagnosis) and were further associated with psychiatric comorbidity, functional impaiment, and treatment received. Intrusive re-experiencing and hyperarousal symptoms were nearly universal, but by themselves were generally unassociated with other psychopathology or impaiment in functioning (Notth et al., 1999).

\section{Demongraphics and riske factors}

NCS data showed that prevalence was clevated among women and the widowed, separated or divorced. The traumas most commonly associated with PTSD were combat exposure and wimessing of violence among men, and rape and sexual molestation among women.

A varicty of factors influence response to trauma and development of PTSD. They include characteristics of the stressor and exposure to it (c.g. repeated trauma increases the tisk); inclividual factors such as gender (females are at higher risk), age and developmental level (the younger are ar higher risk), and psychiatric history, family characteristics, and cultural factors (Pfefferbaum, $1997)$.

\section{Natural conrse}

In the NCS survival analysis showed that more than one-third of people with an index episode of PTSD failed to recover even after many years (Kessler ot 
al., 1995). Among the subjects who had ever sought professional help (58\% of affected respondents) the medarn time to remission was 36 months, among those who did not seck help the median time to temission was 64 months. A study of 61 Vietnam combat veterans with PTSD showed that onset of symptoms typically occurted at the time of exposure to combat trauma in Victnam and increased rapidly during the first few years after the war. Symptoms plateaued within a few years after the war, following which the disotder became chronic and unremitting. Hyperarousal symptoms developed first, followed by avoidant symptoms, and finally by symptoms from the intrusive cluster. The onset of alcohol and substance abuse was associated with the onset of PTSD symptoms, and the increase in use paralleled the increase of symptoms (Bremner et al., 1996). Another recent study of Gulf War vetetans showed that PTSD increases over time, two years after the war $8 \%$ of 2949 veterans developed a PTSD, compated with 3\% immediately following the war Wolfe et al., 1999).

\section{Comorbidity}

Post-traumatic stress disorder in the NCS findings was strongly comorbid with other lifetime DSM-III-R disorders. A lifetime history of at least one disorder was present in $88.3 \%$ of men, and $79 \%$ of women with lifetime PTSD (Kessler et al., 1995). Frequent comorbid diagnoses are: affective disorders (almost $50 \%$ of cases for major depression, $20 \%$ for dysthymia), other anxiety disorders (16\% GAD, 9\% PD, 30\% specific phobia, 28\% social phobia, $19 \%$ agoraphobia), substance use disorders (52\% alcohol and $34 \%$ drugs in men, $28 \%$ alcohol and $27 \%$ drugs in women) and conduct disorder (43\% in men and 15\% in women) (Kessler et al., 1995), and somatization (McCauley et al., 1997).

\section{CONCIUSION}

The authors would like to end by the beginning, referring to the caveats mentioned in the introduction of the present chapter. There are still other matters of concern: the frequent use of lay interviewers in major surveys, recall bias in interviews over lifetime span, the $\mathrm{key}$ issue of defining a threshold for clinical significance, just to name a few. It follows that in spite of the apparent evidence, cxtreme caution should be exercised when interpreting the epidemiology of anxiety. 


\section{REFERENCES}

Aciemo R, Kilpatrick DG and Resnick HS. Postramatic stress disorder in adults relative to criminal victmization: Prevalence, nisk factors, and comotbidin Sagh Ph, Bremet

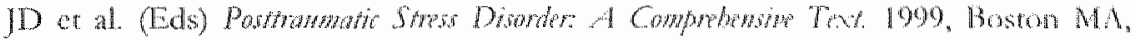
Aly \& Bacon. $44-68$

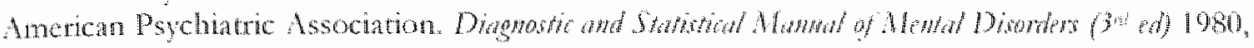
Washington $D C$, American Pychintric Press

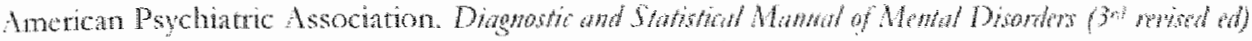
1987, Washington DC, Amutrican Pswchatric Press

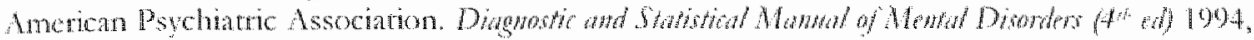
Washoton DC, Amencan Psychiaric Press

Amering M, Bankier B, Berger P. Griengl H, Whohaber I and Katschig H. Panic disoder and cigarette smoking behavior. Confs Pydhaty, 1990:40,35-38

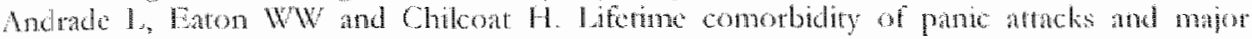
depression in a populaton-based study. Symptom peofics. Br J Prowizhy 1994: 165. $363-369$

Angst J, Merikangas KR and Prewig M. Subrhreshold syndiomes of deprossion and anxicy in

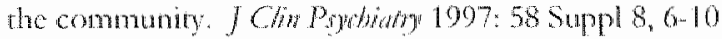

Antony M, Roth D, Swinson RP, Hua V and Devins C M. Tllness intusiveness in individuals with panic disorder, obsessive- compulsive disonder, or social phobia. I Nepu Ment Dis 1998: $186,311-315$

Bebbington PE Epidemiology of obsessive-compulsive disonder. Br Psydiatry 1998 : Suppl $2 \%$.

Biber $B$ and Nkin T. Panic disorder subtypes: differential responses to $\mathrm{CO}_{2}$ challenge. Atn I Psyditu 1999: 156,739-744

Bienwenu Of and Eaton WW. The epdemiology of blood-injection-injury phobia. Pydoh Med 1998: $28,1129-1136$

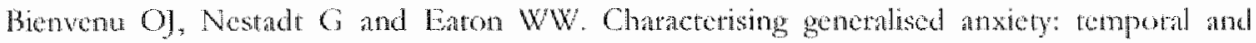
sympromatic thresholds. J Neny Went Dir 1998:186,51-56

Bhack DW and Noyes R. Comorbidity and obsessive-compulsive disorder. Maser ID and

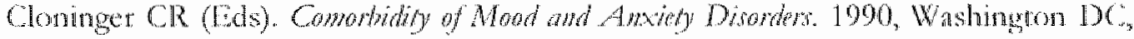
American Psychiatic Press. 305-316

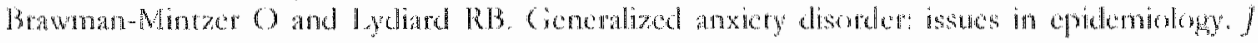
Che Prothoy 1996:57 suppl 7,3-8

Bremer JD, Southwek SM, Damell A and Chamey DS. Chronie PTSD in Vicmam combat

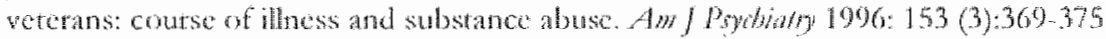

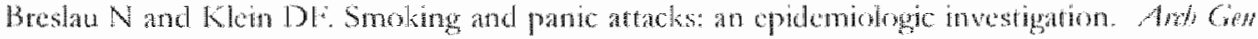
Pothatio $1999: 56,11411147$

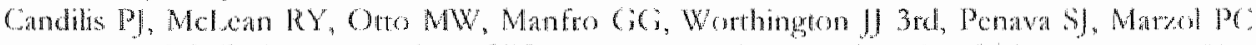

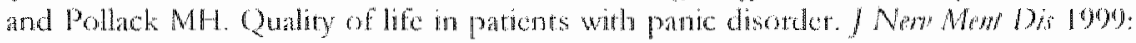
$187,429-434$

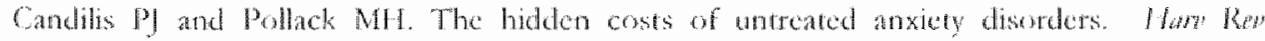
Psydithy 1997: $5,40-42$

Caste DJ, Deale A and Marks IM. Gender diferences in obsessue compulsive diserder. Ahs $N$

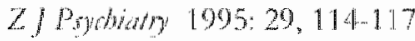

Chapman Th, Fyer $\mathrm{A}$, Manmuza $\mathrm{S}$ and khein Dl. A comparison of treated and untreated smple phobia. Am / Psydroty 1993: 150,816-818

Costa c Siva $1 \mathrm{~A}$. The public health impact of anxicty disorders: a WHo perspective Ath Pryolish Samd 1998: Suppl 393,2-5

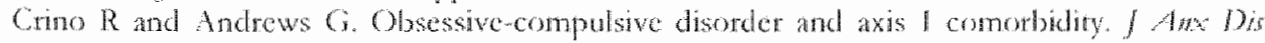
$1906: 10,37-46$ 


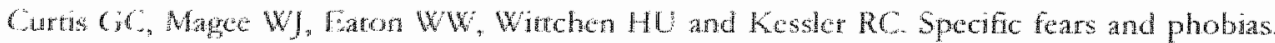
Epideniology and classificaun. Br J Podiatry $1998: 173,212217$

Davidson JR and Conor KM. Mamagement of posteramatic stress disorder: diarnostic and therapoutic iscues. / Clin Psylary 1999: 60 Suppl 18,33-38

Davisum Jl, Hughes Df, Goorge LK and Blazer DG. The epidemiology of social phobia: findings Grom the Duke Epidemiological Catchment Area Srudy. Pyohol Med 1993: 23, 709.718

Caton WW, Kessler RC, Witrohen HU and Magee WI. Panic and panic disorder in the United States. An / Psthiato 1094: 151, 413-420

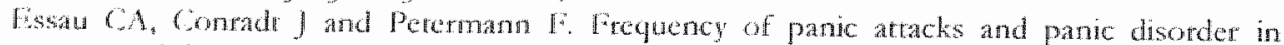
adolescents. Depres Amatery 1999:9, 19-26

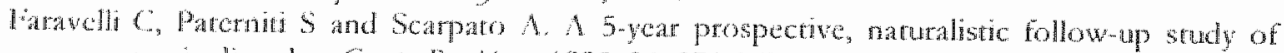
panic disorder. Cowpor Pyodiany 1905: 36, 271-277

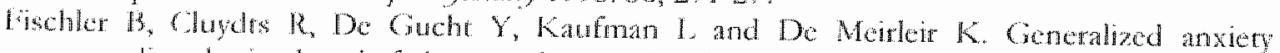

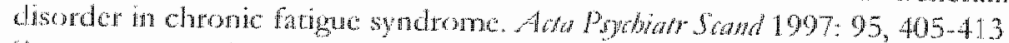

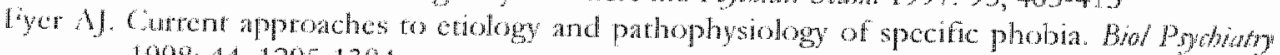
1998: 44, 1295-1304

Goismm RM, Nlswonth J, Kogers MP, Warshaw MC, Goldenberg I, Vaste RG; RodriguczVilla l: Mallya 6 and Kelles Mls, simple phobia as a comorbid anxicty disorder.

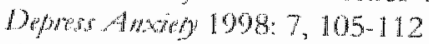

Goisman RM, Warshaw MG; Pererson LC; Rogers MP. Cunoo P, Hunt ME. Tomilin-Abuncse JM, Kaxim A. Gollan JK, Jipstcin-Kayc T, et al. Parnic, agoraphobia, and panic

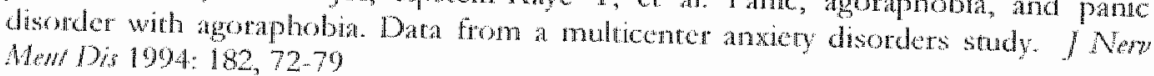

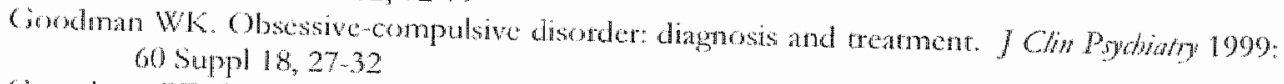

Coconberg PE, Sisicky T, Kessler RC, linkelstein SN, Berndt ER, Davidson JR, Ballenger JC

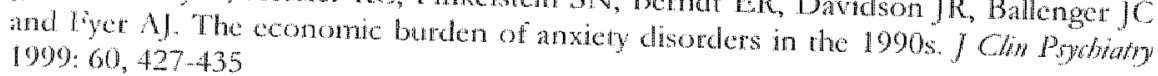

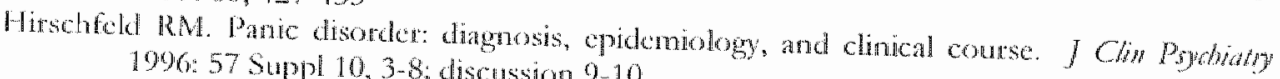
1906: 57 Suppl 10, 3-8, discussion $9-10$

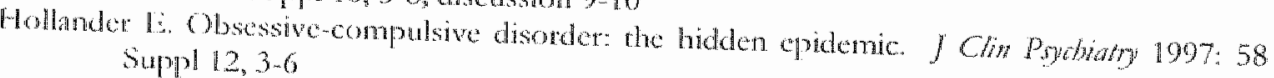

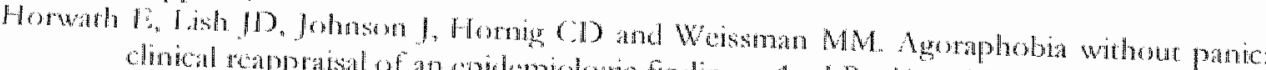

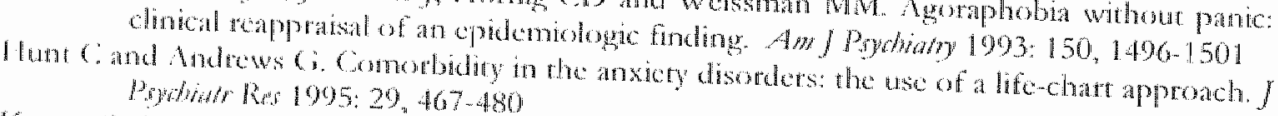

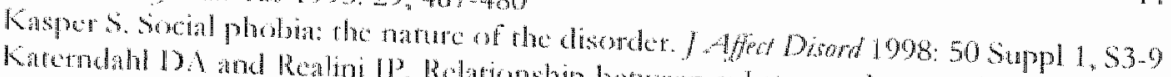

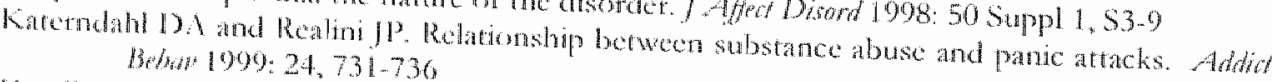

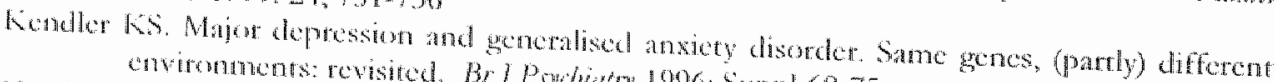

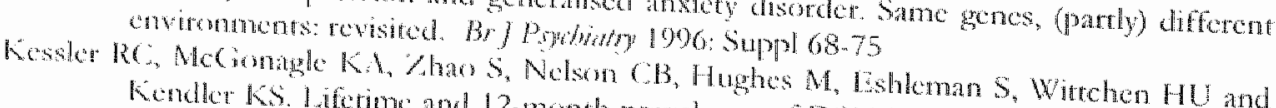

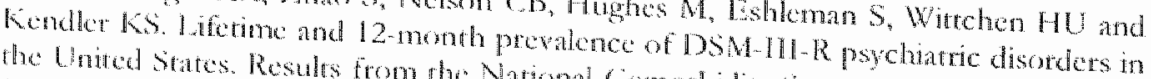

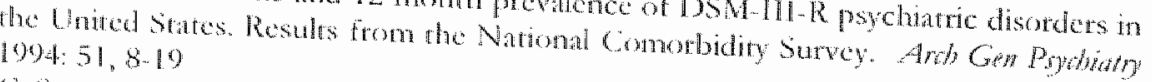

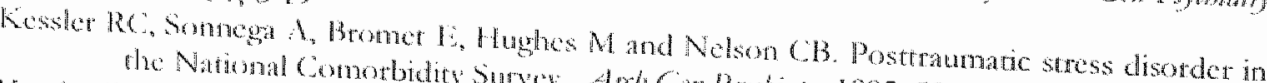

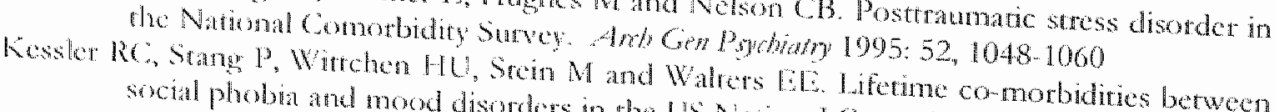
1909: $29,555-567$ 
Kessler RC, Sang PE, Witchen HU, Usmu TB, Roy Byme PP and Walters GL Lfotime panco

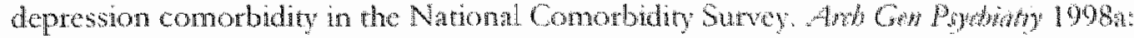
$55,801-808$

Kessler $\mathbb{R C}$, Stein MB and Berglund P. Soctal phobia subtypes the National Comorbidity Survey. Am / Pinchiaty 1998b: 155,613-619

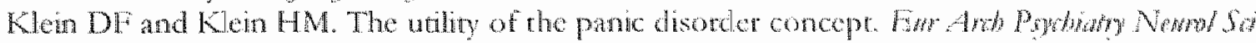
$1989: 238,268-279$

Kleman GL, Weisman MM, Ouellete $\mathbb{R}$, Johnson ] and Greenwald S. Patre atrack in the community. Social morbidity and heath care utilization. $14 M 41991: 265(6), 742$ 746

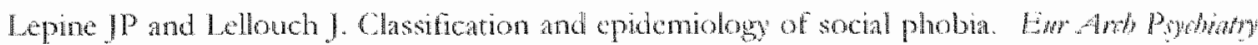
Chn Newori 1995: 244, 290-296

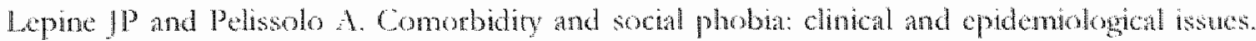
Int Clin Powhophatrhaod 1996: 11 Suppl 3, 35-41

Lepine JP and Pelissolo $A$. Social phobia and alcoholism a complex relationship. I Affot Disom 1998: 50 suppl 1, $\$ 23-828$

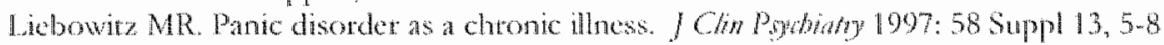

Licbowiz MR. Update on the diagnosis and treatmen of social anxicy disorder. I Chin Pydriatry 1999:60 Suppl $18,22-26$

Lydiard RB. Coexisting depression and anxicty: special diagnostic and treament issues. IClin Psybiatry 1991: 52 Suppl, 48, 54

Macs M, Delmeire I., Schotte C, Janca A, Cteren T, Mylle J, Struy $\mathrm{A}$, Pison $G$ and Rouscheur

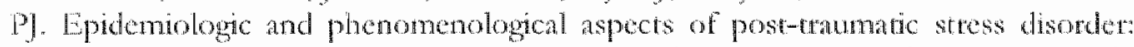
DSM-11L-R diagnosis and clagnostic criterta not validated. Psydoty Res 1998: 81, 179. 193

Magee WJ, Laton WW, Witrchen HU, McGonagle KA and Kessler RC. Agoraphobia, simple phobia, and social phobia in the National Comorbidity Survey. Anh Gen Prodsiatory $1996: 53,159-168$

Marshall JR. Alcohol and substance abuse in panic disorder. / Clin Prydiary 1997: 58 suppl 2, 46-49; discussion $49-50$

Martin P. Medico-socioeconomic impact of anxicty disorders. Enteph bate 1908:24, 280-296

McCanley I, Kem DE, Kolodner K, Dill J., Schroceder AF, DeChant FK, Ryden J, Derogatis

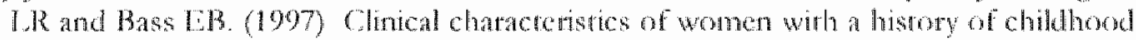
abusc: unbealed wounds. JAMA 1997: 277, 1362-1368

Merikangas KR, Angst J, Faton W, Canino (;, Rubio-Stipec M, Wacker H, Wittichen HU, Andrade L, Essau C, Whitaker A, Kracmer H, Robins IN and Kupfer DD Comorbidiry and boundaries of affective disorders with anxiety disondets and substance misust: resulds of an international task force. Br / Podhory 1996: Suppl 58 67

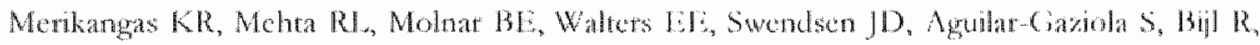

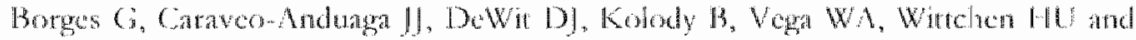
Kessle RC Comorbidity of substance use disorders wirh mond and anxiety

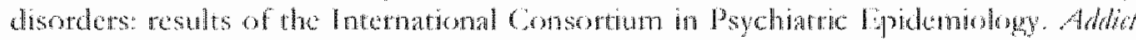
Behop 1998:23,893-907

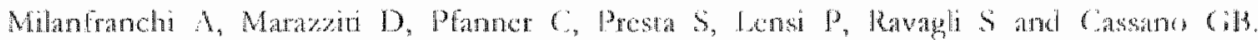

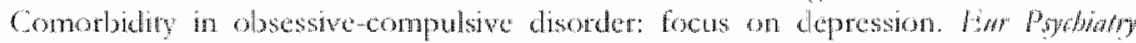
$1995: 10,379-382$

Montgomery SA. Implications of the seweriy of social phobia. A Afer Disond 19g8. 50 Suppl 1 . $\$ 17-\$ 22$

Moore MC and Zébb B. The catastrophic misinferpretation of plyytological distress. Bobo Res Ther 1099: 37, 1105-1118 
Nower CY and Srem MB. The history, epidemology and diferendal dagnosis of social

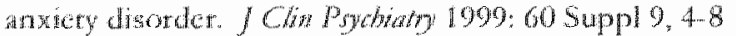

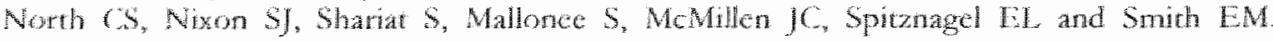
Psychatric discolers among survivots of the Oklahoma City bombing. JAMA 1999: $232,755-762$

Noyes R J, Reich J, Christansen J, Suelaer M, Pfohl B and Coryell WA. Outcome of panic disonder. Relatonship to diagnostic subtypes and comorbidity. Anb Gen Probarm $1990: 47,809-818$

Palssolo $A$ and lepine IP $^{2}$. Epidemiology of depression and anxicy disonders. In: Mongomery

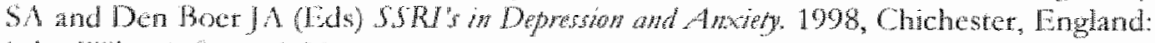
John Wiky \& Sons. $1-21$

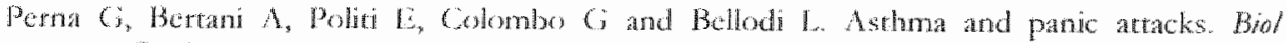
Pyathary 1997: $42,625-630$

Pfelforbam B. Postramiate stress disorder in children a teviow of the past 10 years. I Aw And Chid Adow Prowatry 1997: 36, 1503-1511

Pignot TA. Obsessive-compulsive disonder: symptom overvicw and epidenology. Bull Areminger Chin $1998: 62, \times 4-132$

Pohl R, Yengani VK, Balon R, Lycaki H and McBtide R. smoking in patients with panic disorder, Prydyaty Res 1992: 43, 253-262

Pollack MH and Ono MW Long-tem course and outcome of panic disorder. I Ch Psybiaty $1997: 58$ suppl 2,57-60

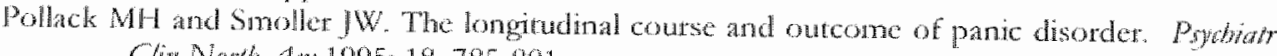
Chin Nom An 1095: 18, 785-801

Rasmusen $S A$ and Eisen Jl. The epidemiology and differential diagnosis of obsessive compulsive disonderi / C/yy Piydrorry 1992: 53 Suppl, 4-10

Rasmeasen $\mathrm{SA}$ and Eisen JI. The epidemiology and diferental diagnosis of obsessive

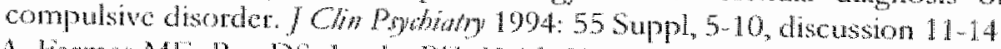

Regier DA, Garmer ME, Roe DS, Locke BZ, Keirh SJ, Judd LL and Goodwin FK. Comotbidity of mental disorders with alcohol and other drug abuse. Resuls from the Ippidemiologic Catchment Area (ECA) Study. JAMA1900m:264, 2511-2518

Regice DA, Nartow WE and Rac DS. The epidemiology of anxicty disorders: the Epidemiologic Catchment Area (ECA) expctience. I Powhos Res 19006: 24 Suppl 2, 3-14

Regier DA, Rae DS, Narrow WE, Kaeber C and scharberge AF. Prevalence of anxigry:

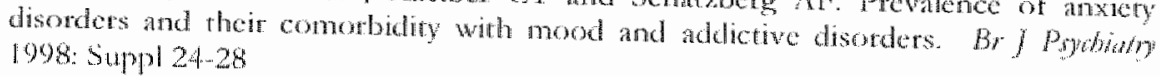

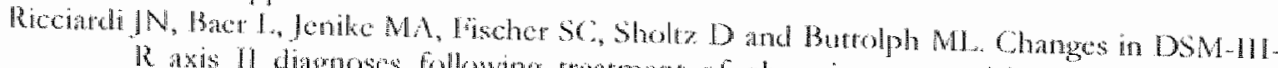

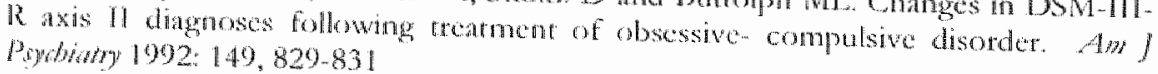

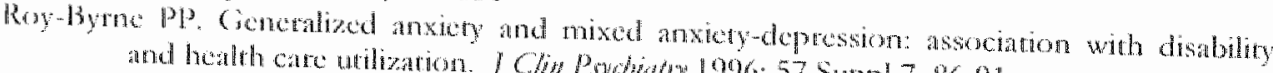

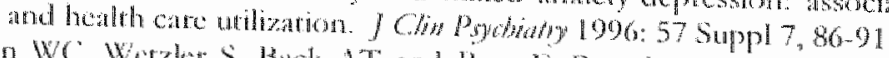

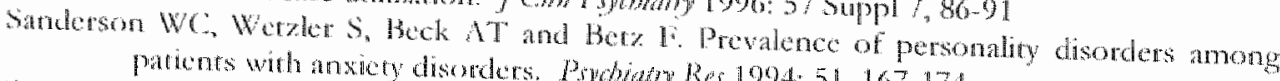
paticnts with anxicty disonders. Pydiator Res 1994:51, 167-174

Sartorius N. Ustun TB, Lecrubier $Y$ and Witchen HU. Depression comorbid with anxiey: pesulds fom the WHO study on peychological disorders in primary health cate. $B \mathrm{r}$ )

compulsive disonter. Lustiz M, lanch I and Hendler T. Epidemiology of obsessirem

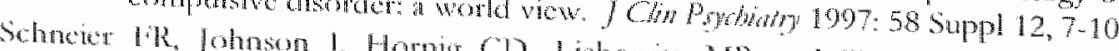
Comobidin and momig CD, licbowitz MR and Weisman MM Social phobia. Comombidity and morbidity in an epidemiologic somple. Am Gen Powhon 1992: 49, 


\subsection{8}

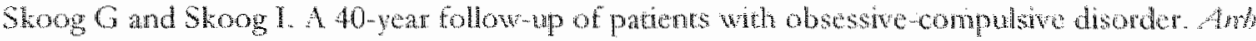
Gen Psybiaty 1999: 56, 121-127

Smoller JW, Simon NM, Pollack MH, Kradin R and Stem T. Anxien in pratents with

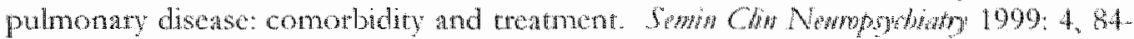
97

Stein MB and Chavira DA. Subtypes of social phobia and comobidiry with depression and other anxiety disorders. Iffet Derom 1998,50 suppt 1, S11-816

Secin MB, Tancer ME and Uhde TW. Mapo depression in pacients with panic disorder fncors associated with course and recurtence. J Affot Dhor 1990: 19,287-296

Stoudemire A. Epidemiology and psychophamacology of anxicty in modical patients. IClo Podraty 1996:57 Suppl 7,6472;73-75

Swendsen JD, Merikangas KR, Canino GI, Kessler RC, Rubio-Sripec M and Angst I. The comorbidicy of alcoholism writh anxiery and depressive disonders in fou geographic communities. Contpr Psodiaty 1998: 39, 1.76-184

Van Ameringen M, Mancini C, Styan $G$ and Donison D. Relaronship of social phobit with other psychiatric illness. Iffor Disom 1991:21,93-99

Verburg C, Griez E and Meifer J. A $35^{\circ} \%$ carbon dioxide challenge in simplo phobias. Ara Prybiat Sand 1994: 90, 420-423

Verburg K, Griez E, Meifer J and pols H. Respintory disorders as a possible predisposing Gactor for panic disorder I Affer Dirom 1995: 33, 129-134

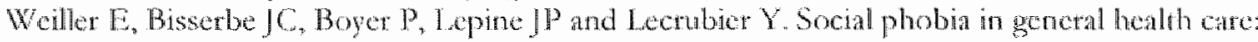
an unrecognised undertreatid disabling disotder. Br/ Prydyatsy $1996: 168,169-174$

Weinstock LS. Gender differences in the presentation and management of social anxicy disordex. I Clin Psydhaty 1909: 60 Suppl 9, 913

Weissman MM, Bland RC, Canino G), Faravelli C, Greenwald S, Hwa HC, Joyce PR, Karam EG, Lee CK, Lelloud J, Lepine JP, Newman SC, Oakley-Browne MA, Rubio-Stipec M. Wells JE, Wickramaratne PJ, Wittehen HU and Yeh RK. The cross-national epidemiology of panic disorder. Arwh Gen Powatry 1997: 54, 305-309

Weissman MM, Bland RC, Canino GI, Greenwald S, Hwu HG, Jee CK, Newman SC, Oakley Browne MA, Rubio-Stipec $M$, Wickramanatne $P \mathrm{~J}$, et al. The cross mational pidemiology of obsessive compulsive disorder. The Cross National Collabotative Ciroup. J Clin Pyoliaty 1994: 55 Suppl, 5-10

Widom CS. Postramatic stress disorder in abused and neglected childien grewn up. Ay Powdialy 1999: 156, 1223-1229

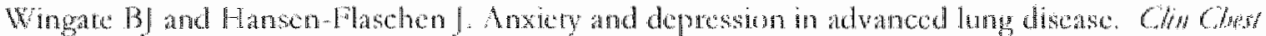
Med $1997: 18,495.505$

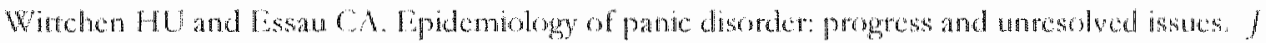
Pydiat Ror 1993: 27 Supp 1, 47-68

Witchen HU, Rssau CA, von Zerssen D, Krigg JC and Zaudig M. Iiforme and six-moth

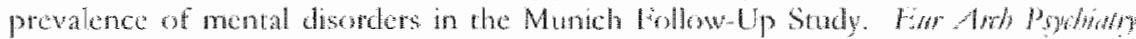

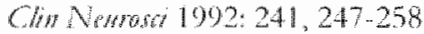

Witchen HU. Reed $V$ and Kesster RC. The relationship of agotaphobia and pante in a

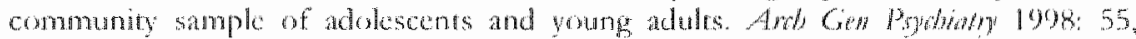
$1017-1024$

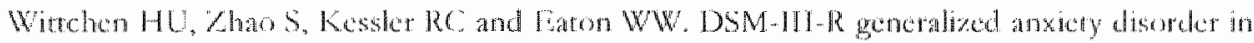

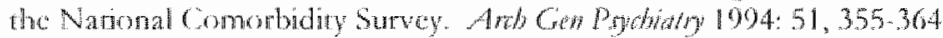

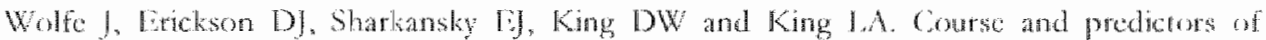
postraumaric stress disotder among Gulf War veterans: a prosipecrive anallysis. fonsult Clin Pyol 1999:67,520-528 
Whodman Cl, Noyes R Jr, Black DW, Schlosser S and Yagla SJ. A 5-year follow-up study of generalized anxicty disotder and panic disorder. Ner Ment Dis $1999.187,39$

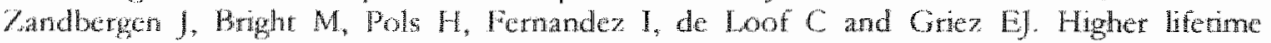
prewalence of respinatory diseases in panic disorder? Ast J Pyohato 1991: 148, 15831.585

Zatuber $\mathrm{TS}$ and Katon $\mathrm{W}$. Panc disorder in the general medical setting. I Psydoson Res 1998 : $44,25-42$

Zimmerman $M$ and Matria II. Is posttraumatic stress disorder underdiagnosed in routine clinical sertings? J Nery Mend Dis 1999: 187, 420-428 
Section 1. Prevellence of depressidn in panic disorder and obsessive-compulswe disonder 


\section{COMORBIDITY OF DEPRESSION AND PANIC DISORDER}

E. Griez and T. Overbeek

Based on: Griez E and Overbeek T. Comorbidity of Depression and Anxicy. In: Honig A, Anseau M and van Praag HM (Eds). Depression: Nenwobologial, Psychopatbological and Therapeatic Adhances. Wilcy \& Sons, Chichester, 1997. pp 41-57 



\section{INTKODUCTION}

In 1984, one of the pioneering studies in the field of comorbidity between depression and panic ended with the following statements: (1) major depression occurs in two thirds of patients, who come to an anxiety disorders clinic with agoraphobia-panic disorder; (2) one half of these patients who have a history of major depression have at least one majot depressive episode prior to and, in most cases, temporally separate from the onset of panic artacks; and (3) patients with agoraphobia-panic disorder with a history of major depression have a more severe anxiety disorder at the time of admission, greater levels of past impairment, and a longer duration of panic disorder as compared with patients with agoraphobia-panic disorder with no history of depression' (Breicr et al, 1984).

Since the publication of Breier et al. study, interest in the relationship between mood and anxiety disorders has continued to grow rapidly. Comorbidity, and particulatly comorbidity between anxiety and depression, has become a favorite concept in the psychiatric literature. Accumulating evidence supports the view that there is a close link between major anxiety disorders and deptession. Overall, studies show that, more than a decade later, the headlines of the Breicr et al. (1984) findings still hold true.

However, the interpretation of this so-called comorbidity has become a matter of debate. Are we facing a phenomemon of true comorbidity, or is this new 'evidence' an artefact produced by present days diagnostic systems?

Basically, comorbidity refers to the presence of more than one disorder in one subject. Comorbidity has been defined as "any distinct additional clinical entity that has existed or may occur during the clinical course of a patient who has the index disease under study" (Feinstein, 1970). Ideally, each 'clinical entity' under consideration should be a true discase, which signs and symptoms are codified, and whose underlying mechanisms are well understood. In that case, the assessment of comorbid conditions is quite an easy task and thete will be little room left for discussion whether, in a particular casc, one should distinguish one or more diseases. However, pathogenic mechanisms of psychiatric conditions remain largely unknown. The codification of signs, symptoms and diagnostic criteria is largely a matter of consensus on basis of fragmentary knowledge (American Psychiatric Association, 1980, 1987, 1994). As long as this situation persists, the delineation of valid 'clinical entities' will be, at best, a series of good approximations. This is to say that the study of peychiatric comorbidity at present relies heavily on the acceptance of current diagnostic and classification systems.

Current diagnostic systems share a number of features. These features do condition comorbidity research. They may explain why comorbidity is betrer 
recognized since these diagnostic systems came into force. On the other hand, they point to some important limitations with regard to the approach to comorbidity. A number of these fearures are of particular importance to the ficld of affective disonders.

Current diagnostic systems, such as DSM-III and its subsequent editions: (1) use a categotical approach based on operational criteria; (2) tend, in case of doubt, to split rather than to lump syndromes and refuse to establish hierarchies amongst them; (3) group anxiety disotders as a separate category with several subcategories.

Present-day psychiatric diagnosis is based on a categorical approach, following the medical tradition; one has or one has not a particular disorder. For each disorder, a number of operational criteria have been clearly defined. Moreover. structured interviews have become available. The emergence of well-defined diagnostic guidclines and the use of standardized interviews have facilitated the recognition of existing comorbid pathology previously neglected in presence of a more pervasive disorder and have favored a more complete screening of the patient's condition.

However, the multiplication of standardized screening instruments may engender an atritude of 'fishing for symptoms' with little consideration for clinical significance. There are no objective cut-off points for clinical anxiety and depression. In particular, insufficiently trained investigators may use very low threshold, and create an artificial high rate of comorbidity. Another problem when using standardized instruments is the halo effect: results in one section may be influenced by answers in the preceding section. For instance, positive findings in the anxicty section may influence the result in the mood section, and vice versa (Frances et al., 1992). The systematic use of structured interviews may give rise to very high rates of 'clinical' diagnoses, twice to three times as many as in routine accessment (Wittchen, 1996). It is possible that such incredibly high metes are vitated by serious artefacts. DSM-IIT, and still more DSM-III-R and DSM-IV, are splitters. The empirical and descriptive apptoach which underlies the system results in a multiplicity of diagnostic carcgorics. In addition, there is lack of organizing principles, as a consequence of the scarce knowledge in the pathogenic mechanisms of most disorders. Thus numerous disorders may be diagnosed and, predictably, the more diagnoses, the higher the chance of comorbidity. The adwantage of
having a large number of clinical pictures potentially diagnosed is that they are
recognized and may be put under the scruring of sciente recognized and may be put under the scrutiny of scientific investigation. In this scnse, a lot of current DSM categories should be considered as working
hypotheses. Regretrably, there is a danger of reification of current diagnostic
categorics without sufficient scientific categorics without sufficient scientific validacion. We may witness the
proliferation of lirtc-credible disorders. An additional limitation due to absence
of hierarchical organization is of hierarchical organization is that researchers are faced with an atomization of 
chinical conditions, while differences in underlyng mechanisms may not exist. In this case the concept of 'spectrum diseases' may be a good remedy.

Since the publication of DSM-III, anxiety disorders have been grouped as a separate category, and split into several distinct disorders. While andery disonders previously tended to form an amalgam with the "newroses", they have now been recognized on their own, with clear-cut diferentiations between panic disorder (PD), agoraphobia with pantc, phobias, obsessivemompulsive disonder and post-tramatic disorder. What happened to the anxicty disorders is a beatiful example of an empirical process at work in the DSM approach. The decision to split anxiety neurosis and to delineate PD was langely inspited by the early clinical and experimental findings of D. Klein and his coworkers (1964). In turn, the defintion of PD fostered its recognition. An impetus of research into this new entity followed, soon resulting in an impressive picce of scientific evidence in suppont of its validity. However, the present classification of anxiety disotders shows its limits as well. Thete has been a continuing debate about the relationship between panic and agotaphobia, and in particular, whether agoraphobia exists without panic attacks. Also, while PD has gained strong validity, the division of anxiery neurosis has left an ill-defined category under the name of generalized anxiery disonder (GAD). Most studies show comorbidity rates of $70-80 \%$ for GAD, strongly suggesting lack of validity.

In sum, is psychiatric comorbidity "fact ot artefact" (Wittchen, 1996)? Undoubtediy, it is not merely a methodological artefact, as witnessed by the core of data in the following sections of this chapter. However, when accounting for the high rates of comorbidity which are found in recent studies, it should be botne in mind that the study of comorbidity telies on the way disorders are defined, and that current diagnostic systems are largely worlwing hypotheses in need of validation. To this extent, the investigation of comotbidity in psychiarry will still be for years a difficult exercise.

\section{PANTC AND DEPRESSION: AN OVERVIRW OT RECWNT DATA}

In clinical practice depression and anxiety often coexist. A considerable number of patients presenting with anxiety disorders have a comorbid depression, and many depressive patients show some anxiety disorder. PD especially is a frequently met diagnosis, as well as GAD or social phobia (Sanderson et al., 1990; Davies et al., 1995). "The reported frequency, however. varies with methodology, defintional criteria used and pationt population (rechimment bias, Starcevic et al., 1992). Some (epidemiologrical) sludics have followed a large non-selected group (e.g. the Epidemiologic Catchment Mrea (ECA) Study of the National Institute for Mcntal Healh NIMH), othet researchers recrut their patients by advertisement, while others purdy use the patent group refered to their clinic by other physicians. It is not surprising 
that the outcome of these different studies is not unequirocal. Apart from differences as mentioned before some studues use strict criteria to include only major depression, others also include minor depression and dysthymia, some do not mention their criteria. Another point of confusion is caused by temporal/chronological issues (Moras and Batow, 1992), as some researchets take both past and present depressive or anxiety symptoms into account, others mention period of within two years from admission, while others investigate liferime prevalence or just actual symptoms. In short, it is not easy to compare the results of these studies. We will briefly review the most representatre studies since the late $1980 \mathrm{~s}$ to get an impression of the frequency of comorbidity between anxiety and depression. We will keep in mind that some contrasting results may be atributable to the aforementioned methodological differences. Because most of the literature pertams to the comorbidity between panic and depression we will restrict out further analysis to PD.

\section{Epideviologial data}

In recent years there have been some teports on (some still ongoing) large epidemiologic studies, based on community samples. Examples are the Epidemiologic Catchment Area (ECA) study and the National Comorbidity Survey (NCS) in the USA, the Zurich Cohort Study in Switzerland and the Munich Follow-up Study in Gemany.

The ECA study reports a lifetime prevalence for PD of $2 \%$, the NCS of $3.5 \%$ (Faton \& Key1, 1995). On the basis of the same $\mathbb{E} C A$ database Chen and Dilsaver (1995) report for PD a lifetime prevalence of $20.8 \%$ in patients with bipolar disorder of $10.0 \%$ for subjects with unipolar depression and for comparison subjects only $0.8 \%$. Andrade et al. (1994) also analyzed a subset of the ECA-files and found a lifetime prevalence of $4 \%$ for major depression and 4\% for PD: $2.1 \%$ had borh, which is 11 times higher than expected by chance if both disonders were unrelared. They further analyzed this comorbid group, and found that $38 \%$ had a concomitant onset, $33.5 \%$ expericnced the PD first, while in $28.5 \%$ deprossion preceded the PD.

Baron et al. (1994) describe some fundings from the NCS. One reason for a higher provalonce tare could be the smallet age range in the NCS (15-54 yeats) as compared with the BCA (18 years and older).

The resuls from the Munich Follow-up Study Witchen et at, 1993) show that betwen $32^{\circ}$ and $50^{\circ}$ of $P D$ patients also fulfilled criteria for lifetime major
depressiton.

Whe Zurich Study (Vollwath and Angst, 1989) repont â $12 \%$ comorbidity at cross-section, but do not mention lifetime figures, which is not surprising because their cohort is a young adult age group. 


\section{Datafrom fantib stwdies}

From the 1980 s on several family studies have been done to investigate the possible genetic liability or clustering in families of depressive and anxiety disorders. More recently Weissman, for example, published a review of genetic studies on this subject (1993), as well as a report on their own data (Weissman et al., 1993). The results of the six reviewed studies clearly indicate the importance of genetics in PD, though morbidity tisks vary from 7.7 to 20.5 in 100 probands. These figures are definitely higher than the overall prevalence rate for PD in the normal population $(1.2-2.4$ in 100). Results from the only twin study published thus far also strongly support genetic influences as monozygotic twins had five times more frequent PD than dizygotic twins, but this study has some methodological shottcomings (Weissman, 1993).

Family studies on the association between anxiety disorder and depression offer contradictory results, however. Weissman et al. (1993) found elevared rates of PD in relatives of probands with PD with or without major depression but not in relatives of probands with major depression withour PD. Conversely, Maier et al. (1993) found elevated rates of major depression in relatives of probands with major depression with or without PD bur not in relatives of probands with PD without major depression. The authors concluded that PD and major depression are separate disorders which ate independently and specifically transmitted, while the comorbid condition does not represent a single, distinct syndrome.

Other studies cited by Weissman (1993) seem to find a higher prevalence only of secondary depression in relatives of PD patients, not of primary depression, thus supporting the separation of depression and PD. The only conclusion Weissman can suggest is that PD is highly familial, and no conclusion can be drawn yet about the comorbid condition.

Also data reviewed by Leckman et al. (1990) showed no increased risk for primary depression in PD relatives, but clearly higher risks for sccondary depression.

\section{Clinical data}

In recent decades various publications have appeated that investigate the comorbidity of depression and anxiety in clinical samples. They differ amongst others in selection procedures and criteria and in methodological aspects. Some only address ctoss-sectional aspects, while others apply to lifetime comorbidity. There are some purely descriptive studies, whereas others relate more ro treatment issues. We will review some of the results of the most recent studies on this subject.

Wetzler et al. (1995) reviewed some studies and found that $24 \%$ (range $7 \%$ $61 \%$ of PD patients have a comorbid depressive disorder, with dysthymia more common than major depression. For lifetime prevalences rhe figures 
increase considerably to $63 \%$. $68 \%$. Of the patients with primary depressive disorders about $14 \%$ (range $9 \%-69 \%$ ) have a comorbid PD. Lifetime rates were not given for this second group. Wetzler et al. state that all studies confirm that PD patients with comorbid depressive disorder have a worse course and symptomatology, but that it is not cleat whether the comorbidity adversely affects response to phatmacological treatment.

In using the life-chart approach, Hunt and Andrews (1995) investigated 100 parients with anxiety disorder and could trace that in $61 \%$ the anxiety disorder preceded the major depression, and in $26 \%$ both disorders were concomitant and co-occurred independently. Their method consists of a fully structured and comprehensive diagnostic interview. The life chart is clearly a valuable progress compared with the questionable reliability of retrospective reports, and can offer a better insight into aetiological aspects on the comorbidity issue in psychiatry in general, and into the relationship of anxiety and affective disorders in particular.

Ball et al. (1995) report on 64 PD patients, most of them recruited by mediaadvertisement for phatmacological reatment. They were diagnosed by using the Structured Clinical Interview for DSM (SCID) or Anxiery Disorders Interview Schedule (ADIS). Of these 64 patients $48 \%$ met criteria for past major depressive episode, as $36 \%$ were in a current depressive episode. Beside these diagnoses, it was found that $60.9 \%$ of the PD patients show two or more clinically significant depressive symptoms not meeting full criteria to assign the diagnosis of depression. This illustrates the high rate of clinically significant depressive symproms at a subdiagnostic level.

Albus and Scheibe (1993) and Albus et al. (1995) performed a nwo- to fiveyears follow-up study on $50 \mathrm{PD}$ patients who were included in a clinical medication trial, and found $40 \%$ of them to be depressive as well at referral. They recruited their subjects by media announcement and included them if meeting DSM IIJ-R criteria for PD with or without agoraphobia. For asscssment the SCID was administered, the Phobia Scale, the Hamilton Anxicty Scale and Hamilon Depression Scale and the Global Assessment Scalc. They report that depressed panic patients do show a poorer outcome on overall measures on depression and anxiety, but there was no difference on mensures concerning specific PD items such as frequency of panic attacks, agoraphobia and anticipatory anxiety.

In a large sample Keller et al. (1994) describe a follow-up study of 309 subjects with PD and mention $25 \%$ of them suffering from major depression at intake. They petformed a prospective, longitudinal naturalistic study on a large cohort of anxiety disorder patients, part of the Harvard-Brown Anxiety Disorders Resarch Project. However, they do not report explicitly on depression at
follow-up. 
Reich et al. (1993) investigated 182 patients with $\mathrm{PD}$, of whon $21 \%$ were in at current depressive episode and 50\% had a lifetime major depression (past and/or current). They also state that thete was no evidence that the major depressive disordet tended to be secondary to the PD, as its onset was almost equally likely to predate or postdate the first panic.

Starcevic et al. (1992) describe 54 PD patients with or without agoraphobia and report an overall comorbidity (current or lifetime) of dysthymia or depression of $61 \%$. The instruments used in this study wete the SCID and Symptom Check List 90 (SCL-90). The findings suggest that the pattern of comorbidiry may differ between PD with agoraphobia, and uncomplicated PD.

Lesser et al. (1988) report on the results of the Cross-National Collaborative Panic Study, which comprises eight sites and 481 subjects (aged $18-65$ years) who were recruted by advertisement and from clinical populations. Subjects were included if meeting DSM-III criteria for PD with or without agoraphobia, but were explicitly excluded if they had a current or past history of major depression which clearly preceded the PD. Still, $31 \%$ of the subjects showed a secondary depression after the onser of the anxiery disorder. Ratinginstruments were: Hamilton Anxiety Scale, Hamilton Depression Scale, Symptom Check List 90 and the Marks-Shechan Phobia Scalc. The treatment part consisted of an eight-week, double-blind, flexible-dose study of alprazolam versus placebo. Results show that the presence of a major depressive episode did not affect treatment outcome for the panic and phobic symptoms. Swinson and Kuch (1990) describe a series of 60 patients with PD of whom 31 $(52 \%)$, by using SCID interviews, reported a history of major depressive episode. Of these $31,40 \%$ had the onset of depression before panic, $20 \%$ concurrently, and the other $40 \%$ after the start of the PD.

From a large clinical study by Mezrich et al. (1990) a figure of $12 \%$ arises, for anxicty disonder patients also suffering from a major depression. They report on 4141 new patients presenting for care at their 24-hour a day walk-in clinic for psychiary in Pitsburgh. They used a standardized evaluation instrument, the Initial Evaluation Form (IEF), according to DSM-III guidelines.

Di Nardo and Barlow (1990) report on their clinical sample of 292 anxicty disorder paticnts, referted to their specialized center for stress and anxicty disorders. Of these, $4.1 \%$ had an additional diagnosis of major depression, $11.3 \%$ of dysthymia. Of the $86 \mathrm{PD}$ patients, the percentages were $6 \%$ and $12 \%$ respectively. If not only concurrent diagnoses but also lifetime figures were considered, the picture changed to a $30 \%$ of past major depressive episodes. The authors attribute their low comorbidity figures to the very specialized nature of their anxiety clinic.

As far as treatment is concerned, we have alrcady reported that lesser et al. $(1988,1990)$ failed to find any influence of comorbid depression on treatment outcome. On the contrary, Noyes et al. (1990, 1993), and Basoglu et al. (1994) 
find a worse outcone for the comorbid depressive panic patients. Rosenberg et al. (1991a) repotted a weak effect of comorbid concurtent depression on the outcome of PD. Fxcept for a small group of PD parients with tecurrent major depression in the past, Maddock et al. (1993) found no overall differences in reatment outcome berwen PD patients with one major depressive episode (primary or sccondary) in their history. These authors suggest, however, that patients with recurrent majot depressions neptesent a more serious condition.

In a review on teatment aspects of cowisting $P D$ and major depression Laberge al. (1992) state that comorbid depression might complicate and obstruct behaviotal therapeutic (exposure) strategies for PD, but not the psychopharmacological approach, at least if sufficient attention is paid to the therapeuric compliance of the depressed panic patients.

Pollack ct al. (1994) investigated a group of depressive PD patients, and found that within this group the severity of anxiety pathology was predictive of outcome. Indecd most authors agree that the presence of depressive symptoms does reflect a more severe illness condition than PD without depression.

Some authors state that mone severe anxiety at baseline ot longer duration of illness ate negative predictors concerning treatment effect (Black et al., 1994; Katschnig ot al, 1995$)$.

Pasnau and Bystritsly (1994) report on the Harvard Anxiety-Panic Disorder Resentch Project which shows that PD patients who suffer from a comorbid depression have pooter theatment outcomes than either non-comorbid group. Finally, Iydiat (1991) cites several clinical sudies which show less favorable treatment outcome for comorbic conditions.

Two man conclusions can be drawn following this brief overwiew. The first refers to our word of caution at the beginning of this review: thete is a wide varicy of different approaches across the studies. Studies range from laxgescale opidomiological survegs in the general populaton, with lay interviewers using structured instruments, to detaled analyses of small patient samples by clinicins during the course of drug traks. Strikingly, the second conclusion is that some fesults do emerge wh a surprising good consistency. Except for two (1.esser al., 1988 and DI Nardo and Barlow, 1990), all clinical studies agree by showing that $1: 2$ to $1: 3$ of PD patients have a lifetime dagnosis of major depression. It is suggested that amongst those who have lifetime comorbidity, half hav primary depression, and half primary PD. In 1:4 to $1: 5$ of cases, the onset is co-occuring panic and depression. These resuls are supported by findings in epidcmiological surveys. Cross-sectionally, most clinical studies repot that $1: 3$ to $1: 5$ of the subjects with $P D$ have concurrent depression although figures vary from a high $40 \%$ (Albus and Scheibe, 1993) to a low 120\% (Mozich et al., 1990).

White most authors suggest that comorbid depression points to a more severe condivon, it is less clear whether this comorbidity affects treament outcome. 
Ar least three studies (Lesser et al., 1988; Maddock et al., 1993; Rosenberg et al., 1991 b) found no, or only weak effects of depression on treatment results but a majority of reports state that comorbid conditions have a poorer outcome.

As we announced in the introduction of this chapter, the above figures largely confirm Breier et al.'s (1984) early findings. There is now sufficient evidence that more than half of the subjects with a PD also have a lifetime diagnosis of depression, and that depressive episodes may precede, follow ort co-occur with the very first panic episode. Beyond epidemiological figures, the question of the relationship between panic and depression remains, however, unsolved. Frances et al. (1992) propose a number of possibilities, of which three are basically pertinent to our data. First, the association may exist just by chance, as both disorders may be independent diseases, which due to their respective high rate of prevalence have statistically an increased probability of co-occuring in one individual. Second, one disease may predispose to the other. Third, anxiery and depression may be two surface manifestations of one single underlying disease. A purely fortuitous assocation as proposed in the first model seems less likely. It is hard to believe that the high base rates of both disorders may fully account for the above figures. The third model cannot be discussed as long as our insight in the pathogeny of both panic and depression remains fragmentary. The predispositional model may suggest interesting hypotheses for further clinical investigations. Although most investigations suggest that in PD, the frequency of primary and secondary depression is equal, at least one recent report (Hunt and Andrews, 1995) found that in a majority of cases depression was secondaty to panic. Most authors, as pointed out above, consider that comorbid depression may indicate a worse course of the anxiety disorder. Moreover, clinicians commonly view depression following anxicty states as a demoralization reaction. Breier et al. (1984) also noted that in the case of comorbid depression the history of the PD was longer, and the impaiment worse. These issues regarding the clinical relationship between panic and depression suggested the study which will now be reported.

THE IINK BETWEEN PANIC AND IDEPRISSSION: ACINICAL APPROACH

\section{Hypotheses}

While half to two thirds of PD patients have a lifetime comotbid depression, the reverse is less frequent: only $10-30 \%$ of mood disorder patients have a lifetime PD (Chen and Dilsaver, 1995). It has therefore been hypothesized that anxiety may predispose to depression (Frances et al., 1992). If (long standing) anxiety predisposes to depression, it will be expected that the probability for a PD patient to become depressed will depend upon the duration and severity of the PD. If depression is a consequence of panic, either via psychological 
mechanisms (demoralization), or via sensitization of neuronal pathways (e.g. downregulation of receptors), it may be expected that patients with comorbid depression will benefit less from a standard treatment than uncomplicated PD subjects. As appears from the above overview, there has been suggestive evidence for several of the above hypotheses. The present study was undertaken to document the frequency of depressive pathology amongst a population of severe PD patients and to confront the above evidence on a causal link between PD and depression. The hypotheses under examination were that among PD patients referted for treatment:

(1) as a group, patients with comorbid depression are older than nondepressed subjects;

(2) parients with comorbid depression will have a more severe anxiety symptomatology than nondepressed subjects, as measured by standardized rating scales;

(3) in depressed PD patients, a cotrelation can be found between the severity of the depressive and the anxiery symptomatology, as appears from standardized instruments;

(4) patients with comorbid depression will benefit less from a standard treatment package, combining antidepressant drugs and behavior therapy.

\section{Methods}

The design of the study consists of a retrospective file analysis of 160 consecutive PD patients who had been referred for treatment at the Academic Anxiety Center of Maastricht from 1993 to 1995. All patients had undergone an extensive diagnostic procedure, comprising a psychiatric examination, a physical check up, and a battery of clinical metrology to assess the symptomatology, with both observer-rated and selfrating instruments.

All patients had been diagnosed on the basis of consensus by 2 experienced clinicians, using DSM-T]J-R criteria.

Anxicty symptoms were assessed as follows:

- The Clinical Anxiety Scale CAS (Snaith et al., 1982)

- The Selfrating Anxicty Scale SAS (Zung, 1971)

- The Srate Trait Anxiety lnventory, state form STAl (Spiciberger et al, 1977)

- The Fear Questionnaire FQ (Marks and Mathews, 1979). We used the total scote (1QT) reflecting all types of phobic avoidance as well as the specific subscone for agoraphobia (FQA).

Depressixe symptomatology was assessed using the Montgomery-Asberg Depression Raring Scale MADRS (Montgomery and Asberg, 1979) and Zungs on the Clinical Global Impression scale (CGD).

After diagnosis, patients entered a standardized reatment procedure. This treatment comprised the administration of a specific serotonin reuptake 
inhibitor (SSRD) at a clinically effective dosage for six weeks, with a complementary standardized exposure treatment from the seventh week on. This protocolled behavioral therapy was designed to last five weeks but the total duration was very flexible, depending on patients" progres. Discharge took place by mutual agreement between patient, behaviot thetapist and psychiatrist. At discharge all initial assessments were repeated.

\section{Restits}

The data of 160 patients with DSM-MII-R diagnosis of PD (and agotaphobia) were suitable for analysis. Of these $104(65 \%)$ were female and 56 were male. Their mean age was 39 years (range: $18-74$ years).

Forty-eight (30\%) of these 160 panic patients also met DSM-III-R criteria for: major depression or dysthymia. Only concurrent dingnoses of depression were accounted for, as the questionable reliability of retrospective lifetime figutes for past depressive episodes does not justify strong conclusions.

The sex distribution was equally on both conditions. The mean age for the depressive subgroup was $41.8( \pm 12.5)$ years, mean age for nondepressed panic patients was 38.0 ( \pm 9.7 ) years, which is a statistically significant difference, $p=$ .042. This finding supports out furst hypothesis.

The second hypothesis on symptom-severity was rested by comparing the mean scores on the vatious instruments at intake for the depressed and nondepressed subgroups (Table 1). We performed a Students' T-test for: untelated samples, and two-tailed significance levels. As shown in Table 1, all measures are statistically significantly higher for the depressed panic patients, although a look at the rough mean scores justifies a question about the clinical. significance of a difference between, for example 26.6 and 21.3 on the FQA, and even more so the meaning of a 0.2 difference on the CGI. We will return to this issue below.

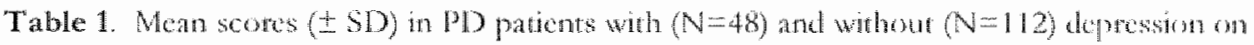
clinical metrology scales ar baseline

\begin{tabular}{|c|c|c|c|}
\hline & Depressed DD & Nondepraturd PD & $p$ \\
\hline MADRS & $15.3( \pm 8.8)$ & $8.5( \pm 6.8)$ & $<0.001$ \\
\hline SDS & $53.7( \pm .5)$ & $46.2( \pm 8.5)$ & $<0.001$ \\
\hline$C A S$ & $10.6( \pm 5.9)$ & $8.3( \pm 5.1)$ & 0.02 \\
\hline$S A S$ & $51.2(18.1)$ & $47.4(+8.2)$ & 0.01 \\
\hline $54 \pi$ & $55.4( \pm 11.3)$ & $509( \pm 11.3)$ & 002 \\
\hline $\mathrm{FQT}$ & $59.7( \pm 24.2)$ & $49.7(-24.8)$ & 002 \\
\hline FQd & $26.6( \pm 12.2)$ & $21.3( \pm 12.5)$ & 0.01 \\
\hline CGI & $49( \pm 0.5)$ & $4.7( \pm 0.5)$ & 0,02 \\
\hline
\end{tabular}


The third hypothesis on the relationship between severity on depressive and anxiery measures was tested by calcularing the correlation between the scores at intake on the MADRS and STAI, SAS, CAS, FQA and FQT. The Pearson correlation coefficient respectively showed to be $0.34,0.43,0.60,0.18$ and 0.27 , all significant $(p<0.05$ ) (Table 2). Correlations between scores on SDS and the anxiery-scales are also shown, all of them were significant $(p<0.05)$.

Table 2. Correlations between scores on Depression and Anxiety scales in PD patients winh and whout depression $(N=160)$

\begin{tabular}{c|c|c} 
& MADRS & $S D S$ \\
\hline CAS & 0.60 & 0.46 \\
$S A S$ & 0.43 & 0.67 \\
STA & 0.34 & 0.55 \\
HOS & 0.27 & 0.38 \\
HOA & 0.18 & 0.34
\end{tabular}

The fourth hypothesis, addressing the treatment-aspects, was tested by means of comparing the dectease in scores on the various questionnaires between the depressive and nondepressive subgroup ( $T$-test for unrelated samples). Results are shown in table 3 . As can be seen, both groups improve tather comparably on treament. On the FQA the depressed group even improves more than the nondepressed.

We also compared the treatment period for each subgroup, and found the mean to be 21.3 ( \pm 13.4 ) weeks fort the depressed, and 22.7 ( \pm 12.6 ) weeks for the nondeptessed.

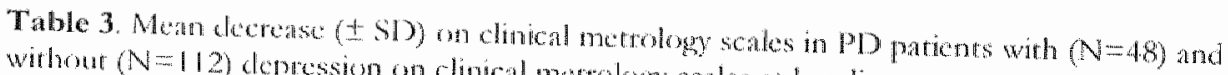
without $(\mathrm{N}=112$ ) clepression on clinical metrelogy sales at bascline:

\begin{tabular}{|c|c|c|c|}
\hline & Doprend PD & Nowdengisted PD & $p$ \\
\hline$M A N R$ & $9.6( \pm 7.3)$ & $5.3( \pm 3.0)$ & 0.001 \\
\hline 109 & $12.0( \pm 10.2)$ & $11.1( \pm 10.4)$ & $0.6(\mathrm{NS})$ \\
\hline$(.41)$ & $59( \pm 4.0)$ & $5.3( \pm 5.5)$ & 0.59 (NS) \\
\hline 819 & $12.1( \pm 10.1)$ & $12.3( \pm 10.9)$ & 0.87 (NS) \\
\hline .9718 & $14.9(135)$ & $16.6( \pm 139)$ & $0.49(\mathrm{NS})$ \\
\hline 101 & $33.3( \pm 23.4)$ & $27.8( \pm 23.1)$ & $0.17 \mathrm{NS}$ \\
\hline 101 & $18.6( \pm 12.1)$ & $140( \pm 12.9)$ & 0.04 \\
\hline$C \mathrm{C} l$ & $5.9(+4.0)$ & $2.2( \pm 1.1)$ & $0.92(\mathrm{NS})$ \\
\hline
\end{tabular}




\section{Conchusion}

The resuits of our own study corroborate existing data on the high prevalence of depressive disorders in patients with PD. In our sample 48 out of $160 \mathrm{PD}$ patients presenting for treatment had concurrent depression. This rate of $30 \%$ compares to the overall $1 / 5$ to $1 / 3$ rate of cross-sectional comorbidity reported in the literature we have reviewed. In our calculation we did not take into account the distinction between major depression and dysthymic disorder which was in force in the DSM III-R. Had we done so, the figure of comorbidity with major depression alone had been lower by about $50 \%$ which stull compares with the $12 \%$ of major depression found by Mczzich et al. (1990) or the $21 \%$ by Reich et al. (1993).

Some have argued that the high comorbidity of anxiety and depression found in clinical samples is in tact related to a recruitment bias, because patients with a comorbid depression ate more prone to seck treatment than those withour comorbidity. However, general population surveys have shown comparable high rates of comotbidity (Wittchen and Essau, 1993).

Thus, it seems that the present study adds some exidence to the existing data on a high cross-sectional depressive comorbidity in clinical samples of patients with a PD.

Three hypotheses addressed the possible causal relationship between PD and depression. We had predicted that PD patients with depression would be older than those without depression. If the existence of a PD predisposes to depression, either via psychological or biological mechanisms, it is perfectly credible that the longer the anxiety disorder exists, the higher the probability that a depressive episode appears. The age of onset of PD is normally distributed around a peak of 25 years, comorbid depressive episodes will tend to be more frequent in older patients. The findings are in line with our prediction: we found significant differences, berween depressives and non depressives, the former being indeed older.

We had predicted that as a group, PD patients with depression would have a more severe anxiery symptomatology than those without depression. If there is a causal relationship between PD and depression, the more severe the former, the mote probable the latter. Again, the results substantiated our hypothesis. On all measures, the anxiety scales consistently showed more severe symptomatology in depressives compared with non depressives. This abservation is in line with several other reports cited above, repeatedly suggesting that the global clinical condition of comorbid paticnts is worse compared with non-complicated panic.

If anxiety causes depression, the more severe the fomer, the mote severe the latter. We had predicted that at an individual level there should be a correlation between the severity of the anxiery disorder and the severity of depressive symptoms. Again, our findings were in line with the expectations. All 
correlations between scales for anxiety and scales for depression were statistically significant.

As far as the two latter predictions are concerned, some cautionary remarks must be made. We uscd standardized instruments, and all clinical metrology was done by an independent rater, who, at least at baseline, was blind to the diagnosis of the patient. However, there is a notorious item overlap between anxiety and depression scales (Snaith, 1993), which is responsible for a serious contamination between the measurement of anxiety and depressive symptoms. This factor may account in part for our findings. Yet, no item overlap with depression scales apply to the FQ, which is a specific instrument designed to measure behavioral avoidance, in particular agoraphobia.

There was an overall positive treatment effect, as shown by Table 4 .

Table 4. Man scores (t SD) on clinical metrology scales post treament, by depression

\begin{tabular}{|c|c|c|c|}
\hline & Dopresied PD & Nomdeprened PD & 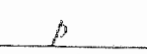 \\
\hline MADRS & $5.0( \pm 4.0)$ & $2.8( \pm 4.0)$ & 0.001 \\
\hline 905 & $41.7( \pm 8.9)$ & $34.7( \pm 10.2)$ & $<0.001$ \\
\hline$C A S$ & $4.8( \pm 3.5)$ & $3.1( \pm 3.7)$ & 0.02 \\
\hline$S A S$ & $39.2( \pm 9.2)$ & $34.9( \pm 9.9)$ & 0.01 \\
\hline $\operatorname{sTA}$ & $40.6( \pm 13.3)$ & $34.2( \pm 11.6)$ & $<0.01$ \\
\hline$F Q T$ & $26.4(t-17.3)$ & $21.9( \pm 21.1)$ & $0.16(\mathrm{NS})$ \\
\hline 104 & $8.0( \pm 6.5)$ & $7.2(+8.5)$ & 0.51 (NS) \\
\hline$G G$ & $2.8( \pm 1.2)$ & $2.5( \pm 0.2)$ & $0.25(\mathrm{NS})$ \\
\hline
\end{tabular}

At discharge, there still was a significant difference on the MADRS and the SDS between both groups of patients. The same applies to the "general" scales of anxiety (CAS, SAS, STAD). However, it should be noted that the ratings of the former depressives were well below any clinically significant threshold on the MADRS, as well as on the SDS. Most importantly, in contrast to the basejine measurement, any between-group difference had disappeared on the sole specific anxiery tating represented by the FQT and FQA vatiables. In line with a number of previous reports, we had expected that a PD patient with a comorbid depression would benefir less from treatment than the PD parients without depression. We tailed to find empirical support for this hyporhesis. The results firmly contradicted our prediction. No single rating suggested that the group of depressives had poorer results than the nondepressives. On the contrary, if anything there was a difference in favour of the patients with depression, who displayed a greater decrease on the agoraphobia subscale of the $F Q$. This may relate to the higher initial value of the depressive group on this variable (law of initial values, cited by Woodman et al., 1994). The resolution of the depressive disorder and the related improvement in activity may have influenced this variable as well. No argument 
was found to suggest that PD patients who are depressed will have less benefit from treatment than other PD patients. We calculated the mean time in treatment for both groups, knowing that the time of discharge had been determined in mutual agreement between clinicians and pationt, based on the overall clinical condition. For this parameter we faled to find any difference between depressives and non depressives. Our results are consistent with a number of recently published studies (Albus et al., 1995; Brown et al., 1995).

The results of the present retrospective study are a good illustration of the state of affairs as far as the comorbidity between anxiety and depression is concemed. The caveats which have been formulated at the beginning of this chapter apply. We accept the current diagnostic systems in use (DSM III, III-R and IV, and ICD-10) as working hypotheses. In these systems, anxiety (e.g. PD) and depression are presented as separate entities. However, there is plenty of evidence that both disorders are strongly interrelated.

Returning to the three models we have discussed:

(1) - association by chance of two diseases with a high basc rate of prevalence;

(2) - one disease predisposing to another;

(3) - two surface manifestations of one underlying proces;

We have found, in the recent literature as well as in the above study, a number of arguments in favout of the second theory. In spite of some reservations due to the retrospective nature of the design, our data support this idea that PD may cause depression. It is woth noting that the reverse may not be true: only a minority of depressive patient seems to develop PD (Chen and Dilsaver, 1995). If this holds true it may be an argument against the third model. A oneway causal relationship is not compatible with merely one single underlying discase. Arguments in favor of one or two diseases are not likely. It seems more likely that as long as the understanding of the parhogenic mechanisms of $P D$ and depression are not fully understood, and matcher with the classification systems, the issue of comorbidity will not be solved.

\section{RMVIRENCES}

Albus $M$ and Scheibe $G$. Outcome of panic disorder with or without concominge alepressiont at 2-ycar prospective follow-up study. Am / Psodidoy 1993:150,1878 1880

Albes M, seheibe $G$ and Scherer J. Panic disorder whth or without concomiant depression 5 yearsatrer ereatment: a prospective follow-up f Afed Digh 1995:34, 109. 115

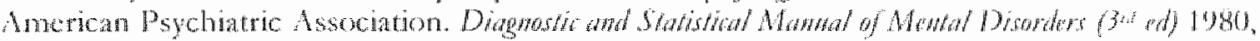
Washington DC, American Psychiatric Prosus

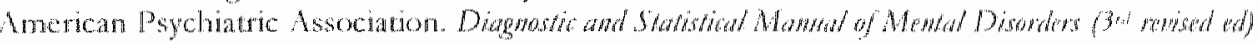
1987. Washington DC. Amcrican Psychatric Prese

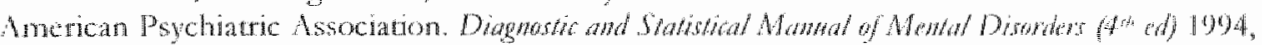
Washington IXC, American Psychiatric Press 
Andrade 1, Luton W and Chiloat H. Lifetime comorbidicy of panic artacks and major depression in a population based study. Sympion profiles. Br J Psybiato 1994165 , $363-36 \%$

Mall $S$, Buchwald $A$, Whded $M$ and Shekhat $A$. Depression and generalixed arxiet symptoms in panic disonder. Implications for comorbidity. I Nen Mers Dren 1995: 183, 304-308

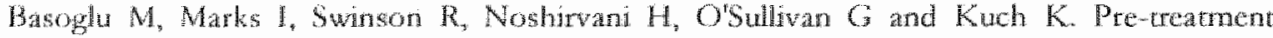
predictors of treament outcome in panic disonder and agotaphobia treated with itprazolam and exposure. I Afor Divori 1994: $30,123-132$

Black D, Wesner $R$, Gabel $J$, Bowers W and Monahan P. Predicrors of shorterm trament response in 66 paticnts with panic disorder. I Affer Disord 1994: 30, 233-241

Broict $A$, Chancy $D$ and Honinger $G$. Major depression in pariches with agotaphobia and panic disorder. Ant Gen Pydoty 1984:41,1129-1135

Beret $A$, Chaney $D$ and Heninger (3. The dagnoseric validity of anxiety disordets and ther relarionship to depressive illness. Am / Psydratry 1985:142,787.797

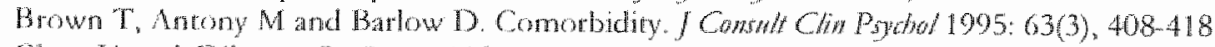

Chen $Y$ and Dilsaver $S$. Comorbidity of panic disonder in bipolar illness evidence from the

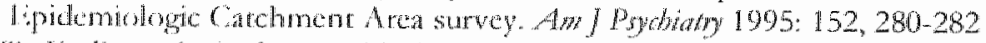

Corycll W, lindicote J, Andreasen $N$, Keller $M$, Chaton $P$, Hirschteld $R$, Scheftren $W$ and Winoku Go Dopression and panic attacks: the significance of overlap as reflected in

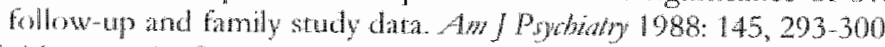

Davics I, Noman R. Correse I. and Malla $A$. The retationship berwech types of anxiety and depression / Nem Ment Diseat 1995: 183,31-35

Di Nardo $P$ and Bandow D. Syndrone and symptom co-aceurence in the anxiery disorders. In:

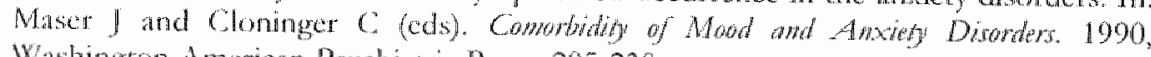
Washingron American Psychiatic Press 205-230

Faton W, Kessler $R$, Wintehen $H$ and Magee W. Panic and panic disorder the Unired States. Any f Pydiding 1994: $151,413-420$

feinstein A. The pre-therapeutic classificarion of comorbidity in chronic distase. I Chros Disease $1970: 23,455-468$

liances $A$, Manning D, Matin D, Kocsis J, McKinney K, Hall W and Kline M. Relationshep of

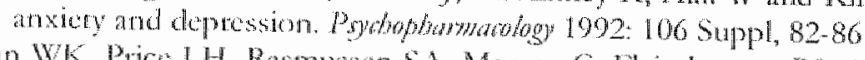

Goodman WK, Price L.H, Rasmussen SA, Mazne C, Pleischmann R, Hill CI, Heninger GR and Chamey DS. The Yale- Brown Obscssive Compulsive Scalc, 1: Develonment, use

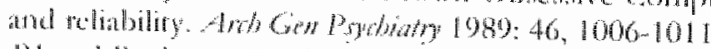

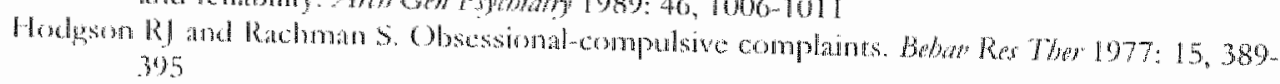

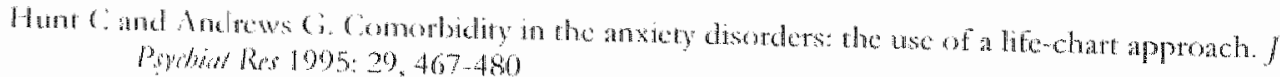

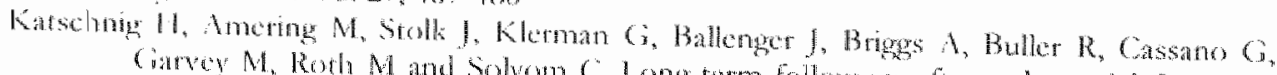

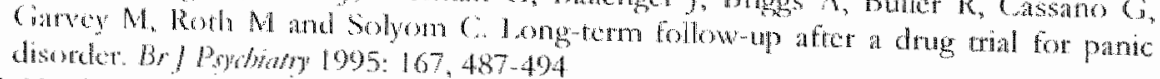

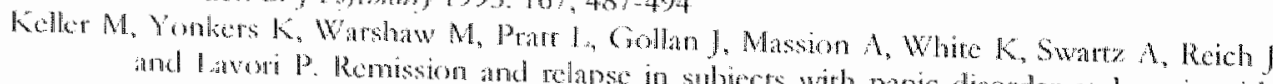
and $L$ avore $P$. Remission and relapse in subjects with panic disorder and panic with $1024: 182,290-296$

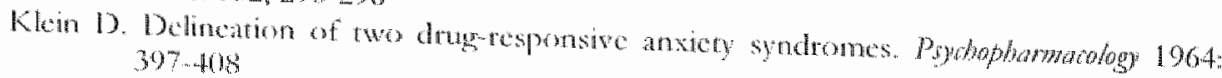

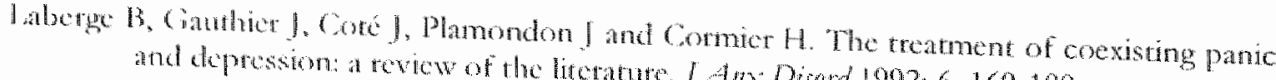

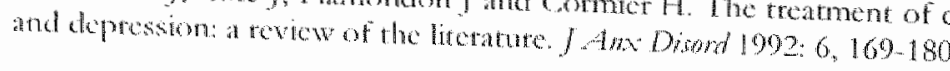


Leckman ], Club $M$ and Pauls $D$. Comorbidty of panic disorder and maino depresaton: a revew

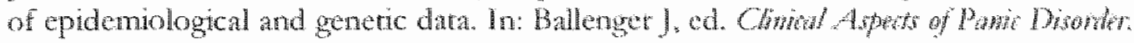
New York: Willey-Liss. 1990: 141-14?

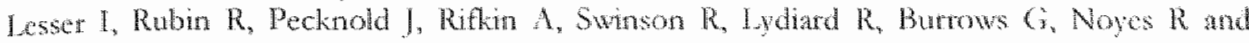
Dupont R. Secondaty deptession in panic disorder and stgenphobia. I. Foquency.

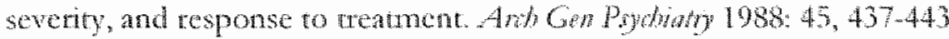

Lesser I. Panic disorder and depression: comoccurtence and treatment In: Ballenger), wo Chiof Aptects of Panc Disomer. New York: Wille-Liss. 1990: 181-191

Lydiard R. Coexisting depression and amxery: special diagnosfic and treathent issues / Chy Pyothot 1991: 51 Suppl 6, 48-54

Maddock R, Carter C, Backet K, Beiman B, Krishnat K, Jefferson J, Lewts C and lidbowty M. Relarionship of past depressive cpisodes to symptom severity and trotment

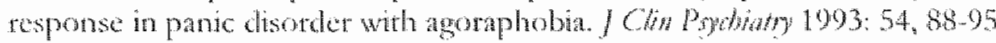

Maice W, Lichermann D. Minges J. Oehrlein A and lianke P. A controlled family study in panic disorder. I Podhut Rerew 1993:27 Suppl 1,79-87

Marks IM and Mathews AM. Brief standard self-rang for phobic particnts. Bohat ke ther 1979 : $17,263-267$

Marks 1, Swinson R, Basogh M, Kuch K, Noshivani H, OSullivan C, l.cllot P, Kirly M, MoNamee $G$, Songun $S$ and Wickwire K. Aprazolan and expessure alone and combined in panic disorder with agoraphobia. A controlled sndy in london and Toronto. Br P Prodiong 1993: $162,776-787$

Mezich , thn C, Fabrega $H$ and Pilkonis P. Patterns of psychatric comotbidiry in a latge population presenting for care. In: Maser J, Cloninger C. ods. Comondidy of Mond and Anxioty Disowders. Washingron: Mmerican Psychatric Press, Inc. 1990: 189-204

Montgomery $S A$ and Asberg $M$. A new depression scale designed to be sensitue to change Br Pydinaty 1979: 134, 382-389

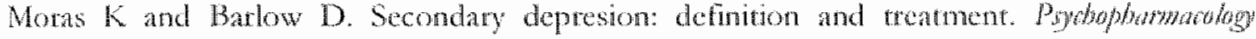
Bulletin 1992:28,27-33

Noyes R, Reich J, Christansen \, Suezer M, Pfohl B and Coryell W. Outcome of panic disoted: relationship to diagnostic subtypes and comorbidity. Ard Ges Paxdraty 1990:47, 809. 818

Noyes R, Wrodman C, Garvey M, Cook B3, Suelzer M, Clancy I and Anderson D. Gicneralized

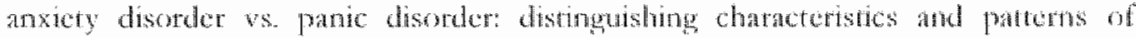
comorbidity. I New Men Dis ase 1992: 180, 369-370

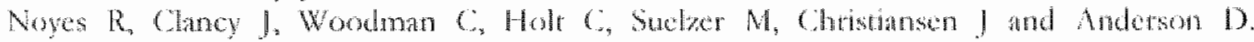
Envtronmental factors telated to the outcome of pantic disoldar. A scuen year follow up study. J Nen Wort Diserse 1993: $\left.181,52^{\circ}\right) 538$

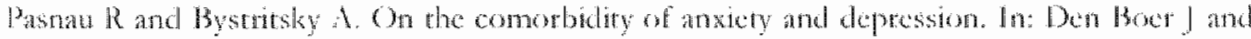

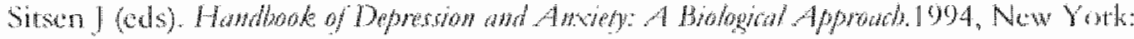
Marcel Dekker. $45-56$

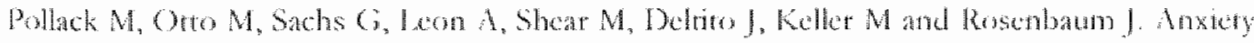
psychopathology predictive of outcome in patients wh panic disurder and depression

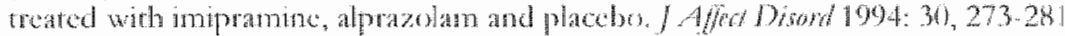

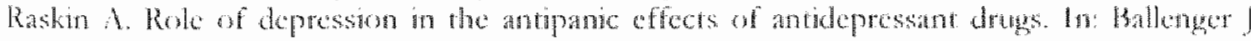

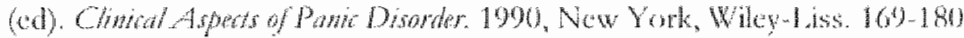

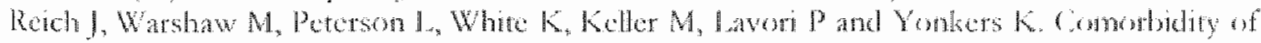

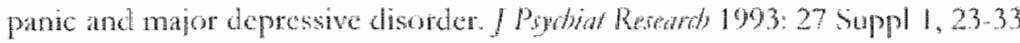

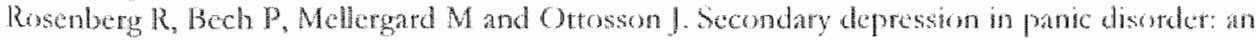
indicator of severity widh a wak effect on outcome in alpratalan and impramine

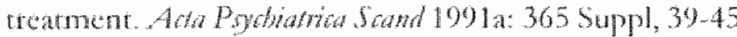


Rosubbrg $R$, Bech $P$, Mellergard $M$ and Otosson J. Aprazolam, impramine and placebo treament of patic disorder predicting therapeutic response. Awa Pyobiar Sakth $1991 \mathrm{~b}: 365$ supp, $46-52$

Roth M. Classification of affective and related psychatric disorders. In: Horton R and Katona $C$

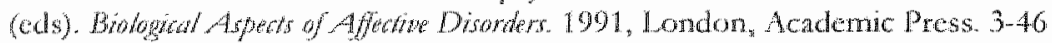

Sanderson W Beck A, Beck J. Syndrona comorbidity in patients with major depression or dysthymia: prevalence and remporal relationships. Am J Psydrato 1900: 147, 1025 1028

Snath RP, Baugh Sf, Chaden MD, Husain and Sipple MA. The Clinical Anxiety Sale an instrument derived from the Hamilton Andety Scale. Br/ Pybowy 1982: 141, 518-523

Snaith R. What do deptession rating scales measure? Bry Porbothy 1993: 163, 293-298.

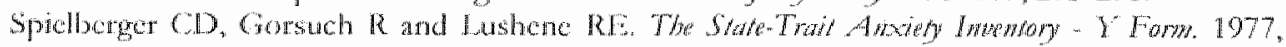
Pallo Aro, Consultant Psychologists Press

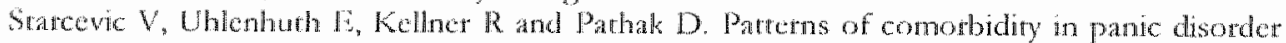
and agraphobia. Powtraty Resarb 1992: 42,171-183

Swinson R, Kuch K. Clinical features of panic and related disonders. In: Ballenger ) (ed). Chined

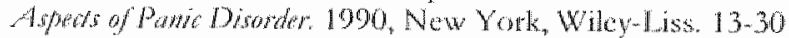

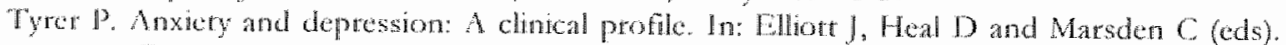

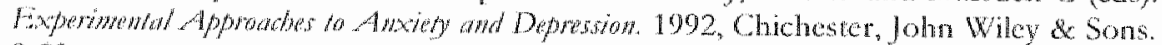
9.23

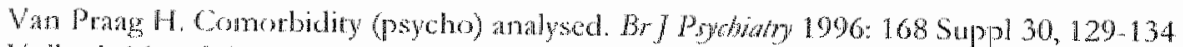

Vollsth $M$ and Angst $)$. Outcome of pantc and depression in a seven-ycar follow-up: results of the Zurich study. Ada Ponchatr biand 1989: $80,591-596$

Woisman M. Family genctic studies of panic disorder. J Psybiat Res 1993a: 27 Suppl 1, 69-78

Weissman M, Wickmanane P, Adams P. Lish J. Howwath $E$, Chancy D, Woods S, Lecman $E$ and lrosch $\mathrm{E}$. The relationship between pantic disonder and major depression: a new

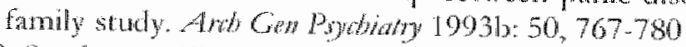

Wetales Sanderson W. Comorbidity of anxicty disonder. In: Asnis $\mathrm{G}$ and van Prag $\mathrm{H}$ (cels).

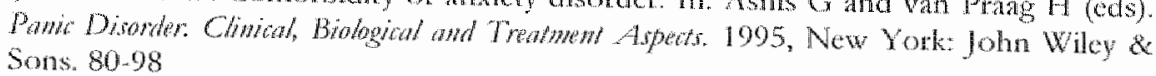

Withenen $H$ and Essau C. Epidemiology of panic disorder: Ptogress and unresolved issues. Podin Reseawh 1993:27 Suppl 1,47-68

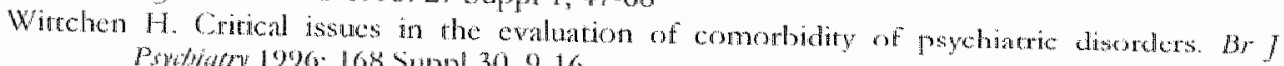
Paydrato 1996: 168 suppl 30, 9-16

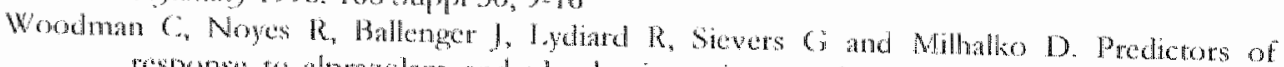

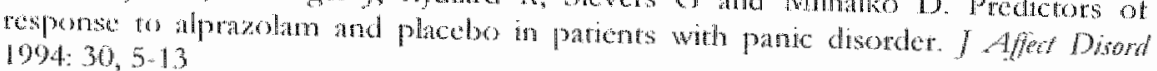

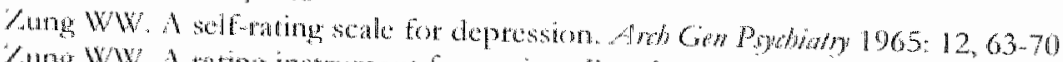

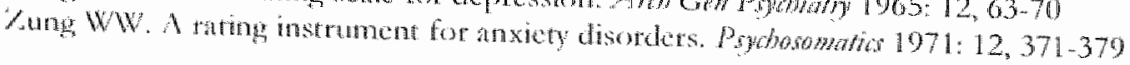


4. COMORBIDITY OF OBSESSIVE COMPulsive DISORder AND DEPRESSION: PREVALENCE, SYMPTOM SEVERITY, AND TREATMENT EFFECT

T. Overbeek, K. Schruers, E. Vermetten and E. Griez 



\section{ABSTRACT}

Bakkgromd: The goal of this study was to investigate the co-occurrence of depressive disorders in obsessive-compulsive disorder (OCD) and the effect of these disorders on combined pharmacologic and behavioral treatment for OCD.

Method: A retrospective chart analysis was performed on baseline ratings of 120 OCD patients and postreatment tatings of 72 of these parients. For depressive symptoms, the Montgomery-Asberg Depression Rating Scalc (MADRS) and the Self-Rating Depression Scale (SDS) were applied, for obsessive-compulsive symptoms the Yale-Brown Obsessive Compulsive Scale $(\mathrm{Y}$-BOCS) and the Maudsley Obsessive Compulsive Inventory (MOCD) were used; and for general anxiety symptoms, the Self-rating Anxiety Scale (SAS), the Clinical Anxicty Scale (CAS) and the State-Trait Anxiety Inventory (STAI-1) were given.

Results: One third of the OCD patients in our sample were found to be depressed. Symptom severity on OCD symptoms at baseline did not differ between depressed and nondepressed OCD patients; on general anxicty symptoms, the comorbid group was more severely affected. Both depressed and nondepressed OCD patients responded well to treatment, as reflected in assessments for depressive, obsessive-compulsive and general anxiety symptoms. However, comorbid depression had a negative effect on treatment: depressed OCD patients showed less improvement than nondepressed OCD patients on most scales.

Concuizon: Depression frequently accompanies OCD and appears to affect treatment ouicome negatively. While both groups of patients improved with combination treatment the OCD-alone group had more improvement than the group that had comorbid depression. 



\section{TNTRODUCTION}

Clinical psychiatric conditions frequently show oxerlap between different psychopathologies. Clinical studies have demonstrated that different diagnoses may coexist. A large number of epidemiological soudies have shown a relationship between anxiety disonders and affective disorders (Angst, 1996; Regier et al, 1998). Since several studies report that over $90 \%$ of individuals with anxiety disorders have a lifetime history of other psychiaric problems, anxiety disorders rarely exist in isolation (Kaufman and Channey, 20000. Comorbidity of any of the anxiety disordets with depression is also very common: panic disorder (PD) with or without agoraphobia, sociall phobia (SP), generalized anxiety disotder (GAD) and obsessive compulsive disorder (OCD) display a higher than expected rate of co-occurrence with depressive disorders (Sanderson et al, 1990; Wittchen et al,, 1999). These studies contribute to speculations about etiology, pathophysiology, psychopharmacology, and behavioral treatment. In the present study, we report on the comorbidity of OCD and depression in an outpatient population that was referred for treatment of OCD.

The magnitude of the comorbidity reported in the literature varies widely (Angst, 1996) and depends on methodology (study design and experience of interviewers), samples (community or treatmenc), and case definition (diagnostic criteria and thresholds). The term comorbidity should be used with caution and should be properly defined. However, in various studies, its use is often vague or erroneous. Maser and Cloninger (1990) mention the large number of definitions that ate commonly used. Ideally, comorbidity should be restricted to disorders and syndromes but is, in effect, also used to describe the co-occurrence of symptoms. Another erroncous use derives from the nature of the current classification system in psychiatry. The Diagnostic and Statistical Manual of Mental Disotders, Fourth Edition (DSM-IV, APA, 1994), is intentionaly designed to serve as a taxonomic instrument and therefote offers criteria for inclusion and exclusion, but pathognomonic signs in psychiatry ate lacking and a diagnosis is cumulatively made based on the presence of clustcrs of symptoms. Another confusing factor is the chronological appcarance of discases, since comorbidity can be present throughour a pationt's lifetince, at any time in the past, of just at the moment that another disorder exists. Because of the absence of a theoretical basis in the classification system, careful use of DSM-IV is wartanted in cases of comorbidity.

The coexistence of more than one psychiatric disorder at a time can also have both theoretical and practical implications. For example, theoretically, the high co-occurrence of more than one psychiatric disease may suggest shared pathogenic or genetic factors. If chronological patterns occur at the same time, 
centain causal links may be established or preventive action taken. Furthermore, practical clinical implications could be that course and response to treatment differ berween patients with one or more diagnoses. For example, it has often been suygested that depressed PD parients are more resistant to treatment than parients with PD alone (Noyes et al, 1990 ).

To interpret prevalence rates of comorbid disorders, individual prevalence rates are needed. For OCD these figures have gradually grown over the years. For a long time, OCD was thought to be quite rare since people are apparently reluctant to request treatment due to fear or shame (Rasmussen and Eisen, 1992). Recent epidemiological studies have shown a six-month prevalence rate of OCD of approximately 1\% (Bebbington, 1998) and a lifetime prevalence rate of $2 \%$ to $3 \%$ (Hollander, 1997; Regier et al., 1998; Sasson et al, 1997; Weissman et al., 1994), which implies that OCD is much more common than formerly suggested. The lifetime prevalence rate for depressive disorders vaties from about 8\% (Regicret al., 1990) to 11.7\% (Witchen et al., 1999).

As reported in several studics (Black and Noyes, 1990), depression is the most frequent complication of OCD. Comorbidity rates in reported studies vary widely, from 19\% to $90 \%$ (Milanfranchi et al, 1995). This is largely due to methodological and semantic differences. Within this wide fange, however, most epidemiological studies show that about one third of OCD patients suffer from a liferime depressive episode. In clinical populations comorbidity tates are increasing to about two thirds (Crino and Andrews, 1996). Rasmussen and Eisen (1992) found that one third of OCD patients suffer from concurtent depression at referral and rwo thirds suffer from lifetime depression. A possible explanation for the discrepancy between clinical and nonclinical studies may be that many OCD patients only seek help when depressed, as suggested by Black and Noyes (1990). As for chronology, it is reported that most often the onset of OCD is before that of depression $(38 \%$ ), whereas transition from depression to OCD occurs in only $11 \%$ of cases (Black and Noyes, 1990 ).

As noted arlice, the therapeutic implications of a comorbid depressive disorder in OCD ate still pootly understood. Comorbidity affects the outcome of behaviotal versus phatmacotherapeutic interwentions. For example, in OCD, severe depression may worsen the prognosis for behavional treatments, whereas most studies suggest that pharmacological treatment with selective serotonin reuptake inhibitors (SSRIS) is equally effective for OCD with or without concomitant depression (Den Boer, 1997).

To berrer understand the previously mentioned wide range of reported comorbidity, to appreciate the limitations of these studies, and to gain insight into questions regarding the impact of treatment, we decided to conduct the following study in our clinical sample of OCD patients. We investigated the prevalence of depressive disorder as a comorbid diagnosis in a sample of OCD pationts in our outpatient clinic, which specializes in anxiety disorders. 
Comorbidity was defined as the coexistence of two syndromes (i.e, OCD and depressive disorder according to the DSM-IV criteria, not only the presence of sub-syndromal symptoms). We also sought to assess the influence of a comorbid depression on treatment outcome for OCD.

Hypotheses were posed as follows: (1) as reponted in orher studies, point prevalence of depressive disorder in OCD will be in the ange of $30 \%$ to $60 \% ;(2)$ the presence of a comorbid depression will be reflected in mote severe symptoms of OCD and, therefore, in higher scores on the Mandsley Obsessive Compulsive Inventory (MOCD) and Yale-Brown Obsessive Compulsive Scale (Y-BOCS); and (3) the effect of combined psychopharmacologic and behavional treatment for OCD will not differ between depressed and nondepressed $O C D$ patients.

\section{MATERIAS AND METHODS}

We performed a retrospective chart analysis. One hundred twenty patients with DSM-IV axis I OCD as their principal diagnosis were included for baseline (prevalence and severity) assessments; for 72 patients, posttreatment data were also available. Patients were referred for treatment to the Academic Anxiety Center Maastricht, the Netherlands, from 1995 through 1999. As part of a standard protocol, all patients were evaluated by means of a semi-structured psychiatric interview, with special emphasis on anxiety and affective spectrum symptoms. A diagnosis was made according to DSM-IV ctiteria and confirmed by two experienced psychiatrists. Patients also teceived a physical examination and were additionally evaluated by means of the following standardized questionnaires and structured interviews: The Yale-Brown Obsessive Compulsive Symptoms (Y-BOCS, Goodman et al. 1989); the self-rating Maudsley Obsessive Compulsive-Inventory (MOCl, Hodgson and Rachman, 1977); the Montgomery-Asberg Depression Rating Scale (MADRS, Montgomery and $\Lambda$ sbetg, 1979); the Self-Rating Depression Scale (SDS, Zung, 1965); the Clinical Anxiety Scale (CAS, Snaith, 1982); the Sclf-Rating Anxicty Scale (SAS, Zung, 1971); and the State Trait Anxicty Inventory, state form (STAI-1, Spielberger, 1977).

Patients were offered combined psychopharmacological and behavioral therapy after the diagnostic procedure was completed. Initially, in the furst phase, patients received phamacotherapy, i.e, a prescription for one of the current SSRIs, in increasing dosages for 10 to 12 weeks (up to effective clinical doses or maximum doses of $300 \mathrm{mg}$ of fluvoxamine, $60 \mathrm{mg}$ of fluoxetine, or $60 \mathrm{mg}$ of paroxetine), with a visit for a global clinical assessment at our clinic every 2 to 4 weeks. In the second phase, behavior therapy was added, bascd on exposure and response-prevention intervention. The dutation of the two phases was flexible, depending on individual clinical progression. For example, 
some OCD patients benefited from medication to such an extent that only a few sessions of behavior therapy were needed to stabilize the symptoms and to obtain satisfactory results, whereas other patients were more complicated in the sense that they needed more prolonged and sometimes extensive behavioral therapy. Discharge was planned by mutual agreement between patient, behavioral therapist, and psychiatrist. At discharge, the inirial psychopathological rating scales were repeated (posttreatment assessments).

\section{Sibjects}

The data of 120 consecutive OCD patients teferted to our center from 1995 to 1999 were included in the study for baseline ratings. For 72 patients, postreatment assessments were also available. Data from this group were analyzed for treatment effect. Patients were included if a diagnosis of OCD was made as the principal diagnosis on DSM-IV axis I. Because of the nature of our clinic, even in comorbid cases, the reason for referral was the OCD. The exclusion critcrion for the present study was missing data at baseline.

\section{Anatyais}

All statistics were performed with Statistical Package for the Social Sciences (SPSS-PC), version 10. Students' T-test for independent samples was used to test differences between depressed and nondepressed OCD subgroups at baseline and after treatment. A T-test for paired samples was used to test differences before and after treatment for the 72 completers. A Chi-square test was applied to test the proportion of males and females having a depression. Chi-square tests were also used to compare the distriburion of depressives in the group of completers and noncompleters. Hypotheses regarding improvement were analyzed using a multivariate analysis of variance (MANOVA).

\section{Risuthos}

\section{Buseline malwes}

Demographics. The majority of the patients in the study had been referred by their family practitioner; some had been referred by psychiatrists. Of the 120 subjects we assessed at baseline, $40(33 \%)$ were male and $80(67 \%)$ were female: Nineteen $(40 \%)$ of the 48 parients who were assessed only at baseline were men, and $29(60 \%)$ wete women (nonsignificant [NS]). Of the 72 patients who atso received a posttreatment assessment, 21 (29\%) Of the 72 patients
$(71 \%)$ were female (NS).

The mean $\pm S D$ age of our 120 baseline subjects was $37.8 \pm 12.1$ years. The mean age of the women was $37.1 \pm 11.7$ years; for the men it was $39.3 \pm 12.8$ years (NS). The depressed parients were $37.6 \pm 11.3$ years of age, and the 
nondepressed were $37.9 \pm 12.6$ years of age (NS). The mean age of the completers was $39.2 \pm 14.0$ years, and that of the noncompleters was $37.0 \pm$ 10.7 years (NS).

Prevalence. To address our first hypothesis on the prevalence of a comorbid depressive disorder, all 120 patients were considered. Of these 120 baseline patients with OCD as the principal axis-I diagnosis, 44 patients $(37 \%)$ also met DSM-IV criteria for depressive disorder at the time of teferral point prevalence). The distribution in the group that had only one assessment was 19 $(40 \%)$ with comorbid depression and $29(60 \%)$ without depression; in the posttreatment group, 25 patients $(35 \%)$ were depressed at baseline, whercas 47 patients (65\%) were not (Chi-square NS).

Notably, the gender distribution in the comorbidity subgroups, as well in the completers as in the noncompleters, was decidedly female. It appeared that (for all 120 baseline subjects) only a minority of male OCD patients suffered from comorbid depression - only $6(15 \%)$ of 40 compared with $38(48 \%)$ of 80 of the female OCD patients (chi-square 12.12, $\mathrm{p}=.001$ ). For the 72 completers, only 2 of 21 men were depressed, versus 23 of 51 women (Chi-square 8.30, $\mathrm{p}=.006$ )

Severity. To answer the second hypothesis on symptom severiry we looked at the mean scores for the 120 baseline subjects and at the subgroups of completers and noncompleters. Mean scores on baseline assessment scales are reported in Table 1. The severity of symptoms at intake for all 120 patients differed for depressed and nondepressed OCD patients only on the general anxiety (CAS $p<.001$, SAS $p=.001$, and STAI-1 $p<.001$ ) and depression measures (MADRS $p<.001$ and SDS $p<.001$ ), not for the specific OCD measurements (MOCI [NS] and Y-BOCS [NS]). The severity of initial symptoms across the subgroups completers and noncompleters only differed. on the Y-BOCS $(p=.035)$, with the important finding that the noncompleters showed a lower mean value. Within the group of depressed OCD paticnts, there were no differences on assessments between completers and noncompleters. Interestingly, however, within the nondepressed OCD paticntgroup it was the completers who had significantly higher scotes on the $\mathrm{Y}$ $\operatorname{BOCS}(p=.017)$ and MOCI $(\mathrm{p}=.049)$. 


\section{Pastreathent values}

To test the third hypothesis on treatment effect, the data of the 72 completers were analyzed (Table 2). Mean treatment duration did not differ significantly betwen the groups: depressed OCD patients were discharged after $29 \pm 9$ weeks and nondepressed patients after $28 \pm 13$ weeks (NS). Although the mean scotes on the MADRS (Figure 1) were not significantly worse for the depressed patients compared with the nondepressed patients posttreatment, on the SDS (Figure 2) the formerly depressed patients still showed significantly more severe $(\mathrm{p}=.001)$ symptoms. Postteatment scores on the Y-BOCS $(\mathrm{p}=.02)$ (Figure 3) and MOCI ( $\mathrm{p}=.004$ ) (Figute 4) were worse for the depressed OCD patients, although on these scalcs depressed and nondepressed patients were equally affected at baseline. Also, symptoms on two of the three general anxiety measures (SAS, $\mathrm{p}<.001 ;$ STAI-1, $\mathrm{p}=.004$ ) were worse for the depressed OCD paticnts (Table 2).

\section{Treatment effect}

Treatment proved to be effective on all measures (Table 2). Paired-samples Ttests showed significant lower mean scores on the posttreatment assessments $(p<.001)$. The repeated-measures MANOVA also revealed significant time effect on all measures for both depressed and nondepressed OCD patients. Differences between the depressed and nondepressed groups were statistically significant for measures on the MADRS, SDS, STAI-1 and SAS, but not statistically significant on the CAS, MOCI and Y-BOCS ( $\mathrm{P}$-values in Table II). MANOVA tests showed a significant time-by-group interaction effect on the MADRS and the MOCI, suggesting that nondepressed patients improved significantly mote than depressed ones on these scales. For the other measurements there were no significant interaction effects. Thus, on these scalcs, both subgroups improved to a similar extent. 

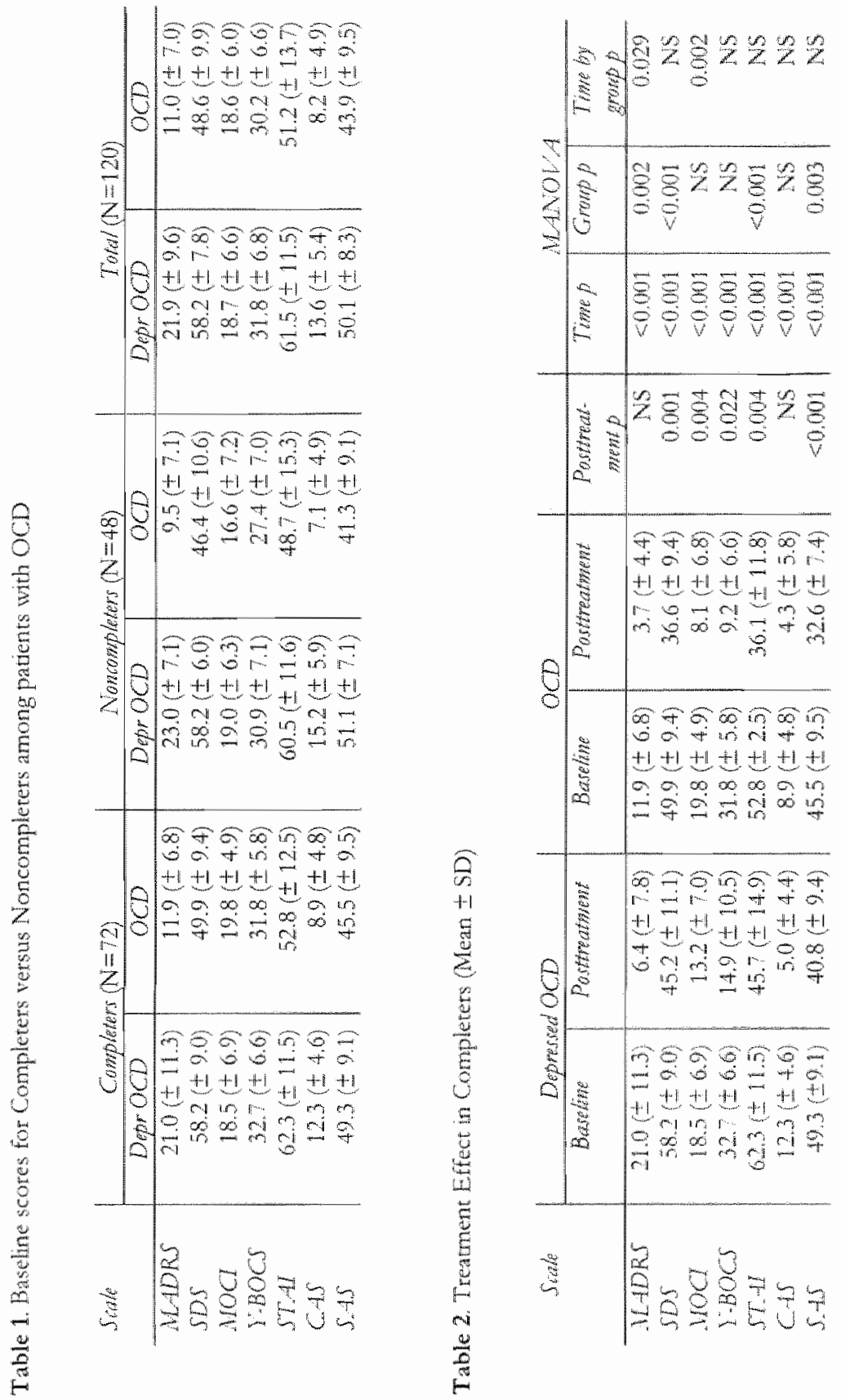


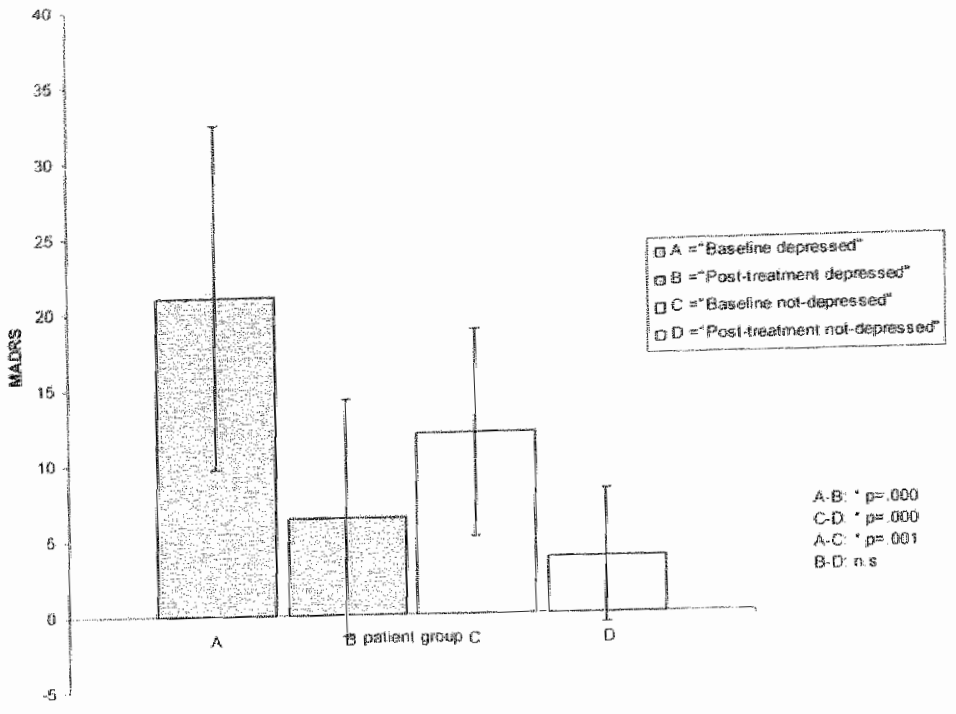

Figure 1. Mear MADRS at Basdine and Pose Treatnent for Depressed and Not-depressed OCD Paticats. Total $N=72$, Depressed $N=25$, Not-depressed $N=47$

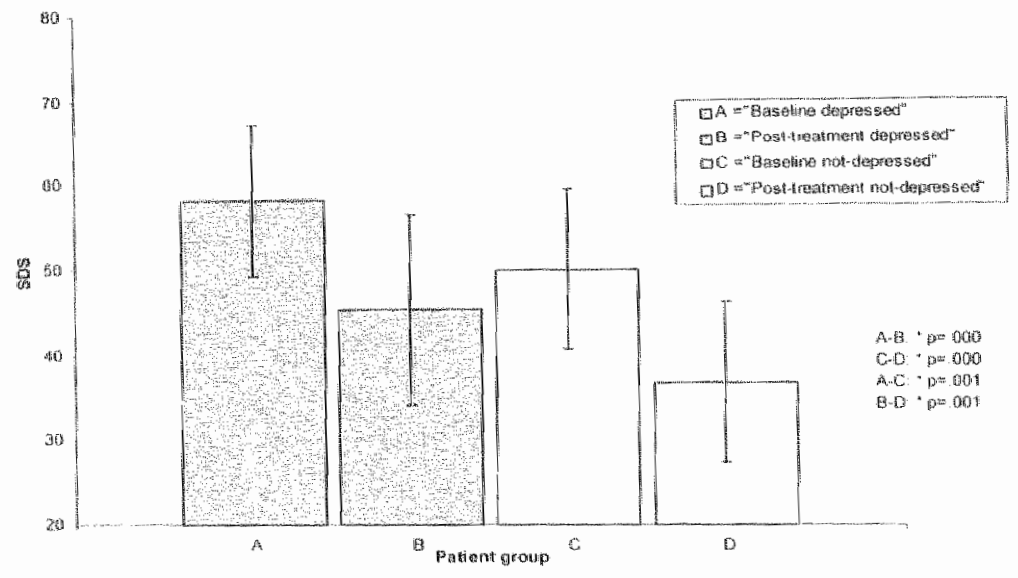

Figure 2. Man SDS an Bascline atud Post Trentment for Depressed and Not depressed OCD Parients. Toual $N=72$, Depressed $N=25$, Not-depressed $N=47$ 


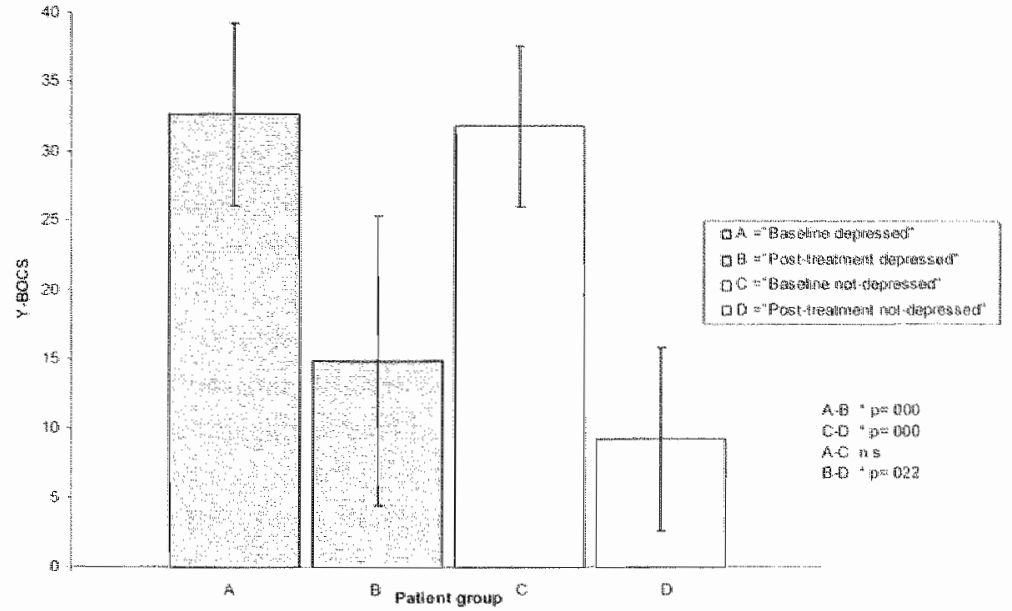

Figure 3. Mean K-BOCS at Baseline and Post Treament for Depressed and Nordeptessed OCD Patients. Total $N=72$, Depressed $N=25$, Not-depressed $N=47$

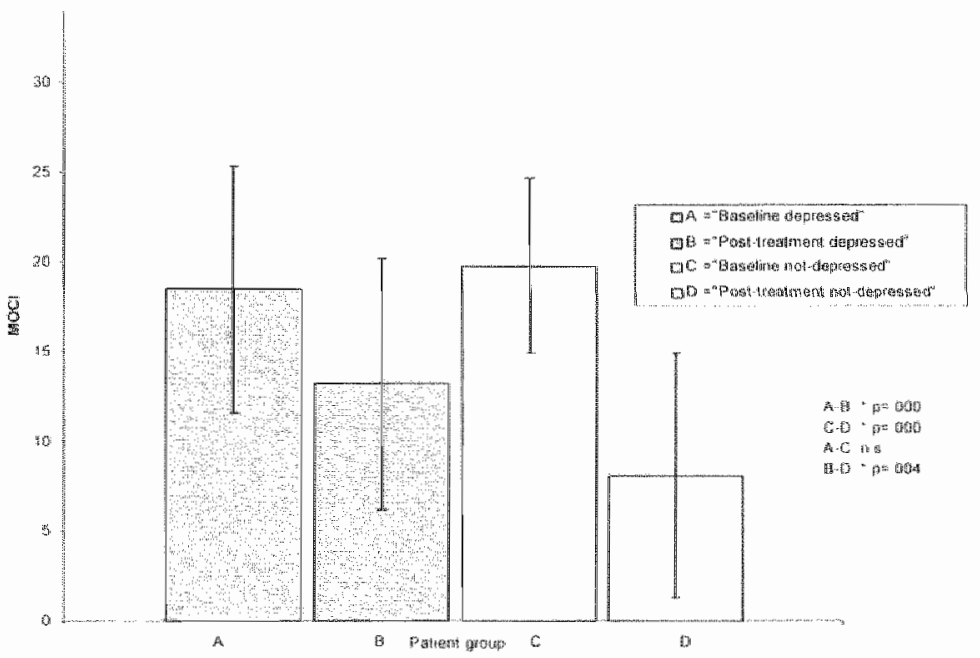

Figure 4. Mean MOCl at Baseline and Post Trearment for Depresed and Not-depresed OCD Patients. Total $N=72$, Depressed $N=25$, Not-depressed $N=47$ 


\section{DHACSSION}

As for our first hypothesis, which defined comorbidity as coexistence of wo separately defined psychiatric disorders according to full DSM-IV criteria, we found a point prevalence of depressive disorder of $37 \%$ in our clinical sample of OCD patients. "This was well within the range we expected on the basis of eatlier cired clinical studics (Black and Noycs, 1990; Perugi et al., 1997). However, it did not support the assumption that the majority of OCD patients only seck help when depressed, since $37^{\circ} / 0$ is nor much higher than most population-based epidemiologic studics (Crino and Andrews, 1996) have reported for concurtent depression. The mean MADRS score for the total group of depressed OCD patients in the present study appeared rather low (mean 21.9, SD =9.6), reflecting depressive disorder of only moderate severity. Moderate depression would seldom be a reason to seek help since depressive symptoms are easily accepted as a rather nomal reacrion to impairment by OCD, whereas severe levels of depression interfere more with daily life and affect the quality of life to a greater extent.

It was interesting to find that there was a significant difference in gender among the group with comorbid depression. There were more females with comorbid $O C D$ and depression in the ratio of $3.2: 1$, in our sample. This was higher than the known (epidemiological) matio of $2: 1$ female:male ratio for depressive disorder alone. A higher ratio for depression in OCD has, to our knowledge, not been reported in other clinical studies before. However, this finding should be interpreted with caution. In the first place, because there are reported general differences in treatment-secking behavior between males and females. Sccondly, there are only few srudies that report on gender differences in OCD in relation to depressive disorder, and in these the additional risk for females did not exced the reported epidemiological gender distribution for depressive disorder. Female telatives of OCD patients seem to have a higher risk of developing depressive disorder (but not OCD) than male relatives (Sciun or al., 1995). Another study by Castle et al. (1995) explicitly addressed gender differences in OCD, and found that more female OCD patients were on antidepressant medication or had a past history of treatment for a depression than male OCD patients, but the distribution was in line with the gender ratio for depression alone.

Our sccond hypothesis, that OCD patients with comorbid depression tend to show more severe symptomatology than nondepressed OCD patients, could not be confirmed for scotes on the specific OCD rating scales Y-BOCS and MOCl. Depressed parients however did show more severe symptoms on the general anxiery scales CAS, SAS, and STAL-1. However, these scales are known 
to measure not only specific symptoms of anxiety disorders but also non specific feelings of stress and show overlap with depressive symptoms (Keedwell and Snaith, 1996). As could be expected, the specific depression assessments MADRS and SDS showed significantly higher scores for the depressed patients. So the most interesting finding regarding symptom-severity is that baseline values of the specific OCD rating scales MOCI and Y-BOCS did not differ significantly between depressed and nondepressed OCD patients. There are at least two possible explanations for this. The first possibility is that OCD and depressive disorder are two separate diagnostic entities. (Delgado and Moreno, 1998) and thus no correlation between depression and OCD scales would be expected. A second explanation could be that the scores on the MOCI and Y-BOCS in our sample were quite high from the start, so there was not much room for significant variation (ceiling effect) and presumably more suffering could only be reflected in the other, more general anxiety-related, scales. In any case, with regard to symptom severity, we can conclude that comorbid, depressed OCD patients showed more severe (general) anxicry and depressive symptoms than nondepressed OCD patients, but their baseline level of OCD symptoms was the same.

As for the third hypothesis on treatment effect, we were able to confirm that both depressed and nondepressed OCD patients ptofit from the combined treatment offered for OCD. Both improved significantly during therapy with a reduction of mote than $50 \%$ on initial scores on the MADRS, Y-BOCS and CAS. The scores on the SDS, MOCI, STAI and SAS also showed significant decreases of between $25 \%$ and $50 \%$. It is interesting to nore that the measurements which show the best improvement are investigator-rated scales, whereas the self-rating instruments show a smaller range of improvement. Tho phenomenon that clinician-scored measures often show more improvement than do the selfadministered questionnaires has been described before (Van Balkom et al., 1994).

Although the baseline scores for the depressed subgroup did not differ on the OCD measures, after treatment the depressed OCD patients scored significantly higher on the $\mathrm{X}-\mathrm{BOCS}$ and $\mathrm{MOCI}$ than elid the nondepressed patients, reflecting mote remaining symptoms. Also, on the gencral sclf-report anxiety scales SAS and STAI-1, after treatment the depressed paticnts still had higher symptom severiry than the nondepressed ones. This finding, that the residual scores on several scales postreatment were highet for the depressed subgroup did point to the fact that a combined occurrence of obsessivecompulsive and affective symptoms showed more resistance to tratment or complicates trearment. Treatment duration, however, was similar in both groups. The frequent co-occurrence of depression in OCD has formerly led to hypotheses about OCD being an affective variant (Zohar and Insel, 1987). This is partly supported by the therapeutic benefir of antidepressant agents for OCD 
(Picinclli et al., 1995). Initial studies mention that levels of deptession at the outset are important for the final ourcome (Marks, 1982). However, later metaanalytic studics have shown that the beneficial effects of antidepressants such as clomipramine and of SSRIs on OCD symptoms are unrelated to the presence of depressive symptoms (Den Boer, 1997; Picinelli et al., 1995; Mavissakalian, 1985), which again undemines this hypothesis and implies another relationship between the wo disorders. Hollander et al. (1991) state that depressive symptoms interfere with the response to both psychopharmacologic and behavional treatments of OCD. Also, Foa (1979) reported behavioral therapy outcome to be negatively influenced by the presence of (severe) depressive disorder. Montgomery (1998) argues that depression scen in OCD should be regarded as part of OCD and not as a separate disordar of major depression, for depressive symptoms in OCD can, in his view, only be expected to respond to effective antiobsessional treatments and not to notadrenergic antidepressive agents. Delgado and Moreno (1998) cmphasize the different etiology and pathophysiology of OCD and depression, as implicated by tryptophan depletion studies and neuroimaging. Although there may be some shared elements or contributions of neural networks, there is no complete overlap. One may generally conclude from these phatrmacologic, depletion and imaging data that, although linked, $O C D$ and major depression are two different psychopathological entities which, if diagnosed carefully, require different therapeutic strategies. These data support the notion that it is mote difficult to treat two psychiatric disorders at a time than one. This is partly confirmed by the present study, as more severe symptoms remained in the initially depressed patient gtoup than in the nondepressed group.

Some shortcomings of this study must be mentioned. First, the nature of the study imposed restrictions on the interpretation of our findings, as retrospcove studies always do. Exen though, we used a semi-structured interview and DSM-IV criteria, and always required diagnostic agreement from two clinicians. Sccondly, as described above, some of our rating instruments were selfrated scales and, as such they were more hable to subjective interptetation and were less reliable. Thirdly, we had at our disposal posttreatment data of only 72 of the 120 patients we examined at baseline. We wete unable to race all subjects. There are various reasons for this Patients sometimes ended their therapy prematurely if there was no clear or rapid effect; others were doing well after treatment and did not show up for posttreatment assessments. What we do know, however, is that the demogtaphics and clinical values at baseline did not differ between the group of completers and the patients we only assessed at baseline. Thus, they were not specifically the most depressed or severe patients who were lost to follow-up, on the contrary, for example within the non depressed subgroup the completers showed more severe symptoms at baseline assessments. 
At the same time, one should see the shortcomings above in relation to the strengths of this study, which are the clear-cut definition of comorbidity and its naturalistic nature. Defining comorbidity as current, co-existing DSM-IVdefined syndromes is one of the most reliable assessments of comorbid conditions. Patients' teports of past lifetime events have never been proven to be very reliable; the only way to counter this is to do longitudinal resentch on large patient groups, and this design has its own drawbacks. An advantage of naturalistic studies like this is, in our opinion, that the results are directly derived from general clinical practice, and this is relevant for patients in the clinical setting. Diagnosing comorbid conditions is of great impottance since they can have an impact on treatment outcome.

\section{REFERENCES}

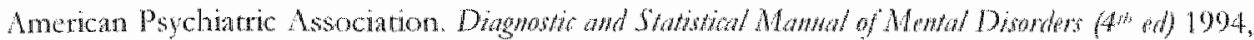
Washingron DC, American Psychatric Press

Angst ]. Comorbidicy of mood disorders: a longindinal prospective studly. Br I Pablabl 1996 : Suppl $30,31-37$

Bebbington PE. Epidemiology of obsessive-compulsive disorder $B r$ I Pothatry 1998: Suppl 35, 2-6

Black D and Noyes R. Comorbitity and obsessive-compulsive disorder. In Maser J and Cloninger $C$ (Eds). Comorbidty of Mood and Amxiety Disorter. 1990 Washington DC, American Psychatric Press

Casrle DJ, Deatle $A$ and Marks IM. Gender differences in obsessive compulsive disonder. Ak: W ZJ Poibiaty 1995:29,114-117

Crino $\mathrm{R}$ and Andrews $\mathrm{G}$. Obsessive-compulsive disorder and Axis I comorbidiry. I Anx Dr 1996: $10,37-46$

Delgado PL and Moreno FA. Diffetent roles for serotonin in anti-obsessional drug action and the pathophysiology of obsessive-compulsive disorder. Bry Pydratm 1998: Suppl 35, 21.25

Den Boer $\mid$ A. Psychophamacology of comorbid obsessive-compulswe disonder and depression. JCho Potsido 1997: 58 Suppl 8, 17.19

Foa EA. Falure in Treating Obsessive-Compulswes. Bebar Rer The 1979: 17, 160 176

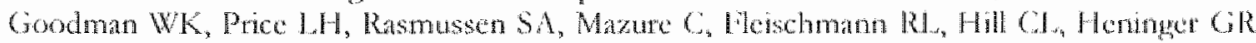
and Chames DS. The Yale-Brown Obsessive Comprasive Scale, I: Development, usio and reliability. Ant Ges Pyobstry 1989: 46, 1006-1011

Hodgson RJ and Rachman S. Obsessional-compulsive complaines Behess Res Ther 1977: 1.5, 384 395

Hollander E, Mullen 1., DeCaria CM, Skodol A, Schnoter Th, Licbowita MR and Klein DU: Obsessive compulsive disorder, depression, and Auoxetinc. I Chm Podinhy 1991: 52, 418.422

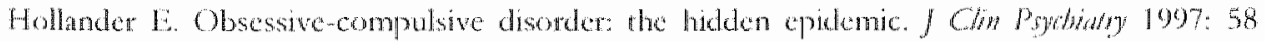
Suppl $12,3-6$

Kaufman J and Charney D. Comorbidity of mood and anxiety disorders. Dopher Amxty. 2000: 12 suppl $1.69-76$

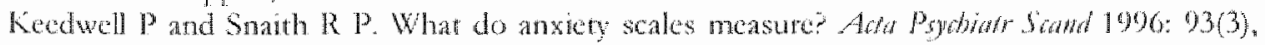
$177-1180$ 


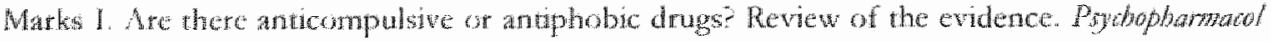
Buil/1982: 18,78.84

Maser JD and Coninger CR. Comobidity of anxiety and mood disorders: Introduction and

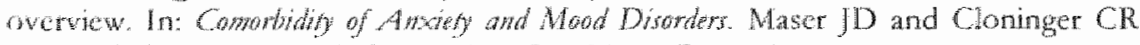
(Eds), 1990 Wrangron DC, American Psychiatic Press. 3-12

Mavissakalian $M_{1}$, Tumer $S M$, Michelson $L$ and Jacob $R$. Tricyclic antepressants in obsessivecompulswe disonder: antiobsessional or anidepressant agents? 11. Am f Pybiato 1985 $142,572-576$

Milanfranchi $A$, Marazili D, Pfamet C, Presta S, Lensi $P$, Ravagli $S$ and Cassano $G$. Comorbidity in obsessivercompulsive disorder: focus on depression. Europeat Porthathy 1995: $10,379-382$

Montgomery $S A$ and $A$ sberg $M$. $A$ new depression scale designed to be sencive to change. $B r J$ Powliatr 1979: 134,382-389

Montgomery SA. Psychopharmacologs of obsessivecompulsive disorder. CNS Sperwms 1998 : $3 \sin 11,33-37$

Noyes R, Reich I, Christansen I, Suelzer M, Pfoh B and Coryell W. Outcome of panic disorder:

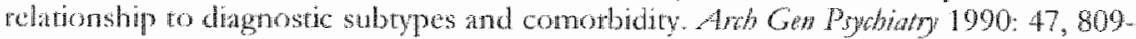
818

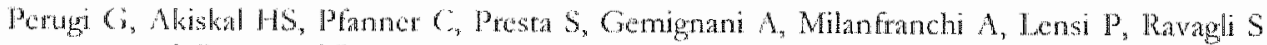
and Cassano $\mathrm{GB}$. The clinical impact of bipolar and unipolat affective comotbidiry on obsessive-compulsive disorder / Affot Dirom 1997: 46, 1.5-23

Piecincli $M$, Pini $S$, Bellantumo $C$ and Wilkinson $G$. Efficacy of drug treament in obsessiwecompulsive disonder: a men- andytic tevew. By f Pybian 1095: 166, 424-443

Rasmussen SA and Eisen JI. The cpidemiology and differential diagnosis of obsessive compulstre disotder. / Clin Psthatry 1992: 53 Suppt, 4-10

Regier DA, Rac DS. Narrow WE, Kaciber CT, and Schataberg AF. Prevalence of anxicty disorders and then comorbidity with mond and addictive disorders. Br I Pyodsoby 1998: Suppl 34,24-28

Regier DA, Narrow WT: and Rae DS. The epidemiology of anxiety disorders: the Epidemiologic Carchment Area (BCA) experience. J Pyohior Rer 1990:24 Suppl 2, 3-14

Sauderson WC, DiNardo PA, Rapee RM and Barlow DH. Syndrome comorbidity in patients

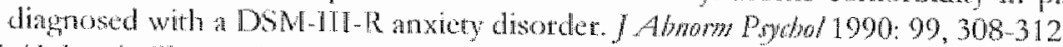

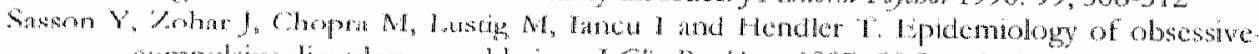

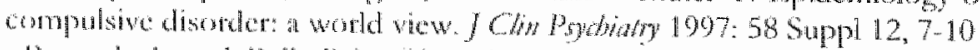

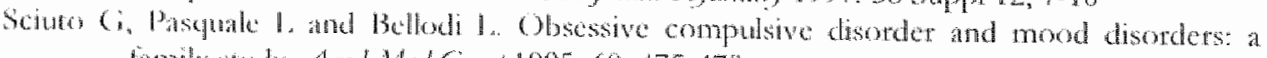
fimily srudy, Am J Wed 6 she $1095: 60.475-479$

Snam RP, Whugh S, Clayden AD, Husan A and Sipple M. The Clinical Anxiery Scake An

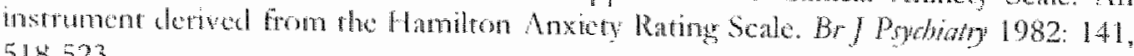
$51 \times-523$

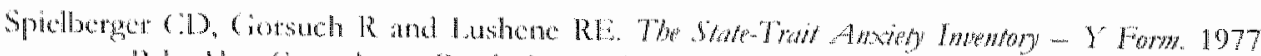
Palo Alos: Consultants Psychologists laress

Van Walkom AIM, Van Oppen P, Vermenton AWA, Van Dipck Ra, Nata MCE and Vorst HCM. A meta-stratysis on the reatment of obsessive compulsive disotder: a

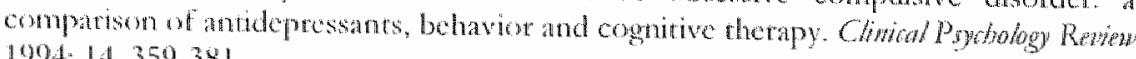
$1094: 14,359-381$

Weissman MM, Band RC, Canmo GI, Greenwald S, Hwu HG, Lee CK, Newman S C, Onkley Butowe MA, Rubio-Sripec $M$ and Wicktamaratne $P J$. The ctoss national epidemiology of abstsine compulswe disorder the Cross Naronal Collaborative Group. I Cht Powhom 1994: 55 Suppl, 5-10

Witrchen HU, licb R, Wunderlich $U$ and schuster $P$. Comorbidity in primary care presentation and conscquences. J Cow Pydoho 1999:60 Suppl 7,20-36 
Zohar $J$ and Insel TR. Obsessive-compulsive disorder psychobiological approathat to diagnosis, treatment, and pathophysiology. Bul Psyowny 1987: 22,667-687

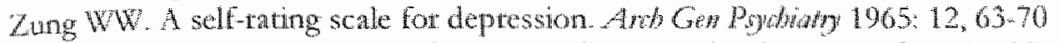

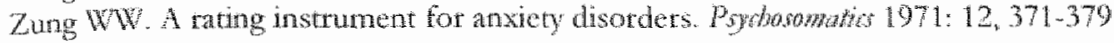




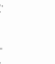

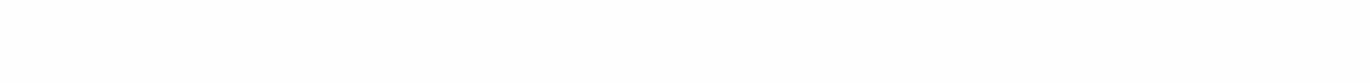

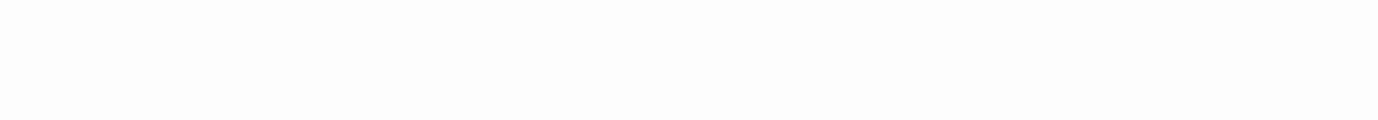

.
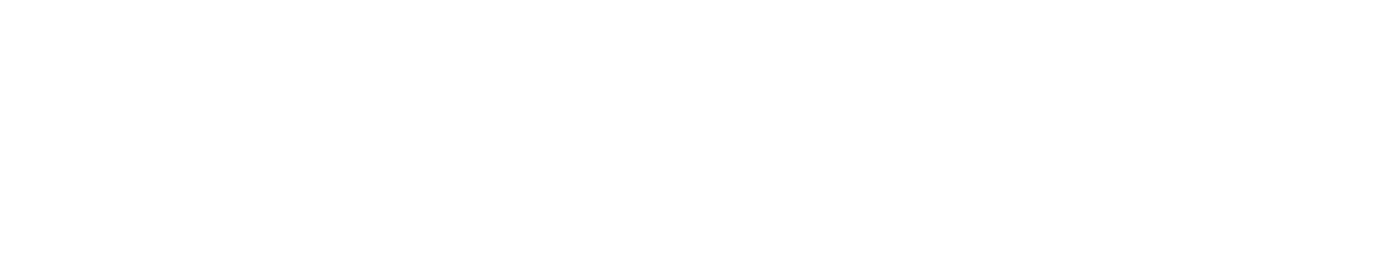
Section II. Prowic disorder and associated phenomenta 



\section{Sutcidal Ideation In Panic Disorder Patients}

'T. Overbeek, J. Rikken, K. Schruers and E. Grie»

In: Joumal of Nenous and Mental Disease 1998, 186:577-580 



\section{INTRODUCTION}

The debate on suicide risk for panic disorder (PD) patients has intensified since publication of the Weissman et al. report (1989), which was based on epidemiological data from the Epidemiologic Catchment Area (ECA) study. The authors stated that PD patients have a $20 \%$ risk for suicide attempts, that $12 \%$ of people with panic attacks but not PD actually attempt suicide and that $4.7 \%$ of all PD patients report suicidal ideation. Because clinicians are only infrequently confronted with PD patients who express sucidal thoughts (Appleby, 1994; Noyes, 1991), these findings were quite surprising. The Weissman et al. study, however, suffered from methodological drawbacks, such as the use of lay interviewers and the nonclinical population investigated. Moreover, they only partly controlled for such lifetime comorbid disorders as substance abuse, depressive disorders, and borderline personality disorder, all of which are known to be associated with increased suicidality. Each comorbid disorder was controlled for separately (e.g. when controlling for depression, they did not control for alcohol abuse).

Subsequent studies gave contrasting results. Reanalyzing the same ser of data from the ECA study and controlling only for axis I comorbid disorders, Johnson et al. (1990) still found a higher suicide risk for uncomplicated PD (7\%, vs. $7.9 \%$ in major deptession). King et al. (1995) showed that a lifetime prevalence of panic attacks and PD contributed substantially (almost rwofold) to suicide risk in depressed patients. The results of studies by Allgulander and Lavori (1991), Anthony and Petronis (1991), Noyes (1991), and Noyes et al. (1991) are consistent with those of Weissman and colleagues. Admittedly, these studies have important methodological differences, but they do indicate an increased suicidaliry in PD patients. Algulander and Lavori studied an inpatient (i.e., more severe) population, and grouped together all 'anxicty ncuroses', this, creating a more heterogeneous group. Noyes et al. did not control for comorbid disorders; they performed a 7-year follow-ap study to investigate predictor variables for suicidal behavior. Very recently, Woodruff-Burden er al. (1997) studied 627 non-clinical subjects (students) and reported a relationship between panic and suicidality in a complex interaction with orther genceral (psycho) pathology; comorbidity was not ruled out.

Another recent study (Kon et al, 1997) reported a higher rate of aguressive tendencies in comorbid depressed panic patients (both inwardly and outwatdly directed) during panic attacks than in nondepressed panic paticnts. These authors allso found a high correlation between panic-associated suicidaliny and aggtession, and measures of impulsivity, suicide tisk, and riolence risk.

Several researchets could not replicate a higher suicide risk in PD. When comorbidity was ruled out, Beck et al. (1991), Griez et al. (1994), and Warshaw et al. (1995) failed to find increased suicidality. Friedman ot al. (1992) and 
Lepine er al. (1993) demonstrated that a higher suicide risk could be attributed completely to comorbid depressive, addictive, or (borderline) personality disordey:

Homig and McNally (1995) also reanalyzed the original ECA data and controlled for combined lifetime comorbid disonders, whereas Weissman et al. only controlled for separate comorbid disorders. The former concluded that PD was not associated with an increased risk for suicide attempts. Cox et al. (1994) found past suicide attempts in PD patients to be related to the context of depressive symptoms, even when they did not meet the full diagnostic criteria for a major depression.

In this context, it must be noted that the studies supporting the idea of increased suicidality in PD are largely epidemiological, and to a lesser extent clinical in nature. Yet, there are several clinical studies that disaffirm this relationship.

The aim of the present study was to look fots suicidality, and in particular suicidal icleation, in PD patients without any comorbid axis I or II diagnosis. It was not our intention to look prospectively for suicide risk. We did inquire about past suicide attempts in an effort to estimate the severity of any existing suicidal thoughts and, thus, of suicide risk.

\section{MITHODS}

The aim of the present study was to assess suicidal ideation and a history of suicide attempts in patients presenting with uncomplicated (i.e., no comorbid DSM-III-R axis I or II pathology) PD with or without agoraphobia. It was hypothesized that patients with 'pure' PD (i.e., without comorbid affective, addictive, or personality pathology) would not be at an increased risk for suicide compared with a group of nomal controls.

\section{Subjents}

Fify parients referred for treatment to the Academic Anxiety Center in Mastricht, a terriary outpatient clinic for anxiety disorders, voluntarily participared in the study. They were included if they met the DSM-III-R criterta $(A P \Lambda, 1987)$ for PD with $(n=40)$ or without $(n=10)$ agotaphobia, and without any comorbid (past or present) axis I or II diagnosis. The mean age of the 30 female and 20 male subjects was 38 years. Close attention was paid to comorbidity. After the clinical interview, another investigator teviewed all files. If there was any doubt about (lifetime) depression, personality disonder, of substance abuse, the patient was excluded from the study. Fifty age- and sexmatched controls without any psychiatric pathology were selected. All subjects were interviewed by a M.D. who presented them with four items (the same ones used by Weisman, 1989) from the Diagnostic Interview Schedule (DIS; 
Robins et al., 1981) regarding thoughts about death and suicide. All subjects also completed the following questionnaires: the Beck Hopelessness Scale (BHS; Beck et al, 1974), the Self-raung Anxiety Scale (SAS; Zung, 1971), the Self-rating Depression Scale (SDS; Zung, 1965), and the Suicide Risk Scale (SRS; Plutchile er al., 1989). Student's t-test for unrelated samples and the chisquare test were used where appropriate.

\section{RISULTS}

As expected, the group of panic patients scored significantly higher on the $S A S$, SDS, and BHS ( $\mathrm{p}<0.001$, Student's t-test) than the nomal control group, with mean scores of 46.73 (SD 8.88), 45.25 (SD 8.13), and 7.04 (SD 4.43), respectively. Controls had mean scores of 25.90 (SD 3.31), 26.92 (SD 4.56) and 2.76 (SD 2.45), respectively. What we had not expected, however, was that the mean score on the SRS would also be higher for the patient group (4.36, SD 2.53) than for the control group $(0.60, \mathrm{SD} 0.99)$. An item analysis (Table 1) puts this finding into perspective. A certain subset of items (items $\mathbb{1}$ to 9 ) account for all of the differences between the two groups, and this will be discussed later.

As for the four DIS items, item 1 - "Though" a lot about deakly" - and item 2 - "Felt like you wated to die"-. were answered in a positive way significantly more often by the patient group than by the controls (chi-square rest, $p=0.002$ and $\mathrm{p}=0.004$, respectively). The responses to item 3 - "Felt so low, thought about smide"- and item 4 - "Made shicide attempts"- were not significantly different. 


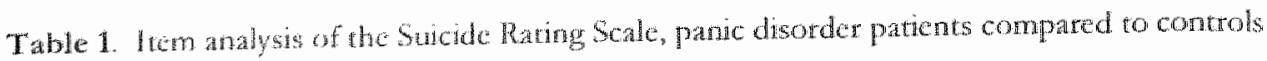

\begin{tabular}{|c|c|c|c|}
\hline Ifom & & Col-selant & E \\
\hline 1 & $\begin{array}{l}\text { Do you take enges such as aspirins or slceping pills } \\
\text { regulary? }\end{array}$ & 14.91 & $<0.001$ \\
\hline 2 & $\begin{array}{l}\text { Thandary? } \\
\text { Do you have rouble falling asleep? }\end{array}$ & 24.00 & $<0,001$ \\
\hline 3 & $\begin{array}{l}\text { Do you somenmes ted that you wil lose control of } \\
\text { yoursele? }\end{array}$ & 44.44 & $<0.001$ \\
\hline 4 & Do you have litue nuterest in being with people? & 20.48 & $<0.001$ \\
\hline 5 & $\begin{array}{l}\text { Do you feel that your furure will be more unpleasant than } \\
\text { plosant? }\end{array}$ & 23.45 & $<0.001$ \\
\hline 6 & Do you ever fee that you are worthless? & 32.19 & $<0.001$ \\
\hline 7 & Do you fecl hopeless about your future? & 10.69 & 0.001 \\
\hline 8 & $\begin{array}{l}\text { Do you often feel so frustrated that you just want to lic } \\
\text { down and gunt srugghing alrogether? }\end{array}$ & 12.36 & $<0.001$ \\
\hline 9 & Do you foel depressed now & 17.64 & $<0.001$ \\
\hline 10 & Are you separated, divorced or whidowed? & 0.10 & 0.75 \\
\hline 11 & Has anyone in your family erer tried to commit sulcide? & 1.00 & 0.31 \\
\hline 12 & $\begin{array}{l}\text { Have you cwer been so angry that you felt you might kill } \\
\text { someone }\end{array}$ & 3.05 & 0.08 \\
\hline 13 & Have you crer thought about comming suicider & 5.00 & 0.25 \\
\hline 14 & Have you cwer told anyone you would commit suicide? & 1.89 & 0.17 \\
\hline 15 & Have you cree tried to commit sucide? & 1.01 & 0.31 \\
\hline
\end{tabular}

\section{DISCUSSION}

Our hypothesis was that pure PD patients (without axis I of II comorbidity) would not show an elevated risk for suicide. Relying on findings by Beck et al. (1991), Friedman et al. (1992), and Warshaw et al. (1995), we assumed that the higher suicidality found by Weissman et al. (1989) could be attributed entirely to ifferme comorbidity of depression, addiction, and personality disorders. Therefore, in the present study, we carefully excluded any and all PD subjects with comorbid parhology. In particular we took great care to derect any clinically establishod liferime clepression.

As expected, patients had higher scores on the BHS and SDS than the control group. PD is known to be a very disabling disease that significantly affects patients" qualing of life. Higher scotes on several items on the BHS and SDS may easily be attributed to the distress caused by the disease without its prostessing to a formal depression. With regard to the higher patient score on the BHS, it is worth noting that Becks et al. (1990) showed a correlation between the BHS score and suicide risk. Yet, their cut-off score (a total of 9) was well beyond the mean of our patient group.

We found a higher total mean on the SRS for the patient group than for controls. A closer look by means of item analysis (Table 1), however, shows that patients differed from controls on the first nine items only. These items 
address such psychological dimensions as feelings of frustration, worthlessness, depressed mood, and difficulty sleeping, all of which reflect the well-known reactive 'demoralization' in anxiety disorders (Breier et al., 1984). "The other items (10 to 15) relate to the more specific sphere of sucidality, $\mathrm{cg}$. as suicidal ideation and past attempts, aggression, and demographic factors (matital starus, past suicide of relatives). On none of these six items were thete any differences between PD patients and normal controls. Thus, it is quite likely that the answers to the first nine items of the SRS reflect the impaired quality of life of the PD patient, as described by Markowitz et al. (1989) and others, rather than a genuine increased suicidality.

Similar arguments may be used to explain the answers to the four DIS items. The fact that item 1 - "Thorght a lot about deally". was scored positively more often by the patients than controls is not surprising since one of the core elements of panic attacks is an overwhelming sense of fright and fear of dying from the attack. The aforementioned demoralization might also be the reason parients numinate about death in general.

Item 2 - "Felt like you wanted to die"- was also answered positively more often by the patient group. At fitst, this difference seemed unexpected and was more difficult to explain in terms of our original hypothesis. Why should PD patients more often feel the (passive) wish to be dead than controls? Onc possible explanation, however, could again be demoralization. Athough the wish to be dead may be interpreted as far more setious than common demoralization, it might reflect the unbearable feeling of total loss of control that occurs during panic attacks. This does not necessarily imply any intention to actively put an end to one's life. Moreover, as items 3 and 4 - "Felt so low, though about commitumg suivide" and "Made suricide attesupts". show that PD patients do not report more suicidal thoughts than controls. Nor did any subject in either group ewer make an attempt to commit suicide.

\section{CONCLUS1ONS}

Three conclusions can be drawn from our findings. [irst, PD paticnts are more preoccupied with death in generat than are controls. Sccond, PD parients sometimes have a (passive) wish to be dead. Third, this rumination occurs without the actual intent of killing themseves. In line with other curtent reseatch, we did not find a higher suicide risk for the PD patient group than for controls. The strength of this study lies in the fact that comorbid disorders were meticulously excluded, both those occurring at the time of the study and those occurring at some time in the past. We explicitly controlled for wellknown factors that could contribute to suicide risk in psychiartic paticnts (addiction, borderline personality disorder, and affective disorder). 
Yet, we must be cautious in drawing the conclusion that, in everyday life, PD patients are not at risk for suicide. Comorbidity cannor be ignored in anxiety disorders in general, and in PD in particular, in relation to suicide. Our sample may not be representative of PD patients presented in clinical practice because comorbid depressive disorder is concurtently present in approximately $30 \%$ of cascs; this grows to $60 \%$ if one includes lifetime comorbidity as well (Breier et al, 1984, Griez and Overbeck, 1997). Personality disorder is diagnosed in almost $40 \%$ (Wetzler and Sanderson, 1995) and substance abuse in about $40 \%$ of cases (Witchen and Essau, 1996), with some overlap. Nevertheless, these considerations do not affect our conclusion that a diagnosis of PD by itself (so called pure PD) is not associated with a higher risk for suicide.

\section{REITERDNCIS}

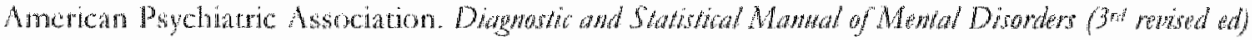
1987, Washington DC, American Psychiatric Press

Algulander C and lavori P. Fxcess mortality among 3302 patcents with 'pure' anxicty neurosis. Ant Gow Probinto 1991:48,599-602

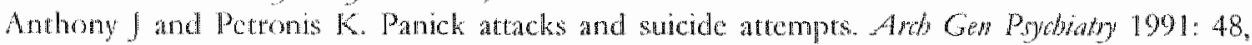
1114

Mppleby 1. Parric and suicidal be haviour; risk of self-harm in parients who complain of parie. $B r$ Dydratio 1994: 164,719-721

Beck A, Brown G, Berchick R, Stewart B and Steer R Relationship between hopelessness and ultimate suicides a replication with psychiatic outpaticnts. Am / Psobaty 1900: 147. $190-195$

Beck A, steer R, Sanclerson W and Skeic T. Pance disorder and sticidal ideation and behavion:

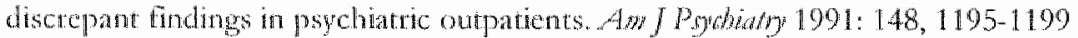

Becti $A$, Weisman A, lester D and Trexler 1. The measurement of pessimism: The Hopolessness Solle.J Con Chu Pbotogy 1974:42,861-865

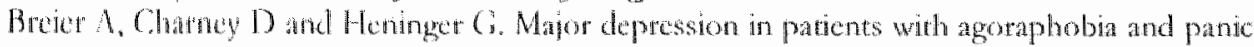

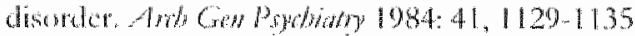

Cex 1 , Dircofiedd D, Swinson R and Norton (i. Sucidal idcation and sucide attempts in panic

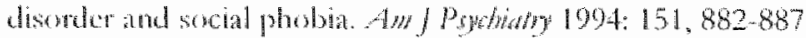

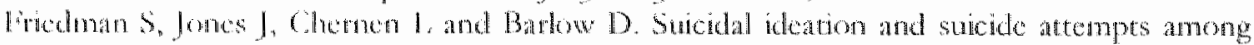

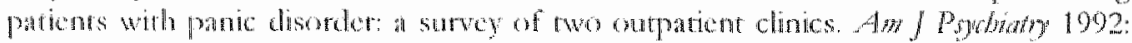
149, $680-685$

Griez and (Ochbek T. Commbidity of depression and anxicy. In: Hong A and Van Prag

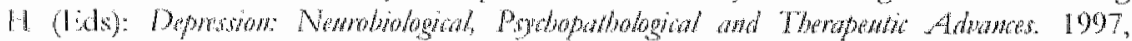
Chahoser, Whly \& Sons. $41-57$

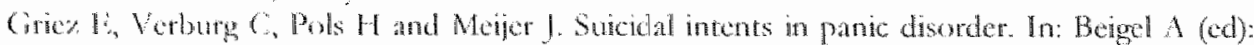

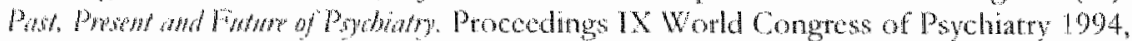
New Jessy, World Secontife Publishing. 618-622

Homig $C$ and McNally $R$. Panic disorder and suicide attempt: a teanalysis of data from the

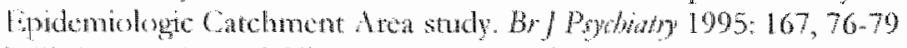

Johnson J. Wossman $\mathrm{M}$ and Klerman $\mathrm{C}$. Panic disonder, comorbidity, and suncide attempts.

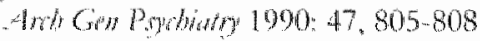

King M, Schmaling K, Cowley D and Dunner D. Sucide artempthistory in depressed parients with and wirhout a history of panic atacks. Compr Pochoby 1995: 36, 25-30 
Kom M, Plutchik $R$ and ran Prag $H$. Panic-associated suicual and aggressive idcation and behavior. / Psydiat Rer 1997:31,481-487

Lepine J, Chignon J and Teherani M. Suicide artempes in patients wht panic disonders. Amb Gat Pindwatry $1993: 50,144149$

Markowitz J, Weissman M, Ouellette R, Lish J and Klerman G. Quality of life in panic disotder. Anc Gen Psythory 1989:46,984-992

Noyes R. Suicide and panic disorder: a revicw. A Afro Disom 199\%:22, 1-11

Noves R, Christiansen J, Clancy J, Gavey M, Strelace M and Anderson D. Predictors of serions stricide attempts among paticnes with panic disorder. Coxmpr Pydithy 1991: 32,261 267

Plutchik $\mathbb{R}$, van Prage $\mathrm{H}$, Conte $\mathrm{H}$ and Picand $\mathrm{S}$. Correlates of sucide and volence risk I: The Suicide Risk Measure. Compr Psymirty 1989:30, 296 392

Robins 1, Helace J, Croughan J and Ratelift $\mathbb{K}$. Narional Instinte of Mental Heath Diagnostic

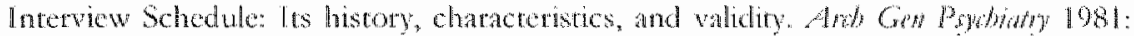
$38,381-389$

Warshaw M. Massion A, Peterion L, Ptatt L and Keller M. Sucidal behavor in pationts with panic disorder: Rerrospective and prospective data. / Afor Drond 1995: 34, 235-247

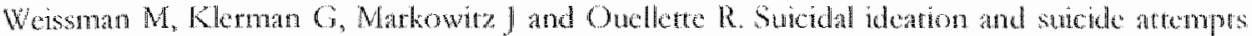
in panic disonder and atacks. N E J Med 1989: 321, 1209-1214.

Wetzler $S$ and Sanderson W. Comobidity of panic disorder. In: Asnis G and wan Pang H

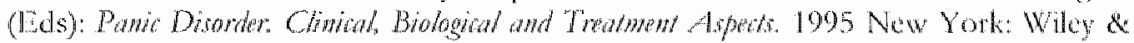
Sons. 80.98

Wittchen $H$ and Essat C. Fpidemiology of panic disorder: Progress and unresolved issues. I Popdiat Rer 1996:27, 47-68

Woodrufe Burden J, Stanley $M$, Lister $S$ atad Tabncehi M. Nonclinical panic and suicidality: Prevalence and psychopathology. Bew Res Ther 1997: 35, 109-116

Zung W. A self-rating depression scale. Awh Gen Powdiaty 1965: 12, 63-70

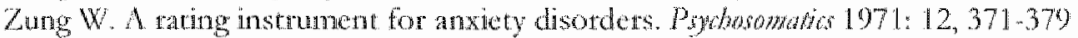





\section{Sleep Complaints IN Panic Disorder Patients}

T. Overbeek, R. van Diest, K. Schruers, F. Kruizinga and E. Griez 

ABSTRACT

Backeground: Patients suffering from anxiety disorders often teport difficulty sleeping.

Purpose: The present study assesses the prevalence of sleep complaints in panic disorder (PD) patients, compares them with sleep complaints in a normal population, and investigates the role of comorbid depression and nocturnal panic attacks in sleep complaints in the PD patients.

Method: Seventy PD patients and 70 healthy controls were asked abour their subjective sleep chatacteristics by means of the Sleep-Wake Experience List, which assesses sleep/arousal complaints over a 24-hour period.

Reswlts: Sixty-seven percent of the PD patients reported sleep complaints compared to $20 \%$ of the controls. Seventy-seven percent of the PD patients with comorbid depression and/or nocturnal panic attacks reported sleep complaints versus $53 \%$ of the 'pure' PD patients.

Conltusion: PD patients demonstrate a higher prevalence of sleep complaints than normal controls; this can only partly be explained by comorbid depression or by the presence of nocturnal panic attacks. 



\section{MTRODUGTION}

Psychiatric disorders are frequently accompanied by sleep complaints (Benca et al., 1992). Most conspicuous are mood disorders, with insomnia being reported in about $80 \%$ of the afflicted cases (Szuba, 2001). Polysomnographic studies have further shown that a shortened REM latency is one of the most consistent deviations in the sleep of depressed pationts (Reynolds and Kupter, 1987).

Patients suffering from anxiety disopders also often report difficuly slecping. For example, in generalized anxiety disorder (GAD) and in post-tramatic stress disorder (PTSD), sleep complaints are one of the major symptoms. Most polysomnographic studies in those disorders suggest some objective impaiment (Mellman, 2003). In panic disorder (PD), slecp complaints do not belong to the diagnostic ctiteria, but in clinical practice they are often encountered as accompanying phenomena. Surveys have documented increased sleep complaints in PD patients compared to control populations, and some polysomnographic studies lave found decreases in slecp efficiency and sleep duration in PD. In general, sleep impaitment was strongly associated with comorbid depression (Mellman, 2003).

The relationship between sleep and $\mathrm{PD}$ is particularly interesting because impaired arousal regulation has been postulated as a potential underlying pathophysiological mechanism in PD (Lepola et al, 1994). Panic attacks may arise either from transient hyperarousal (e.g. anticipation anxiety, excrise), or from transient hypo-arousal (relaxation-induced panic) (Mellman, 2003). Others have put forward that PD is associated with chronic hyperarousal. During sleep this is reflected in more frequent nightly awakenings and more movements, except in nights with nocturnal panic atracks (Uhde et al., 1984; Brown and Uhde, 2003).

A potential link between PD and sleep complants is the presencc of nocumat panic attacks. About $33 \%$ of $\mathrm{PD}$ patients report recurrent nocturnal panic attacks and some $69 \%$ report experiencing them at some point in their tives (Mellman and Uhcle, 1989b). Nocturnal panic attacks not only induce slecp problems because of their sleep-interrupting nature, but also because of subsequent anticipatory anxiety, phobic anxiety of groing to slecp, slecp avoidance and, finally, sleep deprivation, which may futther aggratate anxicty. With respect to the phenomenology of nocturnal panic attacks, one study showed that these attacks do not differ from daytime attacks in mean scverity, duration, or number of symptoms per attack (Krystal et al., 1991).

Another common factor of PD and sleep complaints may be the presence of a comorbid mood disorder. Comorbidity of PD and depression is high, with a reported point-prevalence of about 30-40\% (Lesser et al., 1989; Lepinc, 2001). 
The strong association between depression with sleep complaints on one hand, and the association between depression and PD on the other, suggests that Acpression may mediate the relation between PD and sleep complaints.

A common shottcoming in the assessment of sleep complaints is the lack of a systematic assessment (van Diest et al., 1993). The duration of the sleep complaints is not always reported; consequently, a distinction cannot be made between transient (i.e., $<3$ weeks) and chronic (i.e, $>3$ weeks) sleep complaints. Futhemore, most studies do not consider the entire 24-hour period. Within a 24-hour period, sleep complaints are distinguished as problems initiating slcep, maintaining sleep, early morning awakening, difficulty waking up, tiredness upon waking up, and daytime sleepiness.

In the prescnt study, we tested the hypothesis that PD is associated with an increased prevalence rate of subjective sleep complaints. In addition, we tested the hypothesis that the increased prevalence of sleep complants in PD is accounted for by comorbid depression and/or noctumal panic artacks in these paticnts. For practical reasons we combined PD patients with nocturnal panic attacks and with comorbid depression into one group, the 'comorbid' group. The authors chose to use the term 'comorbid' for these cases-despite the fact that the term does not fully apply hete since nocturnal panic attacks are a symptom of the disorder PD. We therefore put the description in quotation marks. We expected an increased ptevalence of sleep complaints in PD patients with comorbid depression and/or noctumal panic attacks compated to PD patients without these characteristics (the 'pure' group). We also expected that the prevalence of sleep complaints in PD patients without comorbid depression and nocturnal pantc attacks would be similat to that of healthy controls.

\section{Mritions}

Pawtipants: Participants were 70 patients recruited at the Academic Anxiety Center, Mastricht, the Nerherlands, an outpatient clinic that specializes in the diagnosis and treament of anxicty disorders. All patients had a psychiatric intervicy conducted by a MD and they were screened by means of the Mini Intemational Neuropsychatric Intervicw (MINI) (Shechan et al, 1998). Psychiatric diagnoses were made according to DSM-IV criteria (APA, 1994) and were confirmed in consensus with two qualified psychiatrists. Patients with a primary DSM-IV axis I diagnosis of PD (with or without agoraphobia) were asked to participate. Paticnts with other axis I disorders were excluded, except for current depressive disorder or dysthymia. Care was taken to obtain a history of all medication taken in the past 3 months. Patients who used benzodiazepines on a regular basis were excluded. Also, patients on older antidepressants (eg., tricyclics) that are known to have rather sedative side 
effects were excluded. The use of SSRIs was accoted as they are the firstchoice pharmacological treatment for PD. However, because SSRIs can affect sleep (Masand and Gupta, 1999), we perfomed a post-hoc analysis to test whether the use of SSRIs influenced the presence of sleep complaints in out sample. Forty-four PD patients were female $(63 \%)$ and $26(37 \%)$ were male. Their combined mean age was $36.9 \pm 10.9$ years.

Healthy controls were recruited by advertisements. They were age- and gender-matched with the patient group. The mean age of the 44 female and 26 male controls was $35.8 \pm 11.1$ years. None of them used psychotropic medication. They too were screened with the MINI.

All patticipants gave informed consent.

The Sleep-Wake Experiene List: Sleep complaints were assessed by means of the Sleep-Wake Experience List (SWEL) (van Diest et al., 1993). This instrument consists of 15 items covering six types of sleep complaints as they occur within a 24 -hour period. These complaints include problems initiating sleep, maintaining sleep, early morning awakening, difficulty waking up, tircdness upon waking up, and daytime sleepiness. The separate sleep complaints were coded 'chronic' if the complaint was described both as 'trather severc' to 'very severe' and as 'often present' or 'always present' for a period of 3 months. Thus, the severity and frequency of occurrence wete combined to code as sufficiently severe to make a chronic sleep complaint. Other details of the SWEL have been described elsewhere (van Diest, 1990; van Diest et al., 1993). Fot this study, the SWEL was extended with additional items to assess the occutrence of nocturnal panic attacks. Participants were instructed to base their answers upon the last 3 months.

Statistical anabys: The chi-square rest (SPSS for Windows) was used to examine associations of PD with sleep complaints. Students" T-test was applied to compare baseline characteristics of the 'pure" versus the 'comorbid' group. Significance levels were based on two-railed tests with a $p$-value $\leq 0.05$.

\section{RESULTS}

Of the 70 PD patients, $21(30 \%)$ suffered from a comorbid depression ( $N=16)$ or dysthymia $(N=5)$. The severity of depression in this group was mild, a mean score of 18.7 (SD 6.8) on the Montgomery-Asberg Depression Rating Scalc (Montgomery and Asberg, 1979) and a mean score of 54.1 (SD 7.4) on the Selfrating Depression Scale (Zung, 1965).

Some 31 patients $(44 \%)$ reponed nocturnal panic atracks in the last three months. The frequency of the nocturnal panic atracks was as follows: $1-2$ in 13 patients; $3-4$ in 8 patients; $5-6$ in 6 , and more than 6 in 4 patients. Twelve PD patients $(17 \%)$ had both depression and nocturnal panic attacks. 
Combining these condirions yielded 40 patients with either one or both of these chatacteristics, the 'comorbid' group. The 30 PD patients without any of these characteristics made up the 'pure' group. Nocturnal panic attacks were not associated with comorbid depression (chi $2=2.01$; df $1 ; p=0.12$ ). The subgroups did not differ on severity measures for PD. The mean Panic and Agoraphobia Scale (PAS, Bandelow, 1995) for the 'comorbid' group was 29.4 (SD 8.3), versus 27.1 (SD 8.1) for the "pure" group. Mean scores on the Fear Questionnaire (FQ, Marks and Mathews, 1979) was 52.1 (SD 26.1) for the 'Comorbid' group versus 40.9 (SD 24.9) for the 'pure" group. The use of SSRIs was similar in the 'comorbid' and the 'pure' groups (chi $2=0.18 ; \mathrm{df} 1 ; p=0.67$ ). Post-hoc analysis showed no difference in prevalence of sleep complaints between PD patients who used SSRIs and those who did not (chi $2=0.66$; $\mathrm{d}$ 1; $p=0.29)$

\section{Provalence of step complaints}

PD patients $(N=70)$ werws bealiby contwols $N=70)$ : Chronic sleep complaints during the past 3 months were reported by $67 \%$ of patients and by $20 \%$ of controls. The significant association between $P D$ and sleep complaints $(p<0.01)$ supported our first hypothesis; therefore, we tested whether this increased prevalence of sleep complaints in PD patients was due to comorbid depression and/or nocturnal panic attacks in those patients.

Pure' $(N=30)$ urrus comorbid' PD patients $(N=40)$ : The prevalence of sleep complaints was significantly higher in the 'comorbid' group (77\%) than that in the 'pure' group $(53 \% ; p=0.03)$, which supported our second hypothesis.

Pure' PD potients $(N=30)$ wersus Controls $(N=70)$. The prevalence of sleep complaints in the 'pure' PD group $(53 \%)$ was significantly higher than that in the control group $(20 \% ; p<0.01)$, which did not support our second hyporhesis. A posthoc analysis to assess the role of the SSRIs in this compatison yiclded the same results: PD paticnts without depression, nocrumal panic, or medication also reported significantly mote sleep complaints than did healthy control subjects.

\section{Natrre of sleep conyplatints}

In view of these results we decided to investigate the specific sleep complaints repotted by the different subgroups of patients and we compared them to the slecp complaints repotted by healthy controls (Table 1).

PD putients persus Contw/s: PD patients repotred complaints initiating sleep, maintaining slep, catly morning awakening, difficulty waking up, tiredness upon waking up and daytime slecpiness significantly more often (p1 in Table 1).

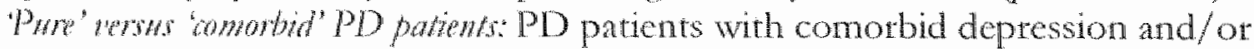
nocturmal panic reported having problems maintaining sleep significantly more 
often than "pure" PD patients (p2 in Table 1). The nwo groups did not differ significantly in any of the other sleep complaints.

"Pare' PD patients versus Controls: 'Pure' PD patients reported having problems initiating sleep, tiredness upon waking up, and daytime sleepiness significantly more often than controls ( $\mathrm{p} 3$ in Table 1 ).

Table 1. Nature of slecp complaints in PD paticnts, patent subgroups, and controls

\begin{tabular}{|c|c|c|c|c|c|c|c|}
\hline Shop mentante & $\begin{array}{l}A / / P D \\
N=70)\end{array}$ & $\begin{array}{c}P D \\
\mathrm{~N}=40\end{array}$ & $\begin{array}{c}p y r p^{2} \\
P D \\
N=30\end{array}$ & $\begin{array}{l}\text { Controls } \\
(\mathrm{N}=70)\end{array}$ & $p l a$ & $p_{2}^{2}$ & $p 3$ \\
\hline Intiating slep & 24.2 & 32.5 & 13.3 & 1.4 & $<0.01$ & 0.06 & 0.13 \\
\hline $\begin{array}{l}\text { Maintaning } \\
\text { sleep }\end{array}$ & 24.2 & 35.0 & 100 & 1.4 & $<001$ & 0.01 & 0.08 \\
\hline $\begin{array}{c}\text { Early moming } \\
\text { awakening }\end{array}$ & 7.1 & 100 & 3.3 & 0.0 & 0.03 & 0.28 & 0.30 \\
\hline $\begin{array}{l}\text { Difficulty } \\
\text { waking up }\end{array}$ & 27.1 & 27.5 & 266 & 12.8 & 0.03 & 0.58 & 0.08 \\
\hline $\begin{array}{c}\text { Tirciness } \\
\text { upon }\end{array}$ & & & & & & & \\
\hline $\begin{array}{l}\text { waking up } \\
\text { Dayome }\end{array}$ & 38.6 & 40.0 & 36.6 & 8.6 & $<0.01$ & 0.49 & 0.01 \\
\hline sleepiness & 41.4 & 500 & 30.0 & 4.2 & $<0.01$ & 0.08 & 0.01 \\
\hline
\end{tabular}

$\therefore \mathrm{pl}=\mathrm{PD}$ compared with Controls

1. $\mathrm{p}^{2}=$ 'Pute' PD compared with 'comorbid' PD

- p3 = "Pure' PD compared with Controls

\section{DISCUSSTON}

This study demonstrates that PD patients suffer from sleep complaints mote frequently than controls. PD patients with comorbid depression and/ot nocturnal panic attacks report sleep complaints more frequently than "pure" PD patients. Moreover, "pure" PD patients have a higher prevalence of slecp complaints than healthy controls. Appatently, comorbid depression and/or nocturnal panic contribute to sleep complaints in PD patients, but they are not sufficient to explain the higher prevalence of sleep complaints in PD.

To date, there have been no recent studics on subjective sleep quality in PD patients. Few studies exist that focus on sleep disturbances in this disorder. Shechan et al. (1980) found that in a sample of 57 PD paticnts (not excluding comorbid depression and nocturnal panic), approximately $70 \%$ reported disturbed sleep. Mellman and Uhde (1989b) conducted a self-report sleep survey in 45 PD patients compared with 26 healthy controls. A majotity of these patients $(58 \%)$ also had lifetime depressive disorder; none had a current 
depression. One-third reported recurrent nocturnal panic attacks. Two-thirds of PD patients reported general insomnia, as did $35 \%$ of controls. They found no differences regarding carly insomnia, but patients reported significantly mote middle and late insomnia than healthy controls. Our finding that PD patients have more difficulty initiating sleep than controls is not in line with carlier reports (Mellman and Uhde, 1989b). However, because of different operational criteria, we should be cautious when comparing the results of these two studies.

Our second hypothesis, regarding the association of sleep problems in PD with comorbid depression and/or the presence of nocturnal panic attacks, was partly supported by the finding that 'comorbid' PD patients reported suffering from sleep complaints more frequently than 'pure' PD patients did. The difference between the 'pure' and 'comorbid' group was specifically reflected in the category of maintaining sleep, where significantly more 'comorbid' PD patients reported having problems than their 'pure' counterparts did. This finding could be explained by the nature of nocturnal panic attacks as well as by the comorbid depressive disorder. Panic attacks that spontaneously occur during a patient's sleep will certainly distupt sleep and keep the patient from getting a good night's rest. Moreover, as difficulty maintaining sleep is a symptom in deptessive disorder, it is not surprising that PD patients with a comorbid depression have problems within this specific symptom category in particular.

Comparing the 'pure' PD patients with the healthy control group yielded wnexpected results. The prevalence rate of sleep complaints appeared to be higher in the "pure" PD patients, and in several individual categories of sleep complaints the PD patients without depression and without nocturnal panic atracks had significantly more complaints than did healthy controls. Our results showed significantly mote difficultics for the "pure" PD patient group in the carcgories of initiating sleep, waking up tired, and daytime sleepiness. Thereforc, 'pure' PD parients also seem to suffer from a poor quality of sleep, regardless of comorbid depression and night panic attacks. Combining this finding with the previously discussed difference between $P D$ patients with and without depression and nocturnal panic, we infer that PD alone can lead to problems initiating sleep, waking up tired and daytime sleepiness. The additional presence of a comorbid depression or of nocturnal panic gives rise to further problems maintaining sleep.

In parienrs with depressive disorder, the presence of subjective sleep complaints has been shown to correlate with objective sleep parameters. In fact, correlations berween subjecrive and objective sleep measures were found to be quite good in a group of depressed patients and controls (Armitage et al., 1997). It might be interesting to link our findings on subjective sleep 
characteristics to those from studies that focus on objective slecp parameters in PD patients. Studies on sleep EEG studies in PD are, however, far from unequivocal. Differences in methodology, comorbidity status, and definirional issues apply here. Most authors have teported only limited changes in sleep duration and sleep architecnute in PD (Arriaga et al, 1996; Ferini-Strambi ct al., 1996; Landry et al., 2002; Stein et al, 1993b). Stein or al. (1993a) already noted the apparent dissonance between PD patients' subjective slecp complaints and the paucity of polysomnographic abnormalities detected in most physiological sudies. Some positive studies, for cxample, include an early study by Mellman and Uhde (1989a) and one by Sloan et al. (1999). However, though most earlier studies on sleep EEG fail to show clear differences between PD patients (without depression) and controls, one recent study suggests that there are some overall differences (Saletu-Zyhlarz et al, 2000). In this study, both objective, and subjective parameters were measured. Eleven PD patients were compared with 11. healthy controls. In baseline objective measurements they report a significant decrease in sleep efficiency, total sleep time, and increased middle and late insomnia in the absence of REM differences. In addition, subjective sleep quality was worse for the paticn group. This could indicate that advanced technological methodology may allow more subtle objective differences to reflect subjective clinical differences. If sleep disturbances in PD are insufficiently accounted for by comorbidity of depression or nocturnal panic, there must be some feature related to the PD itself that also gives rise to problems with quality of skep. Arousal dystegulation is an obvious possibility, as it is hypothesized to be an underlying mechanism in PD (Lepola et al, 1994). Besides the state of arousal during the panic attack itself, arousal dystegulation during the 24 -hour period could also give rise to complaints of diminished sleep cuality and daytime sleepiness. Arousal also relates to the functioning of the autonomic nervous system, which is known to be more unstable in PD patients than in controls. Faravelli et al. (1997) showed a decrease in mean flow velociry of the right middle cerebral artery in response to the tilting table test in PD patients, stiggesting autonomic dysfunction. Several investigators have reported a decreased heart tate variability in PD patients (Klein et al, 1995; Sloan et al., 1999), and PD patients seem to thave a more unstable respiratory pattern than notmal controls (Wilhelm et al, 2001). The precise interrelations between arousal, sleep and autonomic instability in PD patients remain unclear. Further studies, including objective sleep registration studies, together with monitoring physiological parameters, in pure PD patients without nocturnal panic attacks, would be needed to clarify this issue. Other, potentially related factors should also be considered. For instance, $P D$ has been associated with a higher selective attention to physical sensations suggestive of anxicty (anxicty sensirvity), leading to 'catastrophic interpretation' of these bodily sensations (Clark, 1980). 
Another factor that might influence sleep in PD is the extreme fatigue that may occur after a panic attack. This fatigue was found to be the most prominent post-attack phenomenon in $72 \%$ of PD patients (Starcevic, 1991).

Finally, a number of limitations of this study need to be mentioned. The sample size, particularly of the 'pute' PD group, should have been larger. Though many factors can influence sleep (e.g. medical conditions as pain of dyspnea or social citcumstances, Drake et al., 2003), we did not address any other confounders. Also, as mentioned briefly before, it would have been of great value if we had included objective sleep parameters. Nevertheless, despite these limitations, this study inclicates an association between PD and subjective sleep complaints, irrespective of comorbid depression or nocturnal panic.

\section{CONCLUSIONS}

From these data we conclude that PD patients suffer from sleep complaints more frequently than normal controls. The higher prevalence of sleep complaints in PD patients can only partly be explained by comorbid depression or by the presence of nocturnal panic attacks.

\section{REHERENCES}

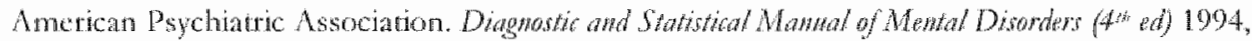
Waslnington DC, American Psychiartic Press

Amitage R, Trivedi M, Hoffmann $R$ and Rush $\mathrm{AJ}$. Relationship between objective and subjective sleep measures in depressed patients and healthy controls. Depress Amxieb $1997: 5,97-102$

Arriaga F, Pava T, Matos-Pires A, Cavaglia F, Jata E and Bastos L. The sleep of nondepressed paticnts with panic disorder: a comparison with normal controls. Anta Prybiar Srand 1996:93,191-194

Bandelow B. 1995. The assessment of efficacy of traments fot pante disotder and

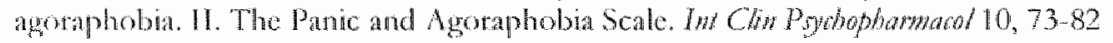

Bencin RM, Obermeyer WH, thisted RA and Gillin JC. Sleep and psychatric disorders a menanalysis. Amb Gis Poflitury 1992: 49, 651-668; discussion 669-670

Brown TM and Uhde TW (2003) Slecp panic attacks: A micromovement analysis. Depress Amw $18: 214220$

C.lark DM. A cognicive approach to panic. Betw Rer Ther 1986:24,461-470

Drake 61 , Rochers T, Roth T (2003) Insomnia causes, consequences, and therapeutics: An averiew. Depret Awate 18:163-176

larawelli C. Marimoni M, Spiri R, Ginanneschi A, Screna A, Fabbri C, Di Matten C, Del Mastio $M$ and Inzitari $\mathrm{D}$. Abonomal brain homodynamic responses during passive orthostaric challonge in panic disorder. Am / Pbdialy 1997: 154,378-383

Vermi-strambi I., Bdlodi I, Oldani A, Bertella S, Smime $S$ and Battaglia M. Cyclic alternating

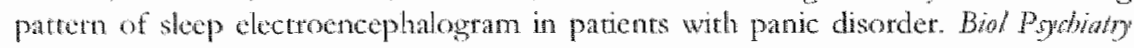
$1996: 40,225-227$

Klein E, Gnami L, Harel T, Brom S and Ben-Haim $S \mathrm{~A}$. Atered heart tate variability in panic Asorder paticnts. Brot Pigdialy 1995: 37, 18-24 
Kirysal JF, Woods SW, Hill CL and Chamey DS. Chancteristics of panic atack subtypes: assessment of spontaneous panic, situational paric, slecp panie, and limited symptom attacks. Compr Pyolodor 1991: 32,474480

I.andry P, Marchand I., Manguy N, Marchand A and Montplaisir I. Electrotncephalography during sleep of paticnts with nocturnal panic disocder. / Nery Men" Dis 2002: 190, 559 562

Lepine JP. Epideniology, burden and disability in depression and anxioty I Clin Psychiatry 2001: 62 suppl 13,4-10

Lepola U, Koponen H and Leinonen E. Sleep in panic disonders. I Pydowors Rer 1994: 38 Suppl $1,105-111$

Lesser IM, Rubin RT, Rifkin A, Swinson IRP, Ballenger JC, Burrows GD, Dupont R. Nayes R and Pecknold $) C$ Secondary depression in panic disorder and agomphobia. II. Dimensions of depressive sympromatology and theit response to tratment. I Affet Disord 1989: $16,49.58$

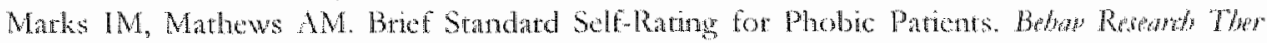
$1979 ; 17: 263-267$

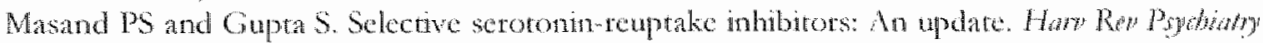
1999:7, 69.84

Mellman TA. Sleep aspects of anxicy disonders In: Amwo Dhordes. Nut Dy and Ballenger $1 \mathrm{C}$ Eds. 2003 Barh UK, Blackwell

Mellman TA and Uhde TW. Electroencephalographic slew in pante disorcen a focus on slecprelated panic attacks. And Gen Powhaty 1989 a: 46, 178-184

Mellman TA and Uhde TW. Sleep paric artacks: new clinical findings and deoretical

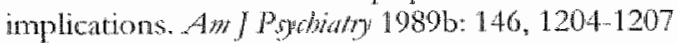

Montgomery $\mathrm{SA}$, Asberg M. A New Depression Scalo designed to be sensitive to change. British Journal of Psychiatry 1979: 134,382-389

Reynolds CF 3 ret and Kupfer DJ. Sleep reseatch in affective illness: state of the art circa 1987. Slogt 1987: 10, 199-215.

Saletu-Zylatarz GM, Anderer P, Berger P, Gruber $G$, Oberndorter S and Saleru B. Nonorganic insomnia in panic disorder: compatative sleep laboratory studics with nomal controls and placebo-controlled trials witly alprazolam. Fryn Psychoparyocol 2000: $15,241-254$

Sheehan DV, Ballenger J and Jacobsen G. Trentment of endogenous anxiety wirh phobic, bysterical, and hypochondriacal symptoms. Amb Gen Powdring 1980:37, 51-59

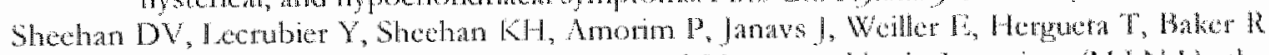
and Dumbar GC. The Mini-Internatonal Newopsychatro Interview (M.I.N.L.): the development and validation of a structured diagnostic pischatric interview for DSMIV and 1CD-10. J Clim Pyoliaty 1998: 59 Suppl 20, 22-33

Sion EP, Natarajan M, Baker B, Dortan P, Mironov D, Batr A, Newman DM and Shapiro CM. Nocturnal and dayeme panic atacks: comparison of silep archicerure, theart atic ariability, and response to sodium lactate challenge. Biol Pyodiaty 1999: 45, 1313 1320

Starcevic $V$. Shoud postartack phenomena be included in the definition and eleseriprion of a panic atrack Asy J Probratry 1991: $148,1752-1753$

Stein MB, Charter M and walker JR. Sleep in nondepressed pationts with panic disorder: 1 . Systematic assessment of subjective sleep quality and slecp disturbance. S/exp $1993 \mathrm{a}$ $16,724-726$

Stein MB, Enns MW and Kryger MH. Slep in nondepressed patients with panic ditorder: II. Polysomnographic assessment of slop architcoure and stecp continuty. I Affet Disond 1993b: $28,1-6$

Szuba MP. The psychobiology of slep and major depression. Depres Amxity $2001: 14,1-2$ 
Uhde TW, Roy Byrne P, Gilin JC, Mendelson WB, Boulenger IP, Virtone B], Post RM. The slecp of patients with panic disorder a preliminary report. Psychatoy Res 1984: 12, 251259

Van Dicst R. Subjective sleep characteristics as cononaty risk factors, their association with Type A behavour and vital exhaustion. J Pryolosom Res 1990: 34, 415 426

Van Dicst R, Milus $\mathrm{H}$, Markuse $\mathrm{R}$ and Snel I. The Sleep-Wake Experience List. In: 5 lep and

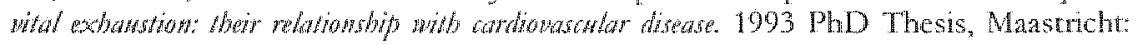
Mastricht University

Withelm $P H, G e v i r z, R$ and Roth WT. Respiratory dystegulation in anxiety, funcronal cardiac, and puin disorders: assessment, phenomenologe, and treament. Behay Modl $2001: 25$, $513-545$

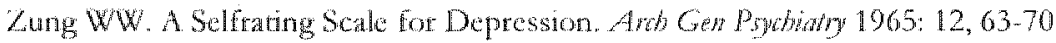


7. BLOOD-INJURY RELATEd PHobIC AVOIDANCE AS PREDICTOR OF NONRESPONSE TO Pharmacotherapy IN Panic Disorder with AgORAPHOBIA

T. Overbeek, H. Büchold, K. Schruers and E. Griez

In: Jowmal of Affertine Disorders 2004, 78:227-233 


\section{ABSTRACT}

Backgrond: Several factors have been investigated as possible predictors of nonresponse to pharmacotherapy in Panic Disorder (PD) patients. In 1995 a study was published by Slaap et al. in the foumal of Affetive Disonters that found high Blood-Injury phobia scores on the Marks and Matrhews Fear Questionnaire wete predictive for a worse treatment-outcome for drug treatment in PD.

Melbods: The present paper describes a replication study with $61 \mathrm{PD}$ parients, by means of a retrospective chart analysis, who were assessed at baseline and after 12 weeks of SSRI-treatment. Nonresponse was defined as still having panic attacks. Response was defined as absence of panic attacks and/or a reduction of at least $50 \%$ on the $\mathrm{PQ}$ Agotaphobia subscalc.

Results: Twenty $(32 \%)$ patients were nonresponders. Nonresponders had a higher score on the FQ Blood-Injury subscale more often $\left(55^{\%} \%\right)$ than responders $(19.5 \%)$, significant at $\mathrm{p}=.008$. These results fully support the findings of Slaap et al. Implications of these findings are further discussed.

Limitations: Limitations of this study ate the retrospective design, and the absence of other psycho-physiological patameters of the specific blood-injury phobic complex.

Condusions: However, it is tentatively concluded that the presence of comorbid blood-injury related phobic symptoms negatively affects trearment for panic disorder and agoraphobia. 



\section{INTRODUCTION}

Panic Disorder (PD) is a common psychiarric illness that causes considerable short- and long-term morbidity. In the absence of effective therapy, PD tends to become a chronic disorder with a low tendency of spontaneous remission (Faravelli et al., 1995; Katschnig and Amering, 1998).

Pharmacological treatment, either with a specific serotonin reuptake inhibitor (SSRT), or one of the older tricyclic antidepressants (TCAs), or even a mono amine oxidase inhibitor (MAOD) has proven effective in the majority of patients (Feighner, 1999). Also cognitive behavioral therapy (CBT) is an effective treatment for PD. Although a recent study by fava et al. (2001) showed that, in spite of successful symptom reduction by CBT, residual symptoms and impaired psychological well-being must not be undetestimated. However, a proportion of PD patients does not respond to any of the currently available treatments. Many factors have been investigated as being possible predictive of nonresponse to both short-term and long-term treatment in PD (for a review, see Slaap and den Boer, 2001). The potential predictors in pharmacotherapy that have been most often investigated are associated with demographic variables, illness variables, or comorbidity. While demographic variables failed to give clear-cut indications of nonresponse, some illnessrelated variables as a long history of $\mathrm{PD}$, frequent panic attacks, and severe agoraphobic avoidance appeared to be negatively correlated with the response to treatment. Some studies found the presence of a comorbid depression to predict nonresponse, mainly on the long term. Personality disorders, or even personality disorder characteristics, in some studies are found to predict nonresponse, whereas other studies find no relationship between personality and treatment outcome but on the contrary even found a significant change in personality disorder characteristics with effective PD treatment (Hofmann, 1998). One may tentatively conclude that long duration of illness and severe agoraphobic avoidance are the most robust predictors of nonresponse to drug treatment, particularly in the long term.

Some years ago, Slaap et al. (1995) reported on an unexpected psychometric dimension they found to be predictive of treatment outcome for PD. They conducted a study to determine clinical baseline variables of 44 PD patients, screening which one might identify responders and nonresponders. It was found that one of the best predictors of nontesponse to drug treatment, in this particular case 29 subjects on brofaromine (a MAOI) and 15 on fuvoxamine (a SSRI), was a high baseline score on the blood-injury phobia subscale of the Fear Questionnaire (Marks and Mathews, 1979). This intriguing finding, and its possible theoretical implications, has received little attention in the litcrature, which led us to undertake this replication study in our own patient population. 
We hypothesized that the scores on the subscales of the Fear Questionnaire were irrelevant for treatment ourcome in PD patients. Responders and nonresponders were expected to show the same mean scores on these subscales, and an equal percentage of 'high' against 'low' scorers.

\section{METHODS}

\section{Sample}

Patients were teferred for treatment to the Academic Anxicty Center Maastricht, the Netherlands, a tertiary outpatient clinic, specializing in anxiety disorders. According to standard procedures in our clinic, all patients were evaluated by means of a psychiatric interview, with spectal emphasis on anxiety and affective spectrum symptoms. A diagnosis was made according to DSM-IV (APA, 1994) criteria (or DSM-III-R; APA, 1987; whichever current at the time of referral), and confirmed by two experienced psychiatrists.

Included for this retrospective chart analysis were 61 PD patients, all of them had agoraphobia. Exclusion criteria were other axis I disorders (including depressive disorder) as a comorbid diagnosis, and missing data at baseline or after twelve weeks of medication.

\section{Treatment}

After completion of the diagnostic procedure, patients were offered a combined psychophamacological and behavioral treatment. Initially, in the first phase, patients received pharmacotherapy, i.e, a prescription for one of the current SSRIs, and were regularly seen for a global clinical evaluation. Fifreen patients were on paroxetine (dosage from 20 to $50 \mathrm{mg}$ ) and 46 patients were on fluvoxamine (dosage from 150 to $250 \mathrm{mg}$ ). There were no differences between both groups at baseline and after drug treatment. The second psychometric assessment took place between week 10 and 12 , before the planned start of behavior therapy, based on exposure and response-prevention intervention. The present study therefore only covers the first phase of tratment.

\section{Arnessment}

Paticnts were evaluated by means of a batrery of standardized questionnaires and structured interviews, among which were the Fear Questionnaire FQ (Marks and Marhews, 1979) and the Montgonnery-Asberg Depression Rating Scale MADRS (Montgomery and Asberg, 1979). The FQ is a selfrating scale, consisting of three subscales, of five items each, to be scored from 0 to 8 , regarding Agoraphobia, Social Phobia, and Blood-Injury Phobia. Maximum score for each subscale is 40 , total maximum thus 120 . The MADRS is an investigator tated scalle, consisting of 10 items on depressive symptoms, to be 
scored from 0 to 6. Patients also standard received a physical examination, including blood tests. Panic attack frequency and intensiry was registered, regarding 2 wecks prior to the start of medication and after ten to welve weeks of pharmacotherapy.

Response in our study was defined as a total absence of panic artacks in week 10-12 until the end of behavior therapy, or a reduction of at least $50 \%$ on the initial score on the Agoraphobia subscale of the Fear Questionnaire. This definition on the whole is similar to the definition used in the original study conducted by Slaap et al. (1995). The only difference with the Slaap et al. study is the period in which we measured the presence or recurrence of panic attacks: we included panic attacks that occurred during the phase of combined drug and behavior therapy. If patients were free of attacks in week 10 to 12 , but attacks recurred somewhere during behavior therapy, they were considered nonresponders. Otherwise, if still having panic attacks duting weck 10 to 12 , but afterwards, duting behavional treatment becoming panic tree, patients were also considered as nontesponders. This makes our definition of response and nonresponse stricter than the original study's definition because we inciude a longer-term response.

\section{Statistical Anabsis}

Statistical analysis was conducted with SPSS-PC, version 7.5. Difrerences between responders and nonresponders were analyzed by $A N O V A$ on baseline variables MADRS, FQ total score (FQT), FQ Agoraphobia (FQA) subscore, FQ Blood Injury (FQB) subscore, and the FQ Social Phobia (FQS) subscore.

Categorization of high versus low scorers on the FQ subscales was defined at a cut-off score of 20 on each subscale. These data were tested with Fisher's exact test (two-tailed). These scores were used as indicator variables to investigate the influence of phobic symproms on nonresponse. A logistic regression analysis: was carried out for all significant baseline variables, with backwards elimination, to make a best-fitting model. These procedures were identical to the procedures used in the Slaap et al. study.

\section{RESULTS}

Patient demographics and clinical wariables at baseline are shown in Table 1. The mean age of the 61 patients was 37.7 (SD 9.3) years. Thirty-seven $(61 \%)$ were female, with a mean age of 35.7 (SD 9.4) years. The mean age of the 24 male subjects was 39.2 (SD 9.0) years (NS). 
Table 1. Mcan scores for Responders and Nonesponders at baseline

\begin{tabular}{|c|c|c|c|}
\hline & Responders $(N=41)$ & Nonresponders $(N=20)$ & $p$ \\
\hline Mean age & $37.7( \pm 9.3)$ & $37.4( \pm 8.8)$ & $\mathrm{NS}$ \\
\hline Malefemale tatio & $15: 26$ & $9: 11$ & NS \\
\hline MADRS & $6.3( \pm 4.2)$ & 7.1. $( \pm 4.0)$ & NS \\
\hline FQ Tokal & $50.1( \pm 21.1)$ & $65.7( \pm 22.7)$ & 0.014 \\
\hline FQ Aporabobias & $23.4( \pm 10.6)$ & $28.8( \pm 9.4)$ & NS \\
\hline 10 Blood longery & $11.5( \pm 8.2)$ & $18.4( \pm 12.7)$ & 0.011 \\
\hline Fu Somal Phabia & $15.2( \pm 9.5)$ & $18.5( \pm 7.5)$ & NS \\
\hline
\end{tabular}

Forty-one patients were found to be responders by our definition, whereas 20 patients did not meet the criteria for response. Gender distribution in the responder group was 26 female and 15 male, in the group of nonresponders 11 were female and 9 male (NS). Mean age for responders $(37.7$, SD 9.3) and nonresponders (37.4,SD 8.8) did not differ.

Mean $\mathrm{FQ}$ scores at baseline for both groups are shown in Figure 1. The mean MADRS for responders (6.3; SD 4.2) and nontesponders (7.1; SD 4.0) did not differ significantly at baseline. The mean baseline FQA neither showed any significant difference, responders scored 23.4 (SD 10.6) and the nonresponders 28.8 (SD 9.4). Also the FQS (before treatment) did not differ significantly berween responders (15.2; SD 9.5) and nonresponders $(18.5 ; \mathrm{SD} 7.5)$. The means on the FQB (and the FQT), however, did differ. The mean baseline score for responders on the Blood Injury Phobia subscale was 11.5 (SD 8.2) and for nonresponders 18.4 (SD 12.7), significant at $\mathrm{p}=.011$. Also the baseline FQT scores were significantly higher (at $\mathrm{p}=.014$ ) for the group of nonresponders $(65.7 ; \mathrm{SD} 22.7)$ than for the responders $(50.1 ; \mathrm{SD} 21.1)$, largely attributable to the FQB score, because if taken rogether, the subscores on FQA and $\mathrm{FQS}$ did not differ significantly between responders and nontesponders. 


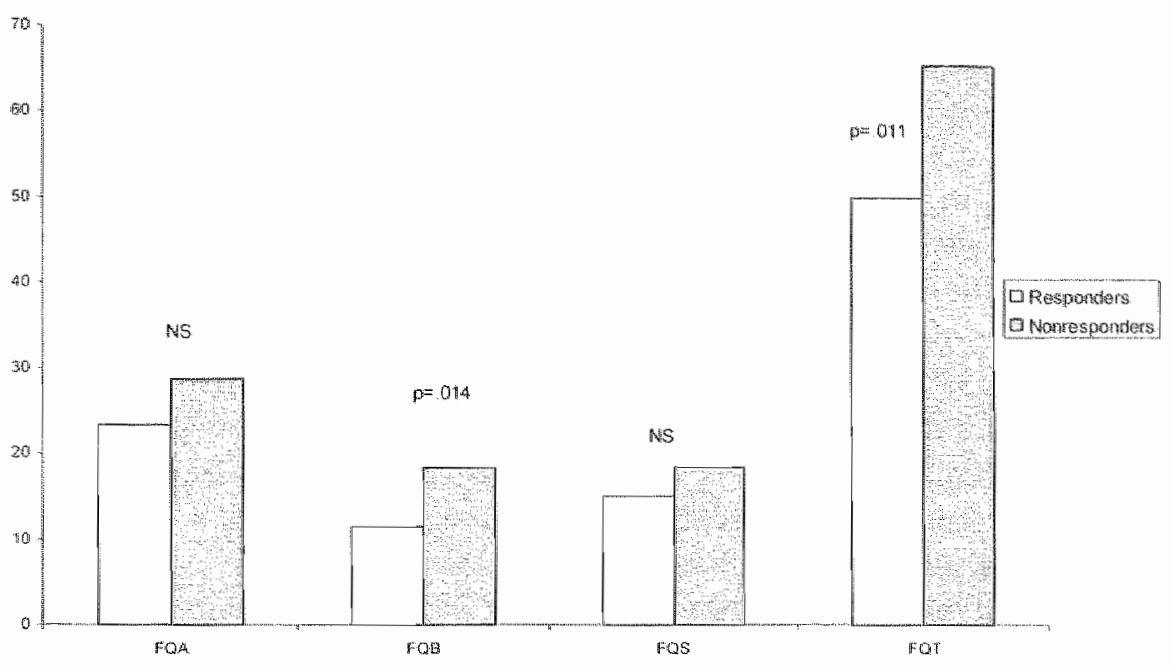

Figure 1. Mean scotes of responders ws nontesponders on the Cear Questionnate and its subscales at baseline

Looking for possible predictors, we used indicator variables, derived from dichotomizing scores on the FQ-subscales in 'high' $(>$ or $=20$ ) and 'low' $(<$ 20) scorers. Combinations of subscales are high' scorers if on all individual subscales the subscores are above the cur-off of 20 . The indicator variables for the FQ-subscales and the combinations of subscales ate given in Table 2.

Table 2. Indicacor variables of FQ-subscales and their combinations.

\begin{tabular}{|c|c|c|c|c|c|}
\hline & \multicolumn{2}{|c|}{ Besponders $(\mathrm{N}=4 \|)$} & \multicolumn{2}{|c|}{$\begin{array}{l}\text { Nomesponders } \\
\qquad(\mathrm{N}=20)\end{array}$} & \multirow[b]{2}{*}{$p$} \\
\hline & $\%$ & $N$ & $\%$ & $N$ & \\
\hline Higl FQA & 61 & 25 & 80 & 16 & NS \\
\hline High FOB & 19.5 & 8 & 55 & 11 & 0.008 \\
\hline High FQS & 36.6 & 15 & 45 & 9) & NS \\
\hline High FOA $+F Q B$ & 19.5 & 8 & 50 & 10 & 0.019 \\
\hline Hig $F Q A+1 Q S$ & 24.4 & 10 & 45 & ) & NS \\
\hline High $F Q B+F Q$ & 2.4 & 1 & 40) & 8 & $<0,001$ \\
\hline High $F Q A+10 B+F Q S$ & 2.4 & 1 & 40 & 8 & 00.001 \\
\hline
\end{tabular}

For the individual subscales, only the Blood-Injury score at baseline significantly differs in percentage berween the responders (19.5\% scoring as high) and nontesponders (55\% 'high'), Fisher's exact test $p=.008$. Combinations of subscores turn out to show significant differences in percentage of high versus low scoring parients, only if the FQB is included. For FQA together with $\mathrm{FQB} \quad 19.5 \%$ responders against $50 \%$ of nonresponders 
score 'high' $(\mathrm{p}=019) ; \mathrm{FQB}$ and FQS rogether show a $2.4 \%$ 'high' responders against $40 \%$ 'high' nonresponders $(\mathrm{p}<001)$; if combining all three subscales $F Q M$ and $F Q B$ and FQS $2.4 \%$ of responders and $40 \%$ of nonresponders are 'high' scoters $(\mathrm{p}<001)$

For the prediction of nonresponse to drug therapy a regression analysis on all significant baseline variables (high $\mathrm{FQB}$, high $\mathrm{FQB}+$ high $\mathrm{FQA}$, high $\mathrm{FQB}+$ high FQS, high FQB + high FQA + high FQS) was carried out. Every single baseline variable significantly predicted nonresponse $(\mathrm{p}<05)$. A best-fitting model was also calculated by carrying out a logistic regression analysis with all significant variables in the initial solution. The backwards elimination process resulted in a prediction based on one variable (set of variables) only. The variable 'having at high score on the FQA and FQB and FQS' was the only variable left in the equation. With this equation, the overall percentage correctly classified patients was $80.3 \%$. Forty responders $(97.6 \%)$ and 9 nonresponders $(45 \%)$ were correctly classified. Incorrectly classified was 1 responder as nontesponder, and 11 nonresponders $(55 \%)$ as responders. The fit of the model was reasonable (Chi-square $3.33 ; \mathrm{p}=.012$ ). Prediction based on only the variable high-low $\mathrm{FQB}$ would provide a cortect overall percentage of $72.1 \%$, with $55 \%$ of nontesponders and $80.5 \%$ of responders cortectly classified (Chisquare $7.67 ; p=.006)$.

\section{DISCUSSION}

The present results show that scores on the Blood-Injury phobia subscale of the Fear Questionnaire are predictive for PD treatment outcome. Higher baseline scores on the $F Q B$ were found in the group of patients that did not respond well to drug therapy. The findings of Slaap et al. (1995), based on a sample of 44 PD patients, were replicated in a larget sample of 61 patients.

Previous studies regarding the comorbidity among the anxiety disorders, have reported large prevalences of other anxiety disorders in PD (Di Nardo and Barlow, 1990). Reported comorbidity rates of simple phobia in PD vary between $6.3 \%$ and $46.6 \%$, and a comorbid social phobia occurs in $9.6 \%$ to $40.7 \%$ in PD paticnts (Slaap et al, 1995). Subthreshold phobic symptoms, that do not reach full diagnostic criteria, are also very common in PD patients (Argyle ct al., 1991). The presence of co-existing phobic symptoms reminiscent of simple phobia, seems to be a plausible explanation for the finding of relatively high $\mathbb{P Q}$ blood-injury phobia scores in PD patients. What is surprising, however, is the importance of these phobic symptoms for treatment outcome. Therefore the question arises whether there is a special relation between PD and blood-injury phobic symptoms. There are some data that provide some clues. 
The special status of blood-injury phobia among the orher specific phobias has been described (Marks, 1987, 1988; Ost et al., 1984). Blood-injury phobia differs from the other specific phobias, in that it has a stronger familial component, and because of its physiological characteristics: a unique biphasic response. In general, phobic stimuli elicit a rise in heart rate and blood pressure. In contrast, in blood-injury phobia, an initial short rise in heart frequency is very shortly afterwards followed by a robust bradycardia and hypotensive weaction. In $80 \%$ of cases this leads to a syncope or presyncope (Marks, 1987; Ost et al., 1984). Further, patients with blood-injury phobia show an abnomal hemodynamic response during experimental head-up tilt and are strikingly prone to vasovagal teactions, compared with normal controls (Accurso et al, 2001). Even in the absence of a blood or injury stimulus, blood pressure and heart rate decreased during the test. The authors state that fainting telated to blood or injury may not be primarily due to a psychiatric condition, but rather due to dysfunction in the autonomic nervous system, which may secondarily lead to the phobia because of repeated syncopal events (Accurso et al, 2001). These studies show that blood-injury phobia is characterized by a special autonomic nervous system response. It is therefore conceivable that blood-phobic symptoms are also associated with autonomous dysregulation.

Previous studies have also related PD to a dysfunctional autonomic nervous system. Initial studies reported general autonomic dysfunctions in eg. heart tate variability and blood pressure. However, more recent studies found no changes in systemic parameters (Fravelli et al., 1997; Wilhelm et al., 2001). Faravelli et al. (1997) have shown abnomalites in central parameters of sympathetic reactivity especially in the regulation of cerebral blood flow. By means of experimental tilting-table test, they found that PD patients responded to the manipulation with a lower mean flow velocity in the right middle cerebral artery, as compated with normal subjects.

From a different approach, an indirect argument in this direcrion could be the observation that patients with refractory neurocardiogenic (vasovagal) syncope can be effectively treated with a selecrive serotonin reuptake inhibitor paroxerine. Downregulation of postsynaptic serotonin receptors in the brain stem, resulting in a blunted response to rapid shifts in central scroronin levels, has been proposed as a possible explanation for this phenomenon (Di Girolamo et al., 1999).

The line of evidence towards a role of a disturbed autonomic nervous system in both blood injury phobia and PD is ser, some (physiological) dysfunction here could explain a relationship between the two. The results of the present clinical study could support this link.

As well as a common physiological basis, another explanation for the present findings could lie in a link between PD and hypochondriasis. Hypochondriasis seems to be related to the anxiety disorders and shows some comparable 
phenomenology. Its DSM classification with the somatoform disotders has been discussed but is now widely accepted (Noyes 1999). However, differentiation from specific illness phobia on the one hand, and PD on the other, is not always obvious. As often described before, PD patients frequently experience hypochondriacal concerns (Noyes et al., 1986; Starcevic et al., 1992; Furer et al., 1997). The high scores on the $F Q B$ we found in our PD sample could reflect 'normal' hypochondriacal preoccupations, as the items of the FQB relate to feat of injections or minor surgery, hospitals, sight of blood, thought of injury or illness, and going to the dentist. Some researchers found that the hypochondriacal symptoms of PD patients improve with treatment of the PD (and agoraphobia), and thus concluded that hypochondriasis was a prominent but secondary feature of the PD (Noyes et al., 1986; Fava et al., 1988c). Wava et al. (1988b) also showed that the common blood-injury phobic symptoms in PD patients, improve with nonspecific treatment (Fava, 1988c). They have used the same assessment tool of the FQ and its subscales as we did. Fava et al. (1988b) suggest that the presence of anxiety may be conducive to hypochondriacal concerns, including fear of blood and injury, and that such fears tend to temit when anxiety decreases. On the other hand, others describe hypochondriasis being present before the onset of the PD in about $50 \%$ of the comorbid patients (Furer et al., 1997; Fava et al., 1988a). This would point in the direction of true (symptom or syndrome) comorbidity and could complicate treament, for hypochondriasis is known to be a condition that is rather resistant to therapy. Moreover, as PD patients, as well as hypochondriac patients, are very attentive to bodily symptoms and prone towards catastrophic misinterpretation, they could suffer more from normal SSRT side-effects, which could endanger their therapeutic compliance. Extensively reviewing cognitive aspects is beyond the scope of this paper, but for future research it would be intresting to include both cognitive and physiological assessments in PD treatment outcome. Bakker et al. (2002a, 2002b) recently have shown the relevance of belief in catastrophic misinterpretations during panic attacks for treament outcome, and the differential effects of treatment modalities on the locus of control orientation in PD patients, CBT. strengthening more internal locus of control, whereas medication influenced the external locus of control. This approach also seems highly relevant in studying blood-injury and hypochondriacal fears.

In sum, there seem to be at least wwo hypothetical lines of explanation regarding the role of subthreshold blood phobic symptoms in the treatment of PD with agoraphobia. Be it the comorbid blood-injury phobia with a common underlying physiological dysfunctional autonomic nervous system, or comorbid hypochondriac symptoms that are reflected in the score of the Fear Questionnaire Blood-injury subscale, the observed clinical importance seems to watrant futher, more specific symptomatic and physiological investigation. 


\section{REFERENCES}

Accurso $V$, Winmick $M$, Shamsuzzaman AS, Wenzel A, Johnson AK and Somerts VK. Predisposition to pasovagal syncope in subjects with blood/injury phobia. Chomation 2001: 104, $903-907$

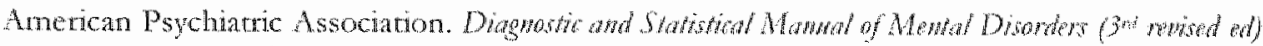
1987, Washington DC, American Psychatric Press

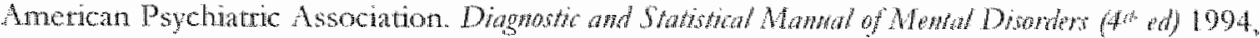
Washington DC, Ametican Psychatric Piess

Argye $\mathrm{N}$, Solyom $\mathrm{C}$ and Solyom $\mathrm{L}$. The structure of phobias in panic divader. Br Pyolaty $1991: 159,378-382$

Bakker A, Spinhoven P, wan der Does A, van Balkom A and van Dijck R. Locus of control

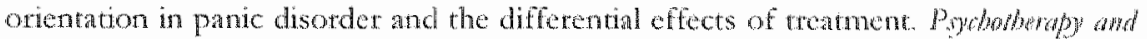
Psychasomation 2002a: 71,85-89

Bakker A, Spinhoven P, van Balkom A and wan Dijck R. Relevance of assessmeme of cognitons

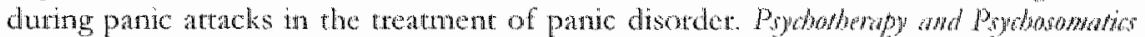
$2002 \mathrm{~b}: 71,158-1.61$

Di Girolamo E, Di Iorio C, Sabarini P, Leonzio 1. Barbone C and Batsoti A. Feffects ot paroxetine hydrochloride, a selective serotonin reuptake inhillitor, on refractory vasowagal syncope: a randomized, double-blind, placebo-controlled study. / $\mathrm{Am}$ Col/ Candiol 1999: 33, 1227-1230

Di Nardo PA and Batlow DF. Syndrome and sympon comorbidity in the anxicty disorders.

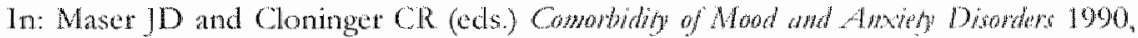
Washington, American Psychautic Press. 205-230

Fanawelli C, Marnoni M, Spiri R, Ginanneschi A, Serena A, Fabri C, Di Marter C, Del Mastio $M$ and Inzitati $D$. Abnotmal brain hemodynamic responses during passive othostatic challenge in panic disorder. Am f Pywhodsy 1997: $154,378-383$

Faravelli C, Patemiti S and Scappato A. A 5-yeatr prospective, naturalistic follow-up shuly of panic disorder. Compr Piydratry 1995:36,271-277

Fava $G A$, Grandi $S$ and Canestrati $R$. Prodromal symptoms in panic disorder with agomphobia. And Pschinty 1988a: 45, 1564-1567

Fava GA, Grandi S and Canestrati R. Blood-injury phobia and panic disorder: a reglected relatonship. Med Sa Rer 1988b: 16,217-218

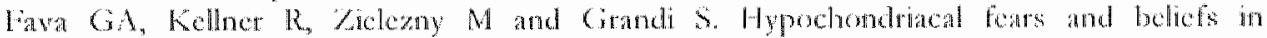
agotaphobia. J Affec Drond 1988c: $14,239-244$

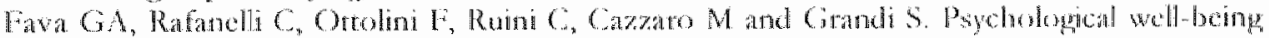

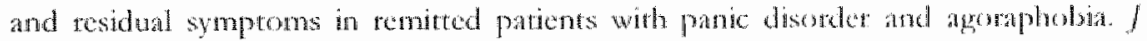
Affeot Disom 2001: $65,185 \ldots 190$

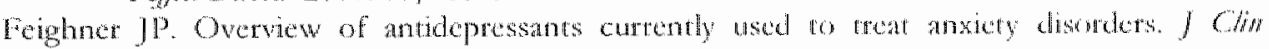
Psidiatry 1999: 60 Suppl 22, 18-22

Furer $P$, Walker $\| R$, Chartice $M J$ and Stem MB. Hypochondracal conceros und sinmatization in panic disonder. Depres Anxteg 1907:6,78-85

Hofmann SC; Shear MK, Batlow DH, Goman JM, Fershberger D, Paterson M and Woods SW. Effecis of panic disotder treatments on personality disorder chatactetistics. Depros Amoty $1998: 8,14-20$

Katschnig $H$ and Amering $W$. The long-term course of patic disorulet and its predictors. I Chm Psolophantarol 1998: 18, Suppl 2, 65-115

Marks 1 and Mathews AM. Brief standard selferating for phobic patients. Bebal Res THex 1979: $1.7,263 \cdot 267$

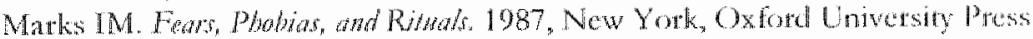

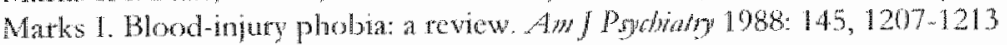


Montgomery $\$ A$ and Asherg M. A New Depression Scale designed to be sensive to change. Br J Pydhithy 1979: 134, 382-389

Noyes R, Reich J, Clancy J and $\mathrm{O}^{\prime}$ Gomm TW. Reducuion in hypochondriasis with treatment of panic disorder. Bry Pychiaty 1986: 149,631-635

Noyes $R$ J. The relationship of hypochondriasis to anxiety disonders. Gen Hosp Psyoury 1999: $21,8.17$

Ost L.C, Stemer U and Lindahl II. Physiological responses in blood phobics. Bebow Rer Ther 1984: $22,109 \div 117$

Stat BR and den Boer JA. The prediction of nonresponse to pharmacomerapy in panic disorder: a rewiew. Depress Amated 2001: 14, 112-122

Slatp BR, wan Vher $1 \mathrm{M}$, Westenberg $H \mathrm{G}$ and den Boer $J \mathrm{~A}$. Phobic symptoms as predictors of nontesponse to drug therapy in panic disorder patients (a preliminary report). I Afot Disord 1995: $33,31-38$

Starcevic V, Kellner R, Uhentuth EH and Pathak D. Panic disorder and lypochondriacal fears and beliefs. J Afect Disorf 1992: 24,73-85

Wilhem WH, Trabert W and Roth WT. Physiologic instability in panic disorder and generalized anxiety disorder. Biol Psybiary 2001: 49,596-605 


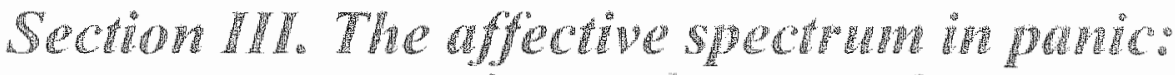
an experinatural approwach 



\section{EXPERIMENTAL AFFECTIVE SYMPTOMS IN PANIC} Disorder PatientS

T. Overbeek, K. Schruers, I. Docters van Leeuwen, T. Klaassen and $\mathrm{E}$. Griez 



\section{ABSTRACT}

Objectitre: To date $\mathrm{CO}_{2}$ challenge tests in panic disorder (PD) patients focused on anxicty as the sole outcome measure. The aim of the present study was to assess a broader range of affective symptoms after a $\mathrm{CO}_{2}$ challenge in a sample of PD patients with and without major depressive disorder (MDD).

Method: We administered a gas mixture of $35 \% \mathrm{CO}_{2}$ and $65 \% \mathrm{O}_{2}$ to $25 \mathrm{PD}$ patients. Nine of these had a comorbid (current or lifetime) MDD and 16 patients did not meet criteria for MDD. At baseline, and immediately after the challenge, subjects wete assessed on a list of panic symptoms (PSI), an adapted profile of mood states (POMS) regarding aggressive and depressive feelings, and visual analogue scales on anxiety (VAS-A), aggression (VAS-Ag) and depression (VAS-D).

Results: All patients reported an increase in anxiety symptoms. PD patients with comorbid lifetime depression showed a higher increase on both aggression and depression than did nondepressed PD patients.

Conclusion: These findings suggest that a comorbid mood disorder in PD patients is related to a response pattem to a $\mathrm{CO}_{2}$ challenge with both anxiety and other affective symptoms. A panic challenge may be both depressogenic and aggressogenic, dependent on the comorbid disorder present. 



\section{INTRODUCTION}

Controlled panic induction by means of experimental laboratory challenges is a well-known procedure. Hypersensitivity to the challenge is often accepted as indicative of panic disorder (PD). One of the avatable provocation methods is the inhalation of a gas mixture of $35 \% \mathrm{CO}_{2}$ with $65 \% \mathrm{O} \%$, orginally described by Griez et al. (1987).

In PD patients, this intervention yields symptoms of anxiery as well as somatic symptoms that very much resemble a real-life panic attack. The merhod has been frequently used to investigate the underlying pathophysiological mechanisms of PD in laboratory setting (Griez and Schruers, 1998; Goman et al., 1990; Pena et al., 1995). It is implicitly assumed that $\mathrm{CO}_{2}$ only provokes anxiety. To date, other affective symptoms have not been assessed in a systematic way. However, it is generally known that anxiety disorders and mood disorders show large overlap of symptoms (Di Nardo and Barlow, 1990). Symptoms of depression, anxiety and aggression have been hypothesized to form a cluster, related to serotonergic (dys) functions (Apter et al., 1990; van Praag, 1998). According to this hypothesis, these serotonergic dysfunctions persist in times of remission. Moreover, feelings of aggression frequently are described in PD patients, and anger attacks have been proposed as a specific variant of panic attacks (Fava et al., 1990; George et al., 1989).

From syndromal perspective anxiety and mood disorders frequently coexist, e.g. approximately $30 \%$ of PD patients suffer from concurrent depression, and $60 \%$ of PD patients have a lifetime diagnosis of depression (Kaufman and Charney, 2000; Levine et al,, 2001). Some authors have hypothesized that mood and anxiety disorders are two expressions of the one underlying affective spectrum disorder.

Therefore, it is interesting to assess if the supposedly panicmspecific challenge test by means of $\mathrm{CO}_{2}$ administration raises other affective symptoms, like aggression and depressive symptoms.

In the present study we assessed the presence of different affective symptoms in a $\mathrm{CO}_{2}$ challenge paradigm. Along with anxiety, symptoms of the depressive and aggressive cluster were assessed. In our analysis we made a distinction between PD patients without (a history of) depression (PD-MDD) and PD patients with comorbid (concurrent or liferime) depressive disorder (PD+MDD). Reasons for this comparison are twofold. First the observation of van Praag (1998) that certain biological features of depression persist in times of temission, and secondly the findings by Verburg of al. (1998) that a subgroup of depressed $\mathrm{PD}$ patients react to the $\mathrm{CO}_{3}$ provocation with increased anxiety symptoms when compared ro nondepressed PD parients. We 
hypothesize that the $\mathrm{CO}_{2}$ challenge will induce aggression and depressive symptoms in only those PD patients with current or lifetime MDD.

\section{METHODS}

\section{Subjects}

Subjects were recruited at the Academic Anxiety Center Maastricht, the Netherlands, an outpatient clinic specialized in anxiety disorders. All patients werc evaluated by means of a clinical psychiatric interview with special emphasis on anxiety and affective spectrum symptoms, and the Mini International Neuropsychiatric Interview (MINI, Sheehan et al., 1998), a semistructured psychiatric interview based on DSM-IV criteria (APA, 1994). The diagnosis was confirmed by two experienced psychiatrists. Additionally, patients had a physical examination and routine blood tests. Those patients that met DSM-IV criteria for PD (with or without agoraphobia), were informed about the experimental intervention and were invited to participate in the study. All participating patients gave informed consent. The study was approved by the Investigation Review Board of the University of Maastricht and was conducted acconding to the declaration of Helsinki. Patients with other axis 1 diagnoses were excluded, except for comorbid major depressive disorder (MDD), current or lifetime. Patients who were currently using benzodiazepines or antidepressant medication, and patients with physical conditions that could be compromised by the challenge were also excluded like those with cardiovascular or pulmonary disease, epilepsy, pregnancy or a known cerebral aneutysm.

Twenty-five PD patients were included in this study. Nine out of these 25 patients $(36 \%)$ met criteria for a comorbid lifetime depressive disorder (PD+MDD). Five out of these 9 subjects had a current depression. Nine patients were men, (one in the comorbid group), 16 were women ( $8 \mathrm{PD}$ and 8 PD+MDD). The sex distribution among PD with and without depression was not significantly diffetent (Chi-square $3.78 ; \mathrm{P}=0.09$ ).

Mean age of the PD+MDD patients was 36.3 (SD 7.0) years, mean age of the PD patients without depression 43.6 (SD 10.2) years. This difference was not statistically significant $(t=1.88 ; \mathrm{df} 23 ; \mathrm{P}=0.07)$.

\section{Intervention}

The experimental intervention was the $\mathrm{CO}_{2}$ inhalation method, which is described in detail elsewhere (Griez et al., 1987; Verburg et al., 1998). This procedure consists of the inhalation of a single breath gas mixrute of $35 \% \mathrm{CO}$. and $65 \% \mathrm{O}$. 


\section{Assessments}

At baseline, just before the $\mathrm{CO}_{2}$ inhalation, patients were asked to fill in the Panic Symptom List (PSL). This is a self-repont scale consisting of 13 items, reflecting the 13 DSM-IV panic symptoms. They are scored on a 0 (not present at all) to 4 (very much present) scale. This scale has been used previously to assess experimental anxiety (Verburg et al., 1995; Schruers et al., 2000).

Patients were also requested to fill in the adapted short Profile of Mood States (POMS) on Aggression (POMS-Ag) and on Depression (POMS-D). The original POMS (McNair et al., 1971) consists of 65 items on 6 affective dimensions, and has been adapted and shortened seyetal times afterwards. For the present study we followed Terry et al. (1999), who selected 7 items from the category Depression (i.e unhappy, miserable, depressed, downhearted, sad, gloomy and lonely) and 7 items on Aggression (i.e. angry, bitter, annoyed, badtempered, furious, spiteful and ready to fight in order to simplify the task for the subjects and shorten the lime needed to complete the experimental procedures. Each irem must be scored on a scale from 0 to 4.

The other scales to be scored were a visual analogue scale (VAS) on Anxiery (VAS-A), Aggression (VAS-Ag) and Depression (VAS-D). For the VAS, subjects were asked to point out how they feel at that moment, regarding anxicty, aggression, or depression on a scale from 0 (not at all) to 100 (the worst possible).

All these assessments were repeated directly after the $\mathrm{CO}_{2}$ challenge.

The occurrence of a panic attack was defined experimentally as an increase of at least $25 \%$ on the VAS-Anxiety and any increase on at least 4 PSL-symptoms (Klaassen et al., 1998).

\section{Statistical analysis}

Data were analyzed with the statistical softwate program SPSS for Windows, version 11.0. Student's t-test was used to test mean age differences. Scx distribution was tested with the Chi-square test. Nonparametric rests were applied to the assessments of the affective symptoms, due to non-normal distribution of the data. The Wilcoxon-test for paired samples was used to test within group effects, between groups differences were tested with the MannWhitney $U$ test for unrelated samples. Significance-levels were set at $p<0.015$.

\section{RESULTS}

Eight of the 16 PD-MDD $\left(50^{\circ} \%\right.$ ) and 7 out of 9 PD+MDD paticnts $(78 \%$ had a provoked panic attack (Chi-square $1.82 ; \mathrm{NS}$ ). After the $\mathrm{CO}_{2}$ inhalation, differences were observed between the PD patient groups with and without depression on all assessments (Table 1 ). 
The post-CO2 scores on the VAS-Anxiety $(p=0.05)$, VAS-Aggression $(p=0.05)$ and VAS-Depression $(p=0.01)$, and on the POMS-Aggression $(p=0.01)$ and POMS-Depression $(p=0.02)$ were significantly higher for the PD+MDD group compared to PD without depression. Regarding the (specific) panic symptoms, as assessed by the PSL, the scores were higher for the depressed subgroup, though not statistically significant.

Both subgroups showed a significant increase for the anxiety symptoms assessed by PSL and VAS-A. PD-MDD patients failed to show an increase on aggression parameters, or on the VAS-Depression. The POMS Depression however did increase after the challenge. The PD + MDD group did show an increase on anxiety measures and significant increases on both depression measures and the POMS aggression, but the increase was not statistically significant for the VAS-Aggression ( $p=0.068$ ) (Table 1 ).

The increase on both aggression scales (VAS-Aggression and POMSAggression) and depression scales (VAS-Depression and POMS-Depression) was significantly higher in the PD + MDD patients compared to the PD-MDD group. Table 2 shows the effect of the $\mathrm{CO}_{2}$ challenge compared for both groups (delta scores: post- $\mathrm{CO}_{2}$ minus pre- $\mathrm{CO}_{2}$ ). The increases on the PSL and VAS-Anxiety were higher for the PD+MDD patient group, but failed to reach statistical significance (Mean \pm SD for depressed on delta PSL $18.2 \pm$ 11.1 versus $9.9 \pm 6.6$ for nondepressed PD patients, and $53.1 \pm 31.0$ on dela VAS-Anxiety for depressed versus $28.7 \pm 23.1$ for nondepressed). Figures 1 and 2 illustrate the differential increase after the $\mathrm{CO}_{2}$ challenge for PD-MDD and $P D+M D D$ patients. 


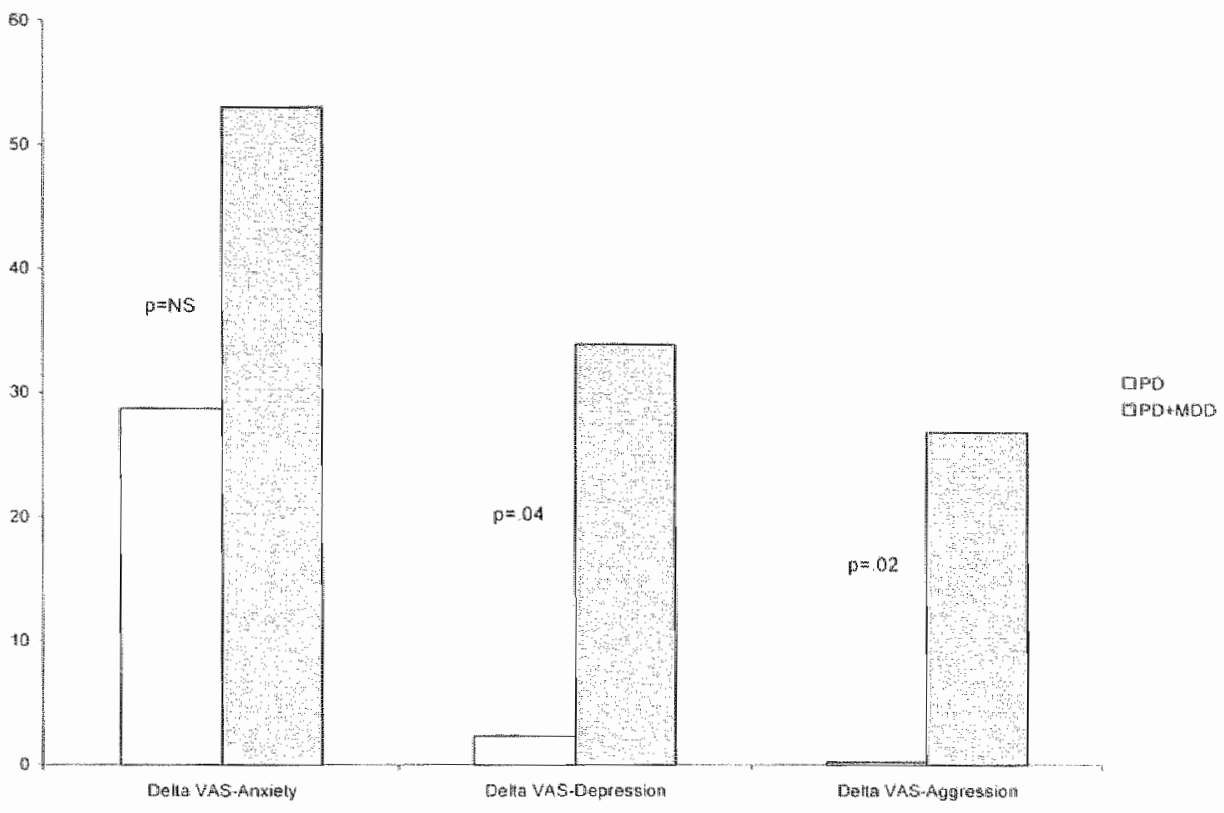

Figure 1. Increase in VAS Amxiety, Depression and Aggression for PD and PD+MDD paticnts afret $\mathrm{CO}_{2}$ challenge

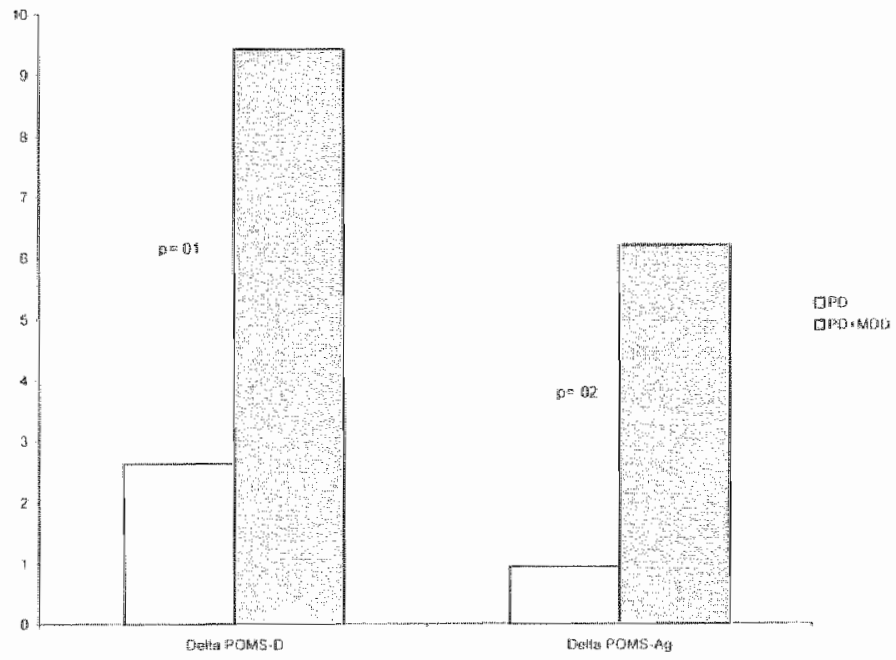

Figure 2. Increase in POMS Aggression and POMS Depression for PD and PD+MDD pationts after $\mathrm{CO}$, challenge 


\section{Discussion}

Inhalation of $35 \% \mathrm{CO}_{3}$ is capable of inducing a broad spectrum of affective symptoms. In this study the effects ranged from anxiety to aggressive and depressive symptoms, and were most pronounced in the PD+MDD group. The $35 \% \mathrm{CO}_{2}$ challenge appeared to induce more affects (anxiery and aggression and depression versus anxicty only) and also induces stronger affects in the depressed PD subgroup.

On the dimensions anxiety, aggression and depression separately, liferime depressed PD patients were more affected than PD patients that never met criteria for depression. Thus, lifetime depressed PD patients (cven in the absence of current depression) can be considered more vulnerable to a $\mathrm{CO}_{2}$ challenge than their nondepressed counterparts.

This is the first study that assessed other symproms than anxiety after $\mathrm{CO}_{2}$ challenge in PD patients. Some studies used the challenge paradigm to assess PD patients with and without comorbid depressive disorder. However, they all are restricted to anxicty symptoms for outcome measures. Concerning the dimension of anxiety, Verburg et al. (1998) reported a bigger $\mathrm{CO}_{2}$ challenge effect on anxiety symptoms in a depressive subgroup of PD patients compared with nondepressed PD patients. The present study confirmed this finding; it showed a higher increase on the anxicty mensures for the PD+ MDD group. In addition, we found a difference on the other affective dimensions of depression and aggression. Our results are in line with the observation that comorbidly depressed PD patients are more severely affected by the $\mathrm{CO}_{2}$ challenge than the nondepressed PD patients.

In another related study (Targum, 1990) four groups were compared. PD patients without MDD, MDD with a history of PD, MDD without panic, and healthy controls were compared. The study uses a challenge with lactate and one with the serotonergic agent fenfluramine. Lactate has been shown to be panicogenic; fenflutamine has shown to be anxiogenic in PD patients. This study reported that with lactate, the PD patient group, as well as the $M D D+P D$, revealed a greater anxiogenic response than the MDD patients without panic attacks of healthy controls. With fenflutamine, patients with PD showed a more robust anxiogenic response than the MDD with PD historygroup, suggesting a 'protective' effect of the MDD. Their conclusion is towards a distinct neurobiological diathesis in the group of patients who are predisposed to panic attacks, which persist in times of remission. However, the MDD with PD history group is not completely comparable to our PD with depression group because the index disorder differs. Also, our results with $\mathrm{CO}_{3}$, point in another direction: with $\mathrm{PD}$ as the index disorder, a comorbid depression predisposes ro an even stronger vulnerability to the panicogenic challenge, whereas Targum found some protection of comorbid MDD + PD for 
the fenfluramine condirion. Certainly we must be very cautious in comparing findings from different provocation methods.

The role of depressive disorder in this respect is not clear. It has been shown before that ventilation in. MDD patients even decreases after a $\mathrm{CO}_{2}$ challenge (Shershow et al., 1976; Damas-Mora et al., 1978), whereas in PD patients there is an increased ventilatory response (Gorman et al., 2001). This physiological reaccion is paralleled by a lower increase in heart rate following a hyperventilation challenge in MDD patients compared with PD and MDD with panic attacks (Nardi et al, 2001). This mild physiological reaction is also reflected in the lack of psychological distress to this hyperventilation challenge, for it did not result in an increase of subjective units of discomfort sensarions (SUDS, comparable to our VAS assessment) in MDD patients. Also Perna ef al. (1995) have shown that patients with a depressive disorder (without panic atacks or $\mathrm{PD}$ ) are not vulnerable to this provocarion method by means of a $\mathrm{CO}_{2}$ challenge, but react as normal healthy controls to a $\mathrm{CO}_{2}$ challenge, when measuring panic and anxiety symptoms. Unfortunately, we have no data on the other affective dimensions of aggression and depression. Neither Perna er al. (1995), nor Verburg et al. (1998) did assess these affects.

From the above data, we could infer that the MDD parients react to a panicogenic challenge in one way, PD patients in another, and in patients where both disorders are present we see yet a distinct reaction. Where both disorders are present, MDD does not protect against the challenge, but the PD seems to determine the response. All this goes against the presence of a common underlying susceptibility.

The present study showed that the $35 \% \mathrm{CO}_{2}$ challenge affects more those PD patients who have ever suffered from a depression, suggesting that one needs to have experienced these affects in real life to be able to re-experience them in the laboratory, or conversely, the challenge may point to a vulnerability which is present. This common vulnerability may be triggered 'by spread' and affect aggressive and depressive feelings in addition to anxiety, but only secms to occur in rulnctable individuals.

Serotonergic dysfunction has been associated with psychopathological dimensions of anxiety, depressed mood, impulsivity, sucide and violence (Apter et al., 1990). Disturbances of aggression regulation are a frequent component of mood disorders, anger attacks have been observed in $30 \%-40 \%$ of depressive disorder (Tava, 1998; Fava et al., 1993; Rosenbaum et al., 1993). Anger attacks also have been proposed as a vatiant of panic attacks (Korn et al., 1997; Fava et al, 1998; George et al., 1989). Van Prag $(1998,2001)$ has proposed, and substantiated with psychopathological and biological data, a subgroup of depressive syndtomes, that are especially linked to a dysfunctional serotonetgic system and whose primary symptoms can be found in the anxicty and aggression cluster, with subsequent depression. These so called 5-HT- 
related, anxiety/aggression-driven depressions are supposedly precipitated by stressors in individuals who are susceptible to the psychologically distupting effects of psychotraumatic events. Our experimental findings very nicely fit in this hypothesis of a specific subgroup of patients who are vulnerable to panic anxiety and depression, as well as experimentally provoked to feelings of aggression (van Praag, 1998, 2001). This holds especially true since van Praag also describes the observation that the 5-HT disturbances persist in times of remission. Our subgroup of lifetime depressive subjects showed $\mathrm{CO}_{2}$ vulnerability (concerning anxiety, aggression and depression symptoms) in currently non-depressive states, similar like currently depressives did. Studies within the experimental paradigm of tryptophan-depletion (TD) have shown that this method also can evoke symptoms of depressive disorder in subjects who are remitted from MDD (van der Does, 2001). In PD patients the effects of TD alone ate not especially panicogenic (van der Does, 2001), but tryptophan depletion may interplay with the $35 \% \mathrm{CO}_{2}$ challenge, in that $\mathrm{TD}$ augments the reaction to a $\mathrm{CO}_{2}$ challenge (Griez and Schruers, 1998; Schruers et al., 2000).

With respect to these observations the neurotransmitter system of 5-HT seems to play a major role. On the other hand, these mechanisms always involve several systems and interrelations, interactions and relative balances. As in depression, where noradrenergic as well as serotonergic influences are known, this probably is the case for anxiety disorders as well, but also for the individual psychopathological dimensions like aggression. (Kahn et al., 1988).

Also, separate from the neurobiological perspective, from a more general and historical perspective, anxiety, depression and aggression have all been linked for a long time by psychopathology and epidemiology. Historically, the frequent co-occurrence of anxiety and other affective symptoms and syndromes has led to many philosophical reflections (Himmelhoch et al., 2001). One could say that phenomenology and psychiatric nosology don't always match that well.

From these perspectives, it is not at all so surprising that these related symptoms could be provoked by a challenge test. On the other hand these tests, especially the $\mathrm{CO}_{2}$ challenge, have been shown to be syndrome-specific i.e. for PD. If then, in a subgroup of comorbid patients, this supposedly specific provocation method gives rise to less specific symptoms like aggression and depression, must we again question the validity of our current psychiatric nosology.

This study just unveils for the first time that a panic challenge may be depressogenic and aggressogenic as well. Some limitations of the present study must be mentioned. The lack of a control group of depressed patients without PD makes it uncertain if a $\mathrm{CO}_{2}$ challenge can induce aggressive and/or depressive feelings in this specific subgtoup. Also, a control group of healthy 
subjects should be included to control for affective symptoms that could be raised by a $\mathrm{CO}_{2}$ challenge. It is known that the $\mathrm{CO}_{2}$ challenge does not induce anxiety symptoms in depressive patients, but it is unknown if the same applies to the other affective symptoms of aggression and depression.

Another limitation of this study is the small sample of comorbidly depressed PD patients. A latger group would have enabled to analyze possible differential effects of the $\mathrm{CO}_{2}$ challenge in the subgroups. It would be interesting to look at the effect of a lifetime clepressive episode (in PD patients) as a trait marker that can induce a lasting vulnetability to the experimental provocation of depressive and aggressive symptoms by means of a $\mathrm{CO}_{2}$ challenge. Future studies using the $\mathrm{CO}_{2}$ challenge paradigm should include these broader assessments of affective spectrum symptoms in addition to anxicty. A future study should assess the effect of a $\mathrm{CO}_{2}$ challenge in pure MDD patients (present and lifetime in separate groups) on the dimensions of aggression and depression. Another study should move to a closer investigation of broader affective symptoms after a panic challenge in pure PD patients, in compatison to comorbid PD patients. 

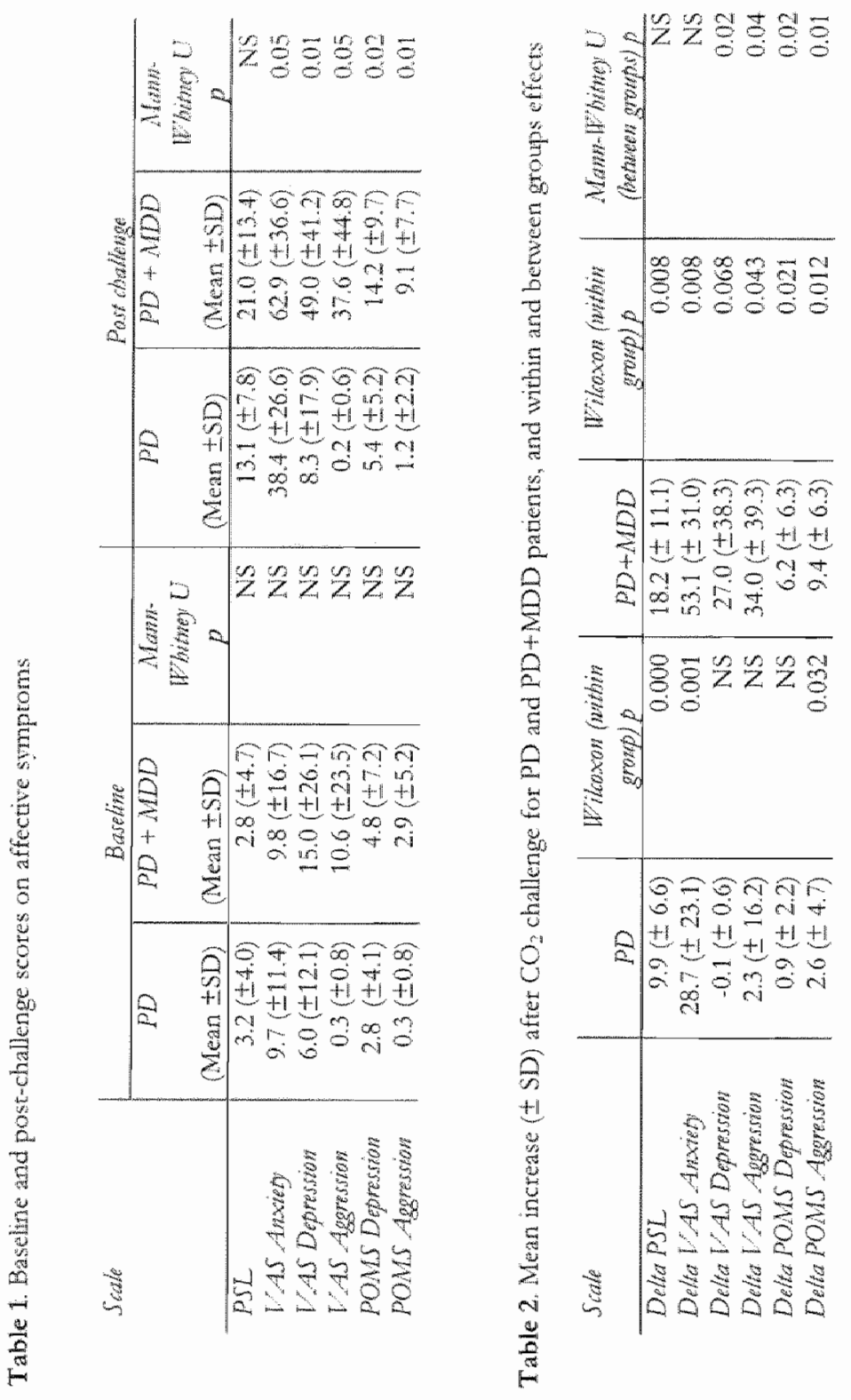


\section{REFERENCES}

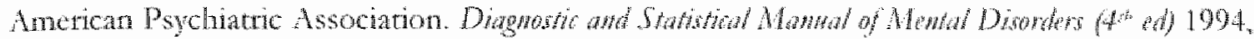
Washington DC, American Psychiatric Press

Aprer $A$, van Prag HM, Plurchik R, Sevy S, Korn M and Brown Sl.. Intertelationships among anxiety, aggression, impulsivity, and mood: a serotonergically linked cluster prydiary Res 1990:32,191-199

Damas-Mora J, Jenner $\mathrm{F}$, Sneddon I and Addis WD. Ventiatory responses to carbon dioxide in syndromes of depression. J Pydroson Res 1978:22,473-476

Di. Nardo PA and Barkow DH. Syndrome and sympom co-occurtence in the anxicy disorders

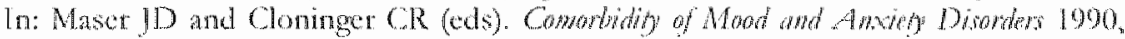
Washingron DC, Anerican Psychatatc Press. 205-230

Fava $M$, Anderson $\mathrm{K}$ and Rosenbaun Jl. "Anger atcacks": possible variats of panic and mago depressive disorders. Am J P.gdhaty 1900: 147, $867-870$

Fava M, Rosenbaum JF, Pava JA, MoCarthy MK, Stoingard RJ and Bowfides $\mathbb{E}$. Anget atnchs in unipolar depression, Part 1: Clinical cotrelates and wespense to thoxerine treatment. Ans 7 Pydiatry 1993: 150,1158-1163

Eava M. Dopression with anger artacks. f Clin Podnaty 1998: 59 Suppl 18, $18-22$

George DT, Anderson P. Nut DI and Limoila M. Aggressive thouglets and betaviot: another symptom of paric disonder? Ada Psydiat Sath 1989:79,500-502

Goman IM, Kent J, Martinez J, Browne S, Coplan J and Papp LA. Physiological changes dung cabon dioxide inhalation in patienes with panic disordet, major depression, and premenstrual dysphoric disorder: exidence for a cental fear mechanism. Awh Go Psyikian' 2001: 58, 125-131

Gorman JM, Papp LA, Martinez J, Goetz RR, Follander E, Liebowitz MR and Jordan L. Highdose carbon dioxide challenge test in anxicty disorder pationts. Brol Psodnatry 1990:28, $743 \cdots 757$

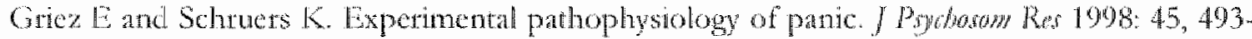
503

Gricz G, Lousbetg H, van den Hout $M A$ and an der Molen GM. COz vulnerability in panic disorder. Pyedisto Rer 1987:20,87.95

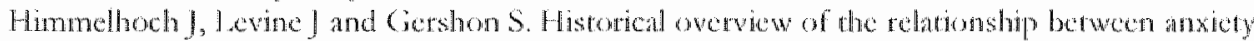
disorders and affecrive disorders. Depres Amogy 2001: 14,53-66

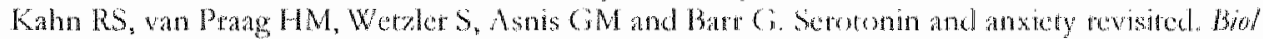
Prydiatry 1988:23, 189-208

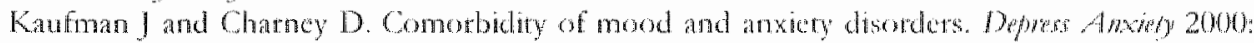
12 Stppl 1,69-76

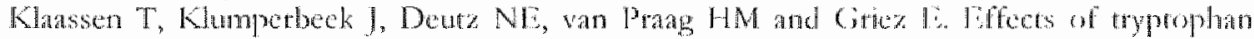

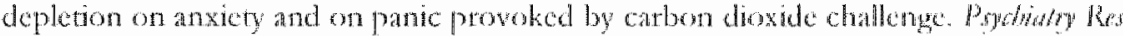
1998: $77,167 \ldots 174$

Korn ML, Petchik R and van Prag HM. Panic associated sucidal and aggressive ideation and behavior / Powhat Res 1907: 31, 481-487

l.cvine J, Cok DP, Chengappa KN and Gershon S. Anxiety disorders and major deptession, together or apart. Depres Anteg 2001: 14,94-104

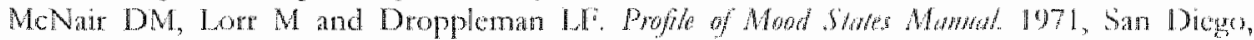
Educational \& Industrial Testing Service

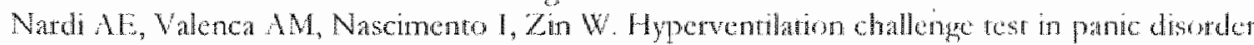
and depression with panic attacks. Pswiatry Row 2001: 105, 57-65 
Perna $G$, Barbini 18 , Cochi $S$, Bertani $A$ and Gasperini $M .35 \% \mathrm{CO}_{2}$ challenge in paric and mood disonders. I Alfec Dinot 1995: 33, 189-194

Perna 6 , Gabrick $A$. Caldirola $D$ and Bellodi L. Hypersensitivity to inhalation of carbon dioxide and panic atracks. Psybargs Res 1995:57,267-273

Roscobaum JW, Fava M, Pava JA, McCarthy MK, Steingard IR] and Bouffedes E Anger attacks in unipolar depression, Part 2: Neuroendocrine correlates and changes following fluoxetine tratment. An / Psthoty 1993: 150, 11641168

Schruers K, Klassen T, Pols H, Overbeck T, Deut N and Griez E. Effects of tryptophandepletion on carbon dioxide provoled partic in panic disorder pacients. Pyohiaty Ros $2000: 93,179-187$

Shechan DV, I cerubier Y, Sheehan KH, Amorim P, Janavs J, Weiller E, Herguea T, Baker R and Dunbar GC. The Mini-International Neutopsychatric Interview (M.M.L.) the development and validation of a structured diagnostic psychatric interview for DSMIV and $1 \mathrm{CD}-10$ / Clm Pshialy 1998:59 Supp 20, 22-33

Shershow JC, Kanatek DJ and Kazemi $H$. Ventilatory response to carbon dowide inhalation in depression. Prychosm Med 1.976:38,282-287

Taggun SD. Differential responses to anxiogenic challenge studies in patients with maton depressive disorder and panic disonder. Biol Pyldiaty 1990: 28, 21-34

Tetry PC, Lanc AM and Koohene L. Development and validation of a mood measure for

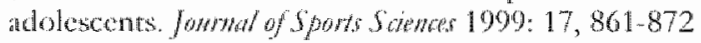

Van dur Does $A$. The effects of tryprophan depletion on mood and psychatric symptoms. I Affor Diond 2001:64, 107-119

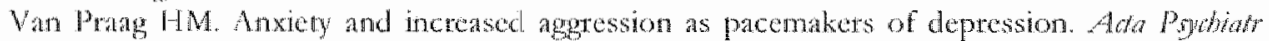
Scand 1928: Suppl 393,81-88

Van Pratg HM. Anacty/aggression-driven depression. A paradigm of functionalization and

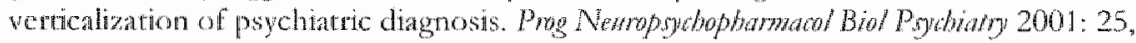
$893-924$

Verburg K, Grice I: Meijer I and Pols H. Discrimination between panic disorder and generalized anxicy disorder by $35 \%$ carbon dioxide challenge. Am J Pshowa 1995: $152,1081-1083$

Verburg K, Klansen T, Pols $\mathrm{H}$ and Gricz E. Comorbid depressive disorder inoreases vulnerability to the $35^{\%}$ carbon dioxide ( $\mathrm{CO}_{2}$ ) challenge in panic disorder patients. Affed Dirond 1098: 49, 195-201

Verburg K, Pols 1 , de leeww $M$ and Griez R. Reliability of the $35 \%$ catbon dioxide panic provocation challonge. Podioty Rer 1998: 78, 207-214 
Section W. The interfoce:

Another approach 



\section{THE INTERFACE BETWEEN DEPRESSION AND ANXIETY: COMORBIDITY AND CONCEPTS}

T. Overbeek and E. Griez

To appear in: Griez EJL, Faravelli C, Nutr D and Zohar J (Iids). Mood Disorders: An Introduction to Clinial Managenent and Rerearito. Wiley \& Sons, Chichester. In press 



\section{MTTRODOCTTON}

The debate on comorbidity between anxiety and depression leans heavily on current nosography. The vast majority, if not all studies describe the cooccurrence of different disorders along the lines of the two main classificatory systems, the successive versions of the Diagnostic and Statistical Manual of Mental Disorders (DSM, American Psychiatric Association), and the International Classification of Diseases and Related Health Problems (ICD, World Health Organization).

As they are defined in the DSM and ICD, depressive and anxiety disorders obviously share a number of clinical features, as well as, most probably, the explanatory pathways to these featutes. However, for all the accumulated knowledge on the epidemiology and neurobiology of affective disorders, the issue of splitting or lumping together remains largely unresolved. The cooccurrence of anxiety and depressive disorders has led to hypotheses about a common etiology, and several models have been suggested to explain associations between anxiety and depression (Frances et al., 1992). Roughly summarized, these models represent either a unitarian view (lumping the disorders together into one "affective" spectrum) or a separist view (spliting the spectrum), with various variants in between (Nemeroff, 2002). Another possibility that deserves attention is the 'artifactual' argument, that presupposes that the problem of comorbidity is inherent to our imperfect current classification systems, which are based on tather atbitrarily defined criteria and thresholds, using strange combinations of various symptoms and featuring a considerable amount of definitional overlap. In consideration hereof, it may be improper to speak of 'comorbidity' in its true sense, the diagnostic framework itself having a deficient validity. Obviously, the way we conceive of psychiatric illnesses, and the constructs we use to describe and classify them, determine the way we explain associations between them. Some of these problems and the nosological challenge they create, are elaborated upon by van Praag (in press).

The present chaptet represents a different approach to the relationship between depressive and anxiety disorders. It departs from the taditional appraisal of comorbidity in the current psychiatric literature and largely leaves aside the debate whether DSM/ICD diagnoses are valid or not. A bricf look at the assessment methods, and a review of the disparate results they yiclded so far in the study of co-existing depression and anxiety has lead us to reflect on the concepts themselves, and the logical relationships that may follow from their meaning. Accordingly, we first discuss a range of clinical scales televant to our subject: they illustrate the various ways how depression and anxicty have 
been conceived of before the introduction of current classifications. To our concern, in general, the use of standardized depression and anxiety scales has been limited to assess progress in treatment studies. Despite their potential usefulness in collecting information on features of emotions like anxiety/fear. and depression/sadness, they remain underexploited to assess these effects. To our knowledge, no major comorbidity study has yet been conducted that used classical depression and anxiety scales as a main assessment tool. Thus, while emphasizing the potential interest of assessing depression and anxiety at a very symptomatic level, we are left with comorbidity data from traditional epidemiology. As a result of this, the next part of this chapter can do no better that to summarize a number of major epidemiological surveys, the DSM/ICD framework taken for granted. After all, for purposes of communication, we need a descriptive instrument to provide an overview of the evidence. The last part goes beyond empirical data and offers a reflection on the interface between anxiety and depression from a different perspective, by conducting a concise inquiry into the basic concepts of emotions, sadness and anxiety in particular.

\section{CINICAL CONCEPTS OF DEPRESSION AND ANXIETY}

The way we assess and classify a conclition reflects the way we conceive of it.

Many quantitative instruments have been developed to assess depression and anxiety, and they cover a broad range of symptoms. It has been assumed that they do not represent diagnostic instruments, but add a quantifiable description of illness severity and profile of symptoms to an existing diagnosis. Because scales themselves can not do anything but assessing -severity of- symptoms, they can be considered as a more sensitive tool to evaluate the details of a clinical condition than the diagnostic interviews, which are aimed by definition at solving a dichotomy (dingnosis wersus no diagnosis) on basis of some -rather arbitrarily-predefined criteria. Despite the claim that classification systems are a-theorctical, they can not, simply because behind each description some form of a-priori framework is present. Paying attention to rating scales represents a plea for a teturn to the basics of descriptive psychopathology. Such a coming back could make sense in further studies on the meaning of basic concepts as depression and anxiety. It is unfortunate that clinical scales have hardly been used in large population surveys. Although they serve no classificatory purpose, their analysis might add worthwhile infonmation on the relative weight of individual symproms in different conditions of depression and anxiety, their cooccurrence and the total profile of symptoms in distinct disorders.

It is not our intention to enter a detailed methodological discussion on rating scales, neither to discuss nor comment on all individual scales. Suffice it to 
mention some representatives of the depression and anxiery scales, and discuss some general aspects relevant to the subject.

\section{The assessment of deptession}

Amongst the most widely used instruments to asses depressive states at a symptomatic level are the Hamilton Rating Salk for Depression (HRSD, also abbreviated as HAM-D, Hamilton, 1960, 1967); the Beck Depresion Inwentory (BDI, Beck et al., 1961); the Montgomery-Asbery Dpprosson Rang Sale (MADRS, Montgomery and Asberg, 1979) and the Zung Selfrating Depression Siale (SDS, Zung, 1965). With many other scales, they differ in various aspects as number of items, nature of items covered, and time needed for completion. Of course, thete are also differences between them in validity, reliability and sensirivity. Scales are usually divided in wo main categoties, the self-rating ('subjective) scales and the clinician-rated ('objective) scales, each category having its own advantages and disadvantages. Faravelli et al. (1986) compared a number of depression rating scales, and showed that one difference between self rating and observer rated scales was that the self rating scales showed more rightward asymmetry (higher severity) and observer rated depression scales tended towards a leftward asymmetry (lesser severity). Moreover, the internal structure of the depression scales, as tested by means of factor analysis, showed considerable differences. Also, the reciprocal correlations between the rating scales are reasonably homogenous, but not particularly high. In the various scales only a subset of items is dedicated to the core symptoms of depression, the other items being apparently dedicated to a variety of accessory symptoms concerning somatic issues, anxiety, or sleep.

In a more recent study Faravelli et al. (1996) analyzed the metits of clinical scales in measuring the severity of depression. They showed that it is not so much the number of symptoms that determines the severity, but rather the presence of cetain symptoms, especially those in the melancholic cluster. Different symptoms had different weights in establishing the gradient of severity. In passing, we note that Faravelli and coworkers' observations may bc of relevance to our subject. If severity of depression is reflected more in the presence of some core (especially melancholic) symptoms, than in the number of symptoms present, we might infer that at some point there is a change in the guality of the affective state when severity increases. However, which symptoms exactly are concerned, and at which degree of severity is difficult to determine. Scales greatly differ in the number of items devoted to particulat core symptoms. Future studies addressing this issue should therefore take into account that information should only be inferred from the apptaisal of individual items on these scales. The issue remains largely underexplored. Another problem worth noting is that, particularly for a descriptive purpose, the total score on a scale does not give any indication as to what specific kind 
of items or clusters of items are important for an individual case. It should be kept in mind that when a broad range of symptoms is covered by a scale (Snaith, 1993), many patterns of response may lead to the same scote.

\section{The assessment of anxiety}

Anxiety scales share the same pitfalls as depression scales, as emphasized in Keedwell and Snath's review (1996). Even more than is the case with depression, the construct of "anxiety' is far from unitary, with its repercussion on the validity of the concept as designating a single or complex affective state. Also, the term anxiety covers a different range of phenomena that is bound to language and culture. Constructs as depression and anxiety, refer to states that may fluctuate over time, displaying broad variations in severity from day to day, even within hours.

The Hamilon Amxity Sicale (HAS, also abbreviated as HAM-A, Hamilton, 1959); the Siate-Trait Anxieg Scale (STAI, Spielberger et al., 1977); and the Clinical Amxiety Sate (CAS, Snaith et al., 1982) are some of the frequently used scales that measure non-specific anxiety.

Large differences have been shown in the emphasis on the various symptomcategories that items can be divided in, like features of anxious mood, anxious cognition, anxiety-bound behavior (avoidance), overarousal, somatic signs, and others (Himmelhoch et al., 2001).

It is worth noting that there are many more scales for anxiety than for depression. Traditional psychiatric nosography clearly distinguishes different types of anxiety disorders. Accordingly, besides 'general' scales covering anxiety as one single concept, other scales are specifically directed at the assessment of particular types of anxiety such as panic/agoraphobia (e.g. the Panic and Agoraphobia Scale, PAS, Bandelow, 1995), social anxiety (1.iebowitz' social anxiety scale, 1987) and obsessive compulsive anxiety (e.g. Maudsley Obsessional Compulsive Inventory, MOCI, Hodgson and Rachman, 1977). This again underscores the complex reality that underlies the term of anxiery.

\section{Differentating depresion and anxicty}

Special mention should be made of the Hospital Anxiety and Depression Sale (Zigmond and Snath 1983, HADS). This instrument has been constructed for use in general (somatic) hospital settings. The authors took special care to diminish the interference of physical symptoms, which was an important abjection against the HRSD. Additionally, they tried to disentangle the constructs of depression and anxiety. Another focus was upon anhedonia, which was considered to be the most reliable clinical marker of likely response to antidepressant drugs. The HADS has been widely used in clinical settings in various countries, is quite easy to complete (containing 14 items) and well 
accepted by patients. It has been shown to have acceptable validity and reliability (Hermann, 1997).

It is remarkable that most scales, that are meant to assess either depressive or anxiety states, contain items obviously related to symptoms of both anxiety and depression. As a consequence, it is risky to differentiate states of anxiery and depression by comparing total scores, even though the scales are supposed to be specific. Bramley et al. (1988) correlated several self rating scales for either depression or anxiety with two criterion observer rated scales (the CAS for anxiety and the MADRS-Modified this is the MADRS without the items on inner tension and reduced sleep- for depression). Their results showed that self rating scales for depression could discriminate between depressive and anxiery states, but anxiety scales did not. This conclusion also applied to the criterion scales of anxiety (CAS) ancl depression (MADRS-Modified). An earlier comparative study by Snaith and Taylor (1985) had reached the same conclusion.

A provisory comment on the issue of clinical rating scales is that caution should be exercised when using them in differentiating depression from anxiety on basis of the global quantification they yield as an end score. On the other hand, scales offer an interesting approach of clinical psychoparhology, which, if used in coniunction with current classification systems, may add useful information at a descriptive level and challenge some taken-for-granted aspects of our present views.

\section{Classifucation of depression and anxiety}

The history of anxiety and depression throughout the development of the DSM and ICD systems is complicated. For an extensive historical overvicw of the relationship between anxiety disorders and mood disorders we tefer to Himmelhoch et al., (2001), and Glas (2003). In DSM I and II ( 1952; 1968) clear distinctions between anxiety and depression were not yet made (Levine et al., 2001). The disorders were more drawn apart from DSM-1II (1980) onwards, especially where DSM-III was designed to be an a-theoretical, symptom-oriented classification. It stated explicit criteria for inclusion and exclusion, and set thresholds for the various disorders. Diagnosing any anxiety disorder in the presence of a comorbid mood disorder was not allowed, major depression always took precedence. This position is actually very interesting from the conceptual point of view, as it attributes a more central role to the emotion of depression than anxicty. We will revisit this point in the final section of our chapter. Many authors challenged the validity of the hicrarchical and exclusionary relationship between anxiety and mood disorders, and in the later DSM-III-R (1987) and DSM-IV (1994) this restriction on axis I was lifted, 
tolcrating diagnosing separate co-existing disorders on axis I. From then on, many epidemiological studies showed the frequent comorbidity of separately predefined disorders. The clinical reality that did not tally with the categorical views on mental pathology was again 'explained' (van Praag, 1996).

Clinical interviews have been developed within the framework of these systems, to reach diagnoses on basis of predefined criteria. Frequently used standardized instruments are for example the Strutumed Camical Intervien for DSM-disorders (SCID; Spitzer et al, 1992); the Diagnostic Intertiew Schedule (DIS; Robins et al., 1981); the Composite Intemational Diagnostic Interniew (CIDI; Robins

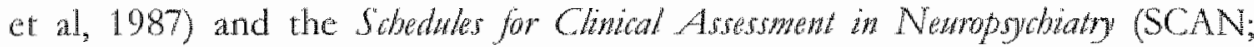
Wing et al., 1990). The Mini International Newopsydiatric Interview (MMN, Sheehan et al., 1998) is a more recently developed tool for both DSM and. ICD diagnoses, and is relatively casy to administer as it takes about 15 minutes to complete. The MINI is increasingly accepted and used for the assessment of psychiatric disorders or screening purposes in epidemiological studies. All have been described in derail elsewhere (Burke et al., 1990; Arbabzadeh-Bouchez and Lepine, 2003). These (semi-) structured interviews often are used in addition to an unstructured interview, to assure that a broad spectrum of disorders has been covered.

The above instruments do not only vary in diagnostic coverage and classification framework they depart from, also the timeframe considered differs.

This summary illustrates the arbitrary way we currently conceive of deptession and anxiety, using the tools at our disposal, whether they are rating scales or sophisticated standardized interviews. The collection of the empirical data that appear below is inevitably endowed with the deficient validity of the existent frameworks. Therefore they should be interpreted with caution, and with the approptiate amount of critical judgment they ate calling for.

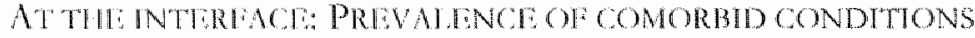

Prevalence figures of comorbidity vary, partly due to a lack of clear conceptualization and definition of the term comorbidity (Wittchen, 1996). Nlso methodological differences regarding assessment instruments, time frame covered (lifetime or concurrent, past month, 6 or 12 months), case definition (diagnostic criteria or sub threshold conditions included), use of expert or layinterviewers contribute to uncertainty and confusion (Wittchen et al., 2001). Different types of anxiety disorder show different comorbidity figures with depression, and different types of mood disorders show different comorbidity figures with the separate anxiety disorders. Comorbidiry-prevalence rates from 
population based, primary care or clinical samples also differ according ro the serting that the figures are derived from.

\section{Population sumeys}

The two largest, and most frequently cited epidemiological surveys stem from the USA. The Epidemiologic Catchment Area (ECA) study was performed among 20,291 subjects from 5 sites within the US, aged 18 years and up (Regier et al, 1990). The ECA used the DIS for DSM-III diagnoses, and worked with lay interviewers. The National Comorbidity Survey (NCS) was dexeloped as the continuation of the ECA and especially addressed the comorbidity of psychiatric disorders. This survey comprised 8,098 subjects from age 15 ro 54 years (Kessler et al., 1994). The NCS used an adapted version of the CIDI for screening, and lay interviewers. It also used a more intensive memory enhancement strategy, and found a considerably higher rate of lifetime disorders. The NCS unfortunately did not include diagnosis of OCD. A rough. overview of estimated comorbidity figures is given in table 1 .

Table 1. Estrmates of litetine comorbidity between anxiety disorders and MDD. After Kautman and Chatney (2000) and Levine et al. (2001).

\begin{tabular}{|c|c|c|}
\hline Diagnonis & 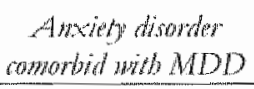 & $\begin{array}{c}\text { MDD womonhd wath } \\
\text { ancery drorder }\end{array}$ \\
\hline Panic Disorder & $40.60 \%$ & $10-30 \%$ \\
\hline Social Phobia & $2035 \%$ & $30 \%$ \\
\hline Generalized Anxiery Disondet & $60 \%$ & $20 \%$ \\
\hline Post Traumatic Seress Disotdey & $30-40 \%$ & $20 \%$ \\
\hline $\begin{array}{c}\text { Obsessive Compulsive } \\
\text { Disonder }\end{array}$ & $30-60 \%$ & \\
\hline Any Anxicty Disode: & $40 \%$ & $60 \%$ \\
\hline
\end{tabular}

Data from the ECA study on anxiety disotders and comotbidity with mood (and addictive) disorders are reported by Regier ot al. (1998). Lifecime prevalence of (any) anxiety disorder was $14.6 \%$ and prevalence of mood disorders was $8.3 \%$ of respondents. A comorbid anxiety disorder was present in $47.2 \%$ of people with lifetime depression.

NCS data were reported by Kessler et al. $(1994,1996)$, and revealed on the individual diagnostic categories that $24.9 \%$ of respondents had one or more anxiety disorder lifetime, a lifetime (any) mood disorder was prevalent in $19.3 \%$, and major depression (MDD) in $14.9 \%$ of the population. One year prevalence rate for anxiety disorder was $17 \%$ and for deptession $10 \%$. Comorbidity figures from the NCS teport that $51.2 \%$ of subjects with MDD had an anxiety disorder in the same 12 -month period. Of the subjects with lifetime depression, $58 \%$ had any anxiety disorder lifetime, $74 \%$ had at least one comorbid 'any' psychiarric disorder. The prevalence of MDD frgures from 
the ECA are lower than the NCS figures, according to Kessler this is due to sampling and ascertainment problems in ECA that led to underestimation of prevalence. Whereas mostly anxicty disorders are shown to be the primary disorder and the MDD secondary, it is an important result from the analysis of the NCS data that this specific association also gives rise to a more persistent course of the depression, and more interference with activities of daily life, suicide and hospitalization for depression (Kessler et al., 1996).

An overview by Kaufman and Charncy (2000) demonstrated that about $30-$ $40 \%$ of anxiety disorder patients (OCD not included) thad a comorbid MDD, with different figures for the individual disorders. Panic Disorder and Generalized Anxiety Disorder have a comorbidity rate of about $65 \%$, PostTraumatic Stress Disorder 40\%, and Social Phobia about 20\%. With MDD as the index disorder, a mean comorbidity rate with anxiety disorders is $20 \%$, the highest figure for the Social Phobia 27\%, the lowest for Panic Disorder $10 \%$. Most frequently the anxiety disorder (social phobia, GAD and PTSD) precedes the MDD; PD equally frequent precedes, follows, or starts simultaneously with the MDD episode.

Levine et al. (2001) summarized that the whole group of anxiety disorders (including OCD) show comorbid lifetime major depression in about $40 \%$. The individual anxicty disorders show some variation around this figure. GAD is in about $60 \%$ of cases seen with comorbid lifetime depression, PD in 40 to $50 \%$, $30 \%$ of the OCD patients has a lifetime comorbid major depression, PTSD patients ate in $30-40 \%$ of cases seen with depression, and $35 \%$ of Social Phobia also suffer from a major lifetime depression.

Starting from the other side, of the patients with major depression, on a lifetime basis about $60 \%$ suffer from any additional anxiety disorder. Twenty $\%$ of these have a GAD, $30 \% \mathrm{PD}, 30 \%$ social phobia.

for $\mathrm{GAD}$ extraordinary high comorbidity figures have been reported (Wittchen et al., 1994). Up to $90 \%$ of GAD patients have a lifetime comorbid psychiatric disorder, mainly mood disorders like MDD $60 \%$ and dysthymia $40 \%$

Another revicw by Merikangas et al. (1996), computed data from a set of cpidemiologic population based surveys, and concluded that there was a strong and consistent association between the mood disorders and anxiety disorders (and substance abuse); magnitude of comorbidity between mood disorders and anxiety disorders was greater than comorbidity between the affective disorders and substance abuse.

Epidemiological data on a newly DSM-TV proposed diagnosis of Mixed Anxiety Depression (MAD), a syndrome combining features of both anxiety and depression (sub threshold conditions) where neither would qualify as a predominant, stand-alone diagnosis (Zinbarg et al., 1994; Rapaport, 2001; 
Barlow and Campbel], 2000), interestingly showed an unexpectedly low prevalence rate of about 1\% (Wittchen et al., 2001).

\section{Primary care studies}

A large-scale study by the World Health Organization has investigated the prevalence of mental disorders in primary health care, a total of 25916 subjects were screened across 15 different countries (Sartorius et al., 1996; Wittchen et al., 1999; Lecrubier and Uston, 1998). In the second-stage assessment of 5438 subjects the CIDI was applied. From this study it was shown that $62 \%$ of all depressive cases also suffer from another mental health problem, most commonly anxiety disorders. Of the patients with anxiety disorders, $45 \%$ had a comorbid depression, of patients with a depression about $40 \%$ had an anxiety disorder as well. It was shown that an advantage of comorbidity was that the likelihood of recognition of mental disorders increased, and also the likelilhood of receiving treatment was highly increased by the presence of comorbid disorders.

\section{Clinical canzorbidity}

Many clinical studies have reported on comorbidity between anxiety and mood disorders (Breier et al., 1984; Starcevic et al, 1992; Ball et al., 1995; Davies et al., 1995). Due to space limitations, we focus on some recently published studics.

Diagnostic comorbidity rates vary between clinical studies because they are influenced by several methodological factors, amongst others the number and nature of disorders assessed, the method of assessment (semi-structured interview versus clinical evaluation), and time period covered (current versus lifetime).

In a clinical population (Zimmerman et al., 2002) with major depressive disorder $(\mathrm{N}=479), 64.1 \%$ of patients also met criteria for at least one comotbid Axis I disorder, and $36.7 \%$ of depressed patients had two or more comorbid disonders. The most frequent comorbid diagnoses belonged to the group of anxiety disorders $(56.8 \%$, with social phobia being the most frequent individual disorder. This study also showed that $14 \%$ of patients had a current (any) comorbid disorder that was in partial remission. Also, Not-OtherwiseSpecified (NOS) categories were rather frequent: $14.6 \%$ had any NOS anxicty disorder, especially sub threshold PTSD and sub threshold PD.

Another clinical study from Finland, the Vanta Depression Study, investigated 269 patients with MDD (Melartin et al., 2002). From this sample, $73^{\%}$ w were female, $83 \%$ were outpatients. This study covered all DSM-IV axis I and axis 11 disorders when looking for comorbidity, and used the semi structured SCAN. Most of the patients $(79 \%$ had at least one current comorbid diagnosis, and even $52 \%$ had two or more comorbid diagnoses. Anxiety disorders were present in $57 \%, 25 \%$ of patients had alcohol abuse or dependence, and $44 \%$ 
had a personality disorder. The last figure, on comorbid personaliry disonder, however, could be distorted by the fact that the SCID II was done while the patiente were depressed. Nonetheless, the conclusion must be that comorbidity among psychiatric patients with MDD is very common, and often multiple.

Finally, let us mention that these recent results are in line with earlier reports that found high comorbidity rates among MDD patients, like Sanderson et al. (1990) who reported $60 \%$ of comorbid axis I disorders, most commonly anxiety disorders. The review by Wetzler and Sanderson (1995) reports a range of $7.61 \%$ (mean $24 \%$ ) of PD patients have a current comorbid depressive disorder, lifetime depression is reported in about $65 \%$ of PD patients. Of patients with primary depressive disorder, about 14\% (range 9-69\% have a comorbid panic disorder, for this group no lifetime data were available.

These prevalence figures apply to the various anxiety disorders and (unipolar) major depression. Several studies have suggested that comorbidity rates for the affective disorder subgroups differ. As was concluded in a review by Freeman et al. (2002), as well epidemiological studies as clinical studies have found a high co-occurrence of anxiety disorders with bipolar disorder. OCD has been suggested to show a high comorbidity rate with bipolar disorder (Chen and Dilsaver, 1995a), but results from different studies are not unequivocal (Kruger et al., 1995; Perugi et al., 1997). For the specific relationship of bipolar disorder and Panic Disorder, there seems to be more evidence, from epidemiologic Chen and Dilsaver (1995b)and from several genetic studies (Mackinnon et al, 2002; Rotondo et al., 2002). Likewise, social phobia and PTSD have been associated with bipolar disorder (Freeman et al., 2002).

\section{RITRAMING CONCTPTS}

The bulk of above surveys notwithstanding, ICD and DSM frameworks offer no explanation for the link they suggest between anxicty and mood disorders. This is little of a surprise. Both systems latgely rely on a surface descriptive approach of clinical constructs, and a good proportion of these constructs suffer from a suspicious validity.

A closer analysis of our basic concepts can make sense here. The definition of concepts determines the logical relationships between them. Clarifying the concepts of depression and anxicty may illuminate their interface.

The remainder of the present chapter is an attempt to pay attention to these issucs. Which emotions, which behaviors, which functions of an organism, do the constructs of depression and anxiety exactly refer to? Pathology will be subsumed and clinical categories somewhat de-emphasized. We will consider disturbed emotions, cndorsing affectivity as the key feature of anxiety and depressive disorders. We will address the nature of emotions, focusing on 
sadness and fear. We assume that there is a close conceptmal telationship between sadness and feat and that the logical link between depression and anxiety can be inferred from this proximity. We expect the following considerations to help shedding light on the aggregation of anxiety and depression in the lifespan of some individuals.

\section{ONTHE NATURE OF EMOTIONS}

The force to exist

In the Ethics (1677), a masterpiece of deductive inference, the Dutch philosopher Benedict de Spinoza, questions the nature of human affectivity. Apparently, Spinoza observes, everything in nature tends to persevere into existence. Inanimate objects simply persist. Living organisms survive: they grow, develop and reproduce. Life appears to be endowed with an appetite for life.

In their striving to be, organisms are driven towards everything that fosters their development, and they refrain from anything that thwarts their force to be. This we observe in unicellular beings approaching the nutriments they need to stay alive and consistently fleeing a drop of acid which threatens their existence. At the other end of complexity humans' struggle for life is more sophisticated. The Ethics (III, prop. 9) posits that in humans, striving for life is conscious and appetite becomes desire. Beside food, water and warmth, humans tend to pursue other goods as knowledge, wealth, honors and social recognition, to name a few. In contrast, they seek to avoid things as illness, poventy and humiliation. They feel the former category to booster their quality of life, in other words their power to be, and the latter to endanger it. Accordingly, items belonging to the former category are called 'goods', while things in the second category are labeled 'cvils' or "adversity'.

\section{Consciowstess of the ability to be}

'Thus, in humans, appetite for life is a conscious decire which rests both in the body and in the mind. As a consequence, for cach change in an individuals" capacity to be these is a concomitant change in his mind. These transitions we call emotions (Ethica, $I I$, prop, 11). Therefore, emotions are the consciousness of the organisms' own capacity of existence.

This may be cither a pleasant or a painful consciousness", depending on whether the power to be' is going stronger or weaker. Fach change in the organism that strengthens life is sensed as pleasurc, and each change that weakens life, as pain. Pleasure is excellence of the mind to the same extent as fitness is excellence of the body. Pain in contrast, is a shrinking of the mind.

Psychologises re fer to the positive or ncgative valcnec of emotions. 
It follows that basically, there are only two emotions, pain and pleasure. Sadness is the prototype of pain and joy the prototype of pleasure. However humans do experience a great diversity of emotions because they tend to associate pain and pleasure with different ideas in various contexts. ${ }^{5}$

Thus emotions essentially are the conscious side of the organism's fitness for survival. Spinoza's fascinating suggestion is consonant with curtent evolutionary views in affective neuroscience (McGuire et al., 1992; Nesse, 1990, 1999; Damasio, 1995). Emotions ate believed to have emerged from ancient brain processes that we, humans have inherited from ancestral species. The function of these homologous brain systems is to energize organisms, helping them to cope with theit envitonment and to maximize their chances of sutvival. Panksepp (1998) posits that emotional systems "generate an animals" egocentric sense of well-being with regard to the most important natural dimensions of lifes". Throughout the ages, the primal issues of maintaining one's physical integrity, finding goods and protecting them, breeding, rearing and securing social support for oneself and the youths progressively generated specific coordinated responses. In higher vertebrates, mammals in particular, these capacities turned out to encompass powerful internal feelings sensed as emotions. Panksepp argues that there is reasonable experimental evidence to identify a number of such 'basic emotional systems' in the brain. Panksepp's Seeking, Foar and Panid/Lass systems are of particular interest for the sake of out inguiry (sce table 2).

\footnotetext{
"love is nothing clse but ploasure accompanied by the idea of an extermal cause; hatred is nothing else bue pain accompanicd by the idea of an exrernal canse. We further see that he who loves necessatily cndcavors to have and kep present wo him the object of his lowe, while he who lates endeavors ro temote and destroy the object of his hatred" (Eabis, MI, prop. 13).
} 
Table 2. Three main cmotional systems corresponding ro threc major evohtionary challenges as suggested by Panksepp (1998)

\begin{tabular}{|c|c|c|c|}
\hline & Sedeng gyom & Fior butews & Puntionas syotw \\
\hline 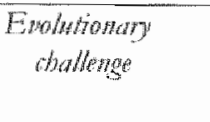 & $\begin{array}{l}\text { Finding resources } \\
(\mathrm{eg} \text { food, water, } \\
\operatorname{sex} \text { ) }\end{array}$ & $\begin{array}{l}\text { Avoiding hatro } \\
\text { and destuction }\end{array}$ & $\begin{array}{l}\text { Maintaning social } \\
\text { bonds and coheston }\end{array}$ \\
\hline 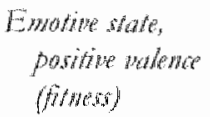 & Desire, strive & (Abrente of forst) & Atachment, lowe, tust \\
\hline 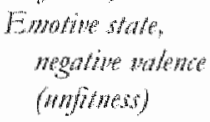 & (Alsence of derio) & Fear, anxicy & $\begin{array}{l}\text { Separacion, distess, } \\
\text { griel, sorrow }\end{array}$ \\
\hline 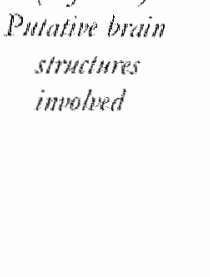 & $\begin{array}{l}\text { Mesolimbic and } \\
\text { mesocortical } \\
\text { dopaminergic } \\
\text { pathways }\end{array}$ & $\begin{array}{l}\text { Central and latcral } \\
\text { amygdald, } \\
\text { anterior and } \\
\text { medial } \\
\text { hypothalimus, } \\
\text { periventricular } \\
\text { gray }\end{array}$ & $\begin{array}{l}\text { Midbrain } \\
\text { periacqueducal gray, } \\
\text { ventral septum, } \\
\text { dorsomedial } \\
\text { thalamus, strat } \\
\text { perminalis, cingulate } \\
\text { gyrus" }\end{array}$ \\
\hline & & & $\begin{array}{l}\text { 1: structures implicated } \\
\text { in Distress } \\
\text { Vucostizations }\end{array}$ \\
\hline
\end{tabular}

Let us quote Panksepp describing the Seeking system. "This emotional system is a coherently operating neuronal network that promores a certain class of survival abilities. This system makes animals intensely interested in exploring their world and leads them to become excited when they are about to get what they desire. It eventually allows animals to find and cagerly mricipate the things they need for survival, including, of course, food, water, warmth and their ultimate evolutionary survival need, $\operatorname{sex}(\ldots)$ it helps fill the mind with interest and motivates organisms to move their bodies effortlessly in seatch of the things they need, crave, and desire. In humans, this may be onc of the main brain systems that generate and sustain curtosity, even for intellectual purstits." Arguably, there is a conceptual analogy between seeking, scnsu Pankscpp, and striving to be, sensu Spinoza. Bur what further about pain, pleasure, and, for the sake of our inquiry, sadness and joy?

\section{SADNESS}

Sadness is the painful awareness of a decay in the capacity to kecp oneself into existence. Therefore sadness is the consciousness of a loss relative to a previous state. The essence of sadness is the collapse from a higher to a lesser degree of fitness. 
There is no emotion in having a particular degree of fitness. The way I am is not a matter of pain or pleasure. The way I am makes me neither happy nor miserable. Pain and pleasure only proced from a difference in the way $I$ am, compared to the way I was. Emotions are driven by desire, and desire constantly compares. Thus, pleasure and pain are not linked to a specific level of abilities; they are a function of passing to a higher or a lesser degree in the power of existence. Only transitions can trigger emotionst.

This explains why emotions are similar in all individuals, regardless of their level of success in coping, survival and self-fulfilment. Pain affects the successful, and the poor feels pleasure. This explains the sad person feeling deprived with no apparent appreciation for the success and the wealth that he or she may still have.

The intimate relationship between the concepts of sadness and loss, has been commandingly conceptualized in Bowlby's attachment theory (1980), and to a lcsser extent in Seligman's notion of learned helplessness (1975).

Bowlby's separation-Joss theory points to the role of the primal bond between the mother and her offspring, and emphasizes the dramatic consequences of its distuption on the survival abilities of the infant. Abandonment of the vulnetable infant through loss of maternal care bears a relationship to prototypal sadness. One of the most fascinating experimental findings in this regard is the phenomenon of the so-called Distress Vocalizations (DV). Animals, rat pups or young chickens separated from their mother and left alone in a strange place, start emitting very specific, usually ultrasonic vocalizations, seemingly to solicit parent's attention. Following separation, the response often is biphasic, with an early phase attended by many vocalizations, intense motor activity and an active search for the caregiver; this is followed by a phase of despair-like behavior, with progressive extinction of the DVs, prostration and immobility. In line with Bowlby, Panksepp (1998) refers to a single Panic/Los/Sorrm system. Laboratory studies have shown structures of this system ro control DVs. Appatently, emotions linked to the Panc/Loss system provide safeguards for infant-mother attachment and social bonding. Noteworthy, the Panic/loss system reaches its highest development in the mammals, which are social beings by excellence; separation and abandonment have dramatic, life threatening consequence for newborn mammals (Panksepp, $1998,2001)$.

Seligman (1975) developed the concept of learned helplessness, which he related to depressive behaviors. In Seligman's experimental paradigm, animals, most often dogs, were submitred to a series of electric shocks they could neirher avoid nor escape. When later presented with similar aversive stimuli,

"Lor if man were born whth the pertection to which he passes, he would possess the same,

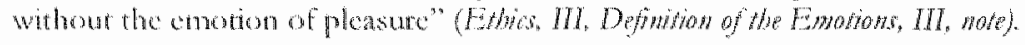


most animals helplessly underwent the events despite having regained the possibility to escape, in an apparent passive attitude towards forthcoming adversity. Seligman's experiments can be reinterpreted as instances of loss of ability in mastering one's environment. Seligman's dogs had lost the ability to exercise control on environmental parameters that profoundly affected them. Such a loss represents a definite shrinking of the organism's ability to live and survive.

FEAR

Fear is pain in the future

Throughout the Middle Ages scholars used to represent the principal emotions in a $2 \times 2$ table (table 3 ) which scheme actually relied on the doctrine of the ancient Stoics.

Table 3. Basic emotions according to the Stoics

\begin{tabular}{l|l|l} 
& Present & Futwre \\
\hline Gonds & Pleasure & Desite \\
Exils & Sadness & Fear
\end{tabular}

Humans' appraisal basically distinguishes between good and bad events. Pleasure is the present experience of good rhings, pain the experience of evils. Regarding the future, humans tend to desire things they believe to be good, and to fear those they believe to be bad. Thus fear is the emotion with a negative valence, pertaining to the future. Fear obviously belongs to the negative emotions, related to evils and associated with pain. Contemporary evolutionaty views emphasize this negative valence of fear as a functionality that helps keeping the organism away from adversiry. Indeed, avoidance is constitutive of fear. Noteworthy, avoidance as a coping strategy dictated by fear makes senuc as long as no irremediable damage has occurred to the organism. Once damage has occurred, it is too late to avoid: there is loss, and actual loss is sadncss. Thus fear tefers to unaccomplished pain, in orher words, pain in the future.

Fear is diverse and the evils a particular organism seeks to avoid, numcrous. Accordingly, naming fears has been a much appreciated pastime of carlice psychopathologists (Campbell, 1981). Yet a closer look at the content of highly prevalent fears is more interesting. Phobias typically represent fears of concrete, circumscribed external objects. Evolutionary vicws on phobias hold that phobic feats are related to innate mechanisms shaped by narure wis safeguard for life in a hostile environment (Ohman and Mincka, 2001; Poulton and Menzies, 2002). Animals have been prepared via natural selection to avoid 
things that may mote or less endanger their survival. Against the background of human psychopathology, Nesse (1990) lists a number of subtypes of anxiety, each of which he tentatively relates to a particular kind of primal danger (table 4).

Table 4. Putative primal dangers related to different types of andiety according to Nesse (after Nessc, 1900)

\begin{tabular}{|c|c|}
\hline Amaty & Pripwal dowger \\
\hline Panic & Present vital thteat (e g attack by a predator) \\
\hline Agoraphobian & Highly unsafe environment (attack likely) \\
\hline Social andiety & Rejection from group membership \\
\hline Separation anxiety & Soctal loss and disruption of protective bond \\
\hline Blood-injury phobia & Blood loss \\
\hline Hoarding compulsions & Lack of food ov other goods \\
\hline Washing compulsions & Infection \\
\hline Animal phobias & (Vial) threat by dangerous animals \\
\hline
\end{tabular}

All fears have pain in common, and pain is the subjective side of a loss in the power to be. Therefore, experiencing pain is facing a loss in one's capacity of survival. For a living being, the ultimate loss is death. Thus, the ultimate fear is a fear of dying, and Epicurius rightly pointed to the fear of death as the core of all human misery (Diogenus Laertius, book IX) ${ }^{7}$. Thus all instances of fear are instances where possibly the organism's very existence is endangered. The case is clear for the prey-predator paradigm, as it is for specific phobias such as fear of heights, enclosed spaces, fire, natural disasters as thunder and storms, sharp objects and animals. In all these situations, the animals' existence is at risk, either acutely (prey-predator) or remotely. Social fears represent a distinct category: they typically apply to higher vertebrates, mammals in particular. Mammals need social support to survive, should it only be for the immaturity of their youths. For social animals, including humans, loss of social integrity may be of vital importance; it is loss of life. This explains social fears in the perspective of an ultimate fear of death".

\footnotetext{
However, Lpicurius furthet reasoned that we should not forat death because in fact we never. have knowedge of death: as long as we are, death is not, and once death is, we are not any mote. An this he may have missod that the painful essence of fear lies in wathgg mow for the furure evil, nor the exil itself. Even though the object of the fear never materializes, fear hurts.

" Trom a conceptual point of view, one may argue that social fears occupy a specific place amongst fears. They are mote recent in the history of evolution and, compared to archaic sategurds as other phobias, they may be a more pertinent feacure for well organized animals, as humans. To a social being as mammals ate, the chreat of stom of of a small animal may have become less silient than due threat of sepatation and abandonment. To this extent social tears may have evolved very close to the image of acute loss, death, sadness and depression
} 
In sum, there is nothing else in fear but pain, pain being conceived of as a deficit in the ability to survive.

\section{Fear is wnertain and therefore inconstant}

In the Ethics, Spinoza conceptualizes of fear as being an inconstant pain. This pain arises from the image of something concerning which we are in doubt. More precisely, the emotion of fear, he further writes, arises from the idea of something past or future, whereof wre to a certain extent doubt the issue. Fear pertains to the future, possibly to the past. As fat as the object of fear is in the future, to some extent the causality of feat is in the future. Now, the future is not certain. Thetefore, uncertainty is constimtive of fear.

Uncertainty relates to unpredictability". There has been quite a lot of experimental work on the link between unpredictability and anxiety (Mineka and Kihlstrom, 1978). Typically, an enviromment that goes unpredictable becomes anxiogenic. In an unpredictable environment cues are not reliable. A typical example in a learning paradigm of classical conditioning occurs when, given the occurrence of the UCS (the signaling event), the probability of occurrence of the CS (the signaled event), equates or approaches the probability of non occurrence of the CS. In such an environment, the danger of loosing control is great. And loosing control on one's environment entails a loss in the organism's ability to face the challenge of survival.

The view of fear as uncertainty may provide a first hint to illuminate its relationship to sadness. Fear is a foreboded loss of control on ones environment. Such a loss of control affects the organism's power to be. Thus fear is a threat of sadness.

Fear is not only uncertain. Fear is also inconstant. Fear is variable and changing over time. Why should we logically expect fear to be an inconstant emotion? The argument may run as follows. The future exists in the subjects' mind as an image only. The same applies to the past. Past and future are kept in existence through images in the mind (Damasio, 1994). However, whille facts are irrevocable, images are prone to change. When the subject has in mind an image of doom and loss, he feels painful and tends to substitute that image by a different one. The mind endeavors to repel images of doom and replace them by images of happiness. The individual narurally seeks a glimpse of success

\footnotetext{
"Fear related to a past ewent is typically obsessive fear. The obsessiqe subject doubls allow past as much as abou future events. To this extent, obsessions are metely a particular case of anxiery. However, we will nor further discuss the concepr of obsessions in the present demonstration.

is Not each instance of uncertainty can be cxplained by unpredictability. Unpredictabiliny may explain uncertainty only as far as funte events are concened. Unpredictability does not encompass uncertainry pertaining to past cuents.
} 
rather than fallure, a glimpse of joy rather than pain"1. Thus there is an inherent instability of fcar. The inconstant pain of fear always mixes to some extent with the inconsunt pleasure of hope. There is neither fear without hope, nor hope without fear, Spinoza insists.

The view of fear as inconstant emotion may provide us with a second hint concerning the relationship between fear and sadness. Take uncertainty away, and hope becomes pleasure. Take uncertainty away, and fear becomes despair (Ethics, III, prop. 17). We might expect fear to become sacness when images of doom overtake images of hope in the mind, making fear less inconstant. Fear closes down to sadness as a function of its constancy, in other words to the degree it is turning chronic.

\section{FROM FEAR TO SADNESS}

\section{When uncertain sadness tarns certain}

At first, the mind of the fearful oscillates, expecting the worst but wishing the best. The subject with fear anticipates doom, but endeavours to keep in account that the threat may not materialize.

Then comes exhaustion, and images of doom start dragging on in the mind. Ups and downs in the subjects' mood flatten, giving way to generalized negative expectations in face of adversity ${ }^{2}$. The fluctuating fear eventually freezes into a static state with a steady negative valence. The fleeting glimpses of disaster, originally mixed up with hope, merge into the protracted contemplation of a looming pain. Loss is now taken for granted. The Ethics emphasizes that if the elements of uncertainty are removed, fear turns into despair (Ethics, III, proposition 18). Despair encompasses the certainty of damage.

\section{Panful expechations, lasting injuries that but, and a place for panic}

In the flow of time, the mind continuously anticipares the future, considers the present and remembers the past. This incessant sequence is the measure of the subject's expectations. The time passing by is the ultimate evidence.

lear looks forward to an uncertain hatm. Sadness reflects on lost excellence. There is an evident temporal relationship between fear and sadness. The object of fear is the future; the object of sadness is the past. Fear and sadness ate lasting emotions, extending by essence beyond the time present. Fear waits for the future to materialize; sadness keeps memory of the past.

\footnotetext{
11 "he who feats, in other words doubrs, concerning the issue of something which he hates also conceves something which excludes the existence of the thing in question: to this extent he teds pleasure, and consequendly to this cxtent he hopes that it will turn out as he desires" (Tithics $11 \%$, Detinitions of the Fmotions, XII).

Goncalized apprethonsive expection: the link between fear and sadness?
} 
In contrast panic is the immediate emotion linked to the assault of unfolding adversity. Panic is the internal experience of the acute threat to the organisms' survival, when its very existence is at stake. It ensues that conceptually, not only fear and sadness are different, but between them there is a logically designated place for the distinct state of panic. This all is consonant with the view that putatively "anxiety prepares the system for an anticipated trauma wherens panic deals with one that is already in progress" (Bouton ct al., 2001).

\section{Fear as suffufilled sadness}

The argument developed in the previous paragraphs suggests a number of ideas about the definition of emotions, and, regarding our original concems, about the nature of sadness and fear. Emotions in general have been related to the drive of life and the striving for survival. They should be regarded as the "contentment," or the absence thereof, of the organism sensing an increase or a decrease in its chances of coping with life. "This satisfacrion must be conceived of as an evolutionary concept, having gtown from reflex-like approach and avoidance reactions in single-cell beings, to conscious desire and complex, cognitively loaded emotions in humans. At least in higher mammals, feat and sadness are essentially the painful perception of a threat of, or an actual loss in the 'power to be'. Fear, leaning forward to the uncertain future, is intermittent sadness, being mixed up with the hope of escaping danger. Sometimes the fearful subject forebodes a loss, sometimes he hopes for the best. Thus, fear is incipient sadness, which reaches completion when time consumes the anticipated loss. It ensues that there is continuity between fear and sadness in the flow of time. In order to become sadness, fear requires that time passes.

The process unfolds in the direction of the arrow of time, and this tells that fear will eventually become sadness, but that sadness is not likely to change into fear.

\section{Anxiery as inconplete depression?}

Several arguments arguably illustrate the idea that anxicty is a purative state of unfulfilled depression.

When assessed on the independent dimensions of positive and negative affectivity, patients with anxiety states present increased ratings on both negative and positive affectivity. In contrast, subjects with depression yicld high scores on negative affectivity only, having seemingly lost any significant profle of positive affectivity. This shows anxicty and depression to share a common profile, depression representing one further degree yet in psychological pathology (Tellegen, 1985; Clark and Watson, 1991).

Van Prang discusses as plausible the possibility that anxiety induces depression, or at least a subtype of depression. He observes that anxiety symptoms, and anxiety related irritability often precede the development of depression. He 
refers to this type of depression as being "anxiety/aggression-driven" and links this construct to serotonergic disturbance (van Praag, in press).

Our analysis presents the passage from anxiety to depression as mediated by a phase of constant and chronic fear. As we have reported earlier in the present chapter $G A D$, the anxiery disorder which arguably yields the highest degree of chronicity, strikingly shows one of the highest degrees of depressive comorbidity. The close proximity between GAD and depression has even lead some authors to speculate on a common diathesis between both disorders (Kendler er al, 1996; Mincka et al, 1998).

Addressing the cognitive correlates of anxiety and depression, Alloy and coworkers (1990) hypothesize that depression, compared to anxiety, is characterized by a sense of certainty encompassing hopelessness. This idea is perfectly consistent with our above analysis. Waikar and Craske (1997) investigated 329 patients with affective pathology and found support for Alloy and coworkers" suggestion.

We further infer that time is an essential dimension in the transformation of fear into sadness. We some years ago examined whether chronicity is a facror towards depression in a population of panic disorder (PD) patients. The results not only support the idea, but suggest as well a direct relationship berween the severity of PD and the development of subsequent depression (Griez and Overbeek, 1997).

If fear 'prepares' for sadness, one should logically expect anxicty with subsequent (lifetime) depression to be more prevalent than depression allone. This is the case (Mineka et al, 1998). Pure depression nevertheless occurs independently, for instance as a result of acute unforeseen loss events, as sudden grief.

In sum, it appears plausible that fear is a logical itinetary to sadness, and that there may be a continum between clinical conditions of anxiety and depression.

\section{A note on the comets of fear and sadness in evolutionary perspective}

The above account of emotions broadly refers to evolutionary views. There is an extensive literature on evolutionary biology, while evolutionary views in psychiatry and clinical psychology are spreading fast. Yet investigators do not all agree in their interpretations. A number of authors tend to consider cmotions in general, regardless of their valence, as being in itself instances of adaptations. Following their view, anxiety and deptession have supposedly been 'invented' by nature as adaptive responses to the challenges of ancient environments (see for instance: Nesse, 1999, Troisi and McGuire, 2002). Accordingly, they deploy a lot of heuristic efforts to explain the potential virtues of painful conditions as depression and other psychiatric illnesses 
(Nesse, 2000). Others have challenged these "adaptatonusts" positions. Criticism has been voiced on some methods used in evolutionary psychatry (Mcloughin, 2002, Lane and Luchins, 1988, Dubrovsky, 2002).

The conceptual analysis in the present chapter is consistent with modern neutoscicnces (Panksepp, 1998, Damasio, 1994). However, it should be noted that our analysis does not present each emotion as being a blessing of nature in itself. Emotions are the intemal sense of wellbeing that corresponds to the capacity for life, of the futness of the organism. For each increase in hiness there is an emotion with a positive valence, for each decrease, an cmotion with a negative valence. Fear and depression are the emotional side of a loss of power for life. Consequently, they express a dectease in fitness. From this point of view, the andogy drawn beween anxiety and depression on one hand, cough and fever on the other hand (Nesse, 1999) may be conceptually wrong. Fear and sadness are not the consequence of a loss of life, let aside an adaprive reaction to it; they are loss of life and express a lack of fincss. Depressive individuals present homonal and immunological disturbances, a sign that they are at increased vulnerability (van West et al, in press), Another striking case is the increased prevalence of affective disorders in physically ill subjects, amongst others, cardiac patients Griez et al., 2000; 1.eet et al, 2000; 1'rasureSmith et al., 1993); in cardac patients in particular, the occurrence of affecrive pathology has been associated to a poorer vital prognosis.

\section{EPHOGUE}

Our analysis intends to clarify concepts. It does not invalidate or replace empirical research. From a conceptual point of view, there is continuity between fear and sadness but no overlap. The continuty may be consistent with the idea that anxiety and deptessive disoters belong to a same spectrum. The absence of ovetlap however argues against the idea of a diagnostic pleonasm (van Prags, in press). To the extent that foar is not mercly sadness, anxiety is no depression. Feat is fordboded sadness, modorated by uncetanty. It is from this point of view that one might argue that anxicty disotedes are conceptually less severe than depression.

\section{RELERDNCES}

Moy I.B, Kelly KA, Mincka $S$ and Clements CM. Comonbidiy of anxicy and depressive disorders: A helplessness bopelessness perspective. In: Maser ID) and (dominget (CR

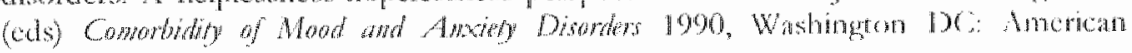
Psychatric Pross

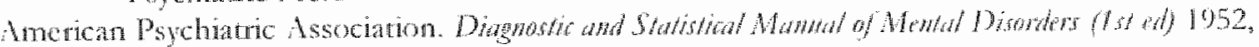
Washington DC: Anerican Psychiaric Pifess

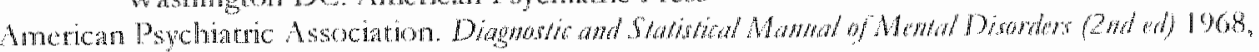
Washington DC: Ancrican Psychatric Press 


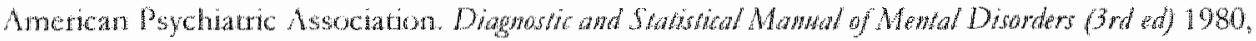
Washington DC: American Psychiatric Press

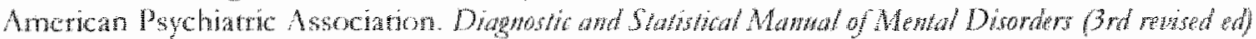
1987. Washington DC: Amorican Psychiatric Press

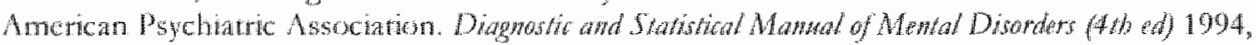
Washington DC: American Psychiatric Press

Arbabadah-Bouchez $S$ and Lepine $\mathrm{I}$. Maasurements of depression and anxiety disorders. In:

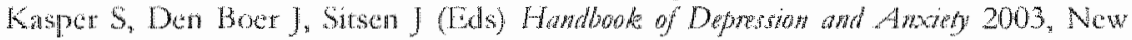
York, Maicel Dekker

Ball $S$, Buchwald A, Waddell M and shekhat $A$. Depression and generalized anxiety symptoms in pande disorder. Implications for comorbidity. N Nerv Men Dirase 1995: 183, 304-308

Bandelow $B$. The assessment of effeacy of teatments for panic disonder and agoraphobat. II. The Panic and Agoraphobia Scake. In Clw Psyophomolatogy 1995: 10,73-82

Parlow DH and Campbell LAt. Mixed anxiety-depression and is implications for models of mood and anxicty disorders. Compr Pyoliainy $2000: 41,5560$

Beck MT, ward CH. Mendelson M, Mock JE and Eibaugh JK. An inventory for mensuring depression. Ambiner of Gem Poibialy 1961: 4, 561-571

Beck A and Clark D. Anxixy and Depression: an infomation processing perspecrive. Amzaty Revem/s 1988: 1, 23-36

Bouton ME, Mincka $\mathrm{S}$ and Batow DH. A Modern learning theory perspective on the etiology of panic disorder. Pychalagical Remow 2001: $108,4.32$

Bowlby I. Alardongenf and Lass. 1980, Waw York, Basic Books

Bramley PN, Easton MM, Monky $S$ and Snaith RP. The differentiation of anxiery and depression by rating scalles. Acha Pswtudr Shand 1988: 77, 133-138

Breider A. Chamey D and Heninger $(3$. Major depression in patients with agoraphobia and panic disorder Ant Gow Pathatry 1984: 41,1129-1135

Burke JD, Witchen HU, Regice DA and Sartoris $N$. Extracting in ormation from diagnostic interviews on co-occurrence of symploms of anxiety and depression. In: Maser JD and Cloninger CR (cds) Connowdity of Mood and Amrity Disorders 1990: Washington DC, American Psychiatric Press

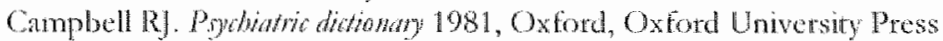

Chen $\mathrm{YW}$ and Dilsaver SC. Comodbidity for obsessive-compulsive disorder in bipolar and unipolat disorders. Pabliaty Res 1995a: 59, 57-64

Chen YW and Dilswer SC. Comorbidity of panc disotder in bipolar illness, evidence from the Lpidemiologic Catchment Area Survey. Am / Pydiaty 1995b: 152, 280-282

Chath. L and Watson D. Triparte model of anxicty and depression: Psychometric evidence

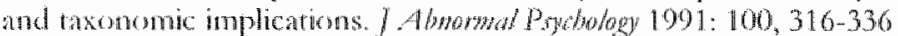

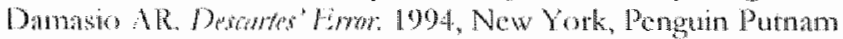

Damasion SR. On some hunctions of the human prefromtal cotrex. Am N Y Akd Sa 1995: 769, $241-251$

Davius 1: Notmm R, Cortese 1, and Mallat $A$. The relationship between types of anxicy and deperesion. J Now Ment Distat $1995: 183,31 \ldots 35$

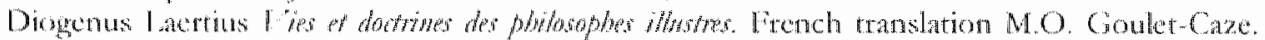

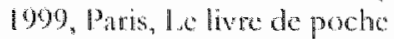

Dubromsk B. Wvolutionary paychatry. Adaptanions and nonadaptationist conceptuatizations.

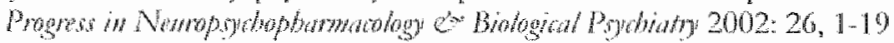

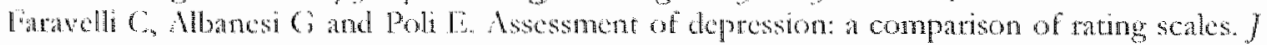
Aforo Dirot 1986:11,245-253

linaclli C. Servi P. Arends JA and Strik WK. Number of symproms, quantification, and qualification of depression. Cowpr Pondstry 1996:37, 307-315 
Feer $R$, Lavoic $K$, Beiman BD. Is paric disorder associated with coronary artery disease?

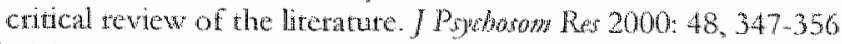

Frances A, Manning D, Marin D, Kocsis I, Mckinney Kall W and Kline M. Rehationship of anxiety and depression. Pbophowmolog (Bey) 1992: 106, Suppl $582-586$

Frasure-Smith N, Lesperance F and Talaic M. Deptession following myocardial intarction. Impact on 6 -month surwival. LAMA1. 1993:270, 1819-1825

Freman MP, Freeman $S A$ and MCElroy $S L$. The comotbidicy of bipolar and anxiery disotders: prevalence, psychobiology, and treatmene issucs. Affer Dirond 2002: 68, 1-23

Glas, G. A conceptual history of anxiety and depression. Im: Kasper S, Den Boer J, Sirsen J

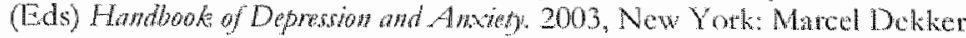

Griez E and Overbeck $\mathrm{T}$. Comorbidicy of Depression and Anxicy. Tr: Honig A, Anstau M and

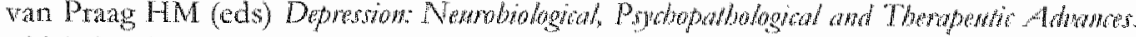
1997. Chichester, Wiley \& Sons

Griez EJ. Mammar N, Loirat JC, Djega N, Trochut JN and Bowhour JB. Panic disorder and idiopadic cardiomyopathy. I Psyoronz Res 2000: $48,585-587$

Hamilon M. The assessment of anxiety states by rating. Br fof Med Powdogy 1959: 32, $50-55$

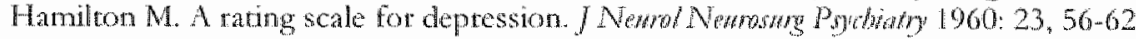

Hamilon M. Development of a rating scale for primary depressive illness. Br J Soc Chit Psyol $1967: 6,278-296$

Hermann C. Intemational experiences wh the Hospial Anxicty and Depression Scate: A review of validation data and clinical results. I Psoloson Ro 1997: 42, 17.41

Wimmethoch $]$, Levine and Gershon 5 . Historical overvew of the relationshp between andery disorders and affective disorders. Detrer Amoty 2001: 14, 53-66

Hodgson RJ and Rachman S. Obsessional-Compulsive Complaints. Botsa Rar Tow 1977: 15, $389-395$

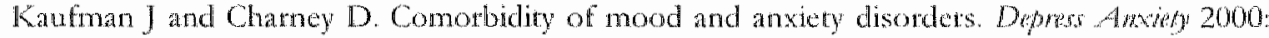
12 Suppl 1, 69-76

Keedwell P and Snaith RP. What do anxiety scales measure? Awa Pyomat Sand 1996: 93, 177. 180

Kendler KS. Major depression and generalised anxiety disorder. Same genes, (party) differeno enviroments: revisited. BrJ Psybialy 1996: Suppl 68-75

Kessler RC, McGonagle KA, Zhao S, Nelson CB, Hughes M, Eshleman S, Wituhen MU, and Kendler KS. Liforime and 12-month prevalence of DSM-III-R psychiatric disorders in

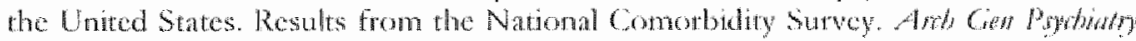
1994: 1,819

Kescler RC, Nelson CB, MCGonagle KA, Lu J, Swat: M and Blaxer DC. Comorbidity of

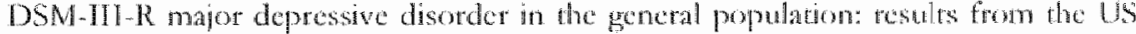
National Comorbidty Survey. Br J Powhow 1996: Suppl, 17-30

Kruger S, Cooke RG, Hasey GM, Jorna T and Persad T. Comorbidity of obsessive compulsive disomer in bipolar disonder. J Afen Disord 1995:34, 117-120

Lane LW and Luchin D. Evofutionaty appraxches to psychiaty and problemes of mothod, Conpr Pyobatry 1988: 6, 598603

Jecrubier $Y$ and Ustun TB. Panic and depression: a worldwide primary care perspective. Im Citu Pothoparmat 1908 : 13 Suppl 4, S7.S11

levine J, Cole DP, Chengappa KN and Gershon S. Anxicty disorders and mator depression, rogether of apart. Depres Awwiefy 2001: 14,94-104

Licbowitz MR. Social Phobia. Mod Pwol Phymphopsydiaty 1987:22, $141-173$

Mackinnon DF, Zandi PP, Conper J. Potash JB, Simpson SG, Gershon L, Numberger I, Reich T. Depaulo JR. Comorbid bipolar disonder and pance disorder in families with a high prevalence of bipolar disorder. Am / 19 ghimg $2002: 15 \%, 30-35$ 
Marks JM and Nesse RM. Fere and fincss: an ewolutionaty analysis of anxiefy disorders. Eibolog and Sociobiology 1994: $15,247-261$

Mchure MT, Marks I, Nese RM and Trosis A. Ewolutionary biology: a basic science for

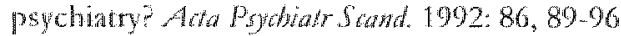

Mcloughin $G$. Is depression normal in human beings? A critque of the evolutionary perspective, [n/ J Menth Heath Nursing 2002: 11, 170-173

Melartin TKK, Rytsala HI, Leskela US, Lestela-Michonen PS, Sokero TP and Isomersa ET. Current comorbidiry of psychatric disorders among DSM-IV major depressive disorder patients in psychiatric care in the Vanta Depression Study, I Clin Pshowat 2002: $63,126-134$

Merikangas KR, Angse J, Eaton W, Canino G, Rubio-Sipec $M$, Wacker $H$, Witchen $H U$, Andrade L, Fssu C, Whitaker A, Kracmer H, Robins LN, Kupter DJ. Comorbidity and boundaries of affecrive disotders with anxiety disorders and substance misuse: results of an international task force. Br J Pydiatry 1996: Suppl, 58-67

Mincka $S$ and Kihlstrom J. Unpredictable and uncontrollable events: a new perpective on experimental neurosis, $J$ Abs Pydology 1978:87,256-271

Mineka 5, Watson D and Clark LA. Comorbidiry of anxiery and unipolar mood disorders. Amw Rew Psyotology 1998:49,377412

Montgomery SA and Asbery M. A new depression scale designed wo be sensitwe to change. Br Pivcliato 1979: 134, 382-389

Nemeroff CB. Comorbidity of mood and anxiety disonders: the rule, not the exception? Am I Pspliator 2002: 159, 344

Nesse RM. Exolutionary explanations of emotions. Homman Natwr 1990, 1:261-289

Nesse RM. Proximate and evolutionary studies of anxiecy, stress and depression: symergy at the

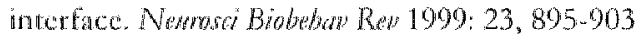

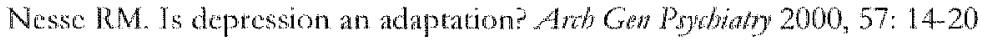

Ohmon A and Mincka S. Fears, phobias, and preparedness: toward an ewolved module of fear atnd fear learning. Porbo/ Rep 2001: 108, 483-522

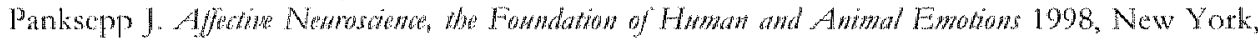
Oxford University Press

Perugi $G$, Akiskal HS, Ptaner C, Ptesta $S$, Gemignani $A$, Milantanchi A, Rensi $P$, Ravagli $S$, Gasano GB. The clinical impact of bipolat and unipolar affective comorbidity on obsessive-compulsive disorder. I Affor Dirsh 1997:46, 15-23

Poutom $\mathbb{R}$ and Mentes RCi. Fears bom and bred: roward a more incluswe theory of fear acquisition. Bethor Res Ther 2002 : $40,197-208$

Rapapont MH. Prevalence, recognition, and treatment of comorbid depression and anxiety. I Chin Pybrat 2001: $625 \mathrm{sup}$ 24, $6-10$

Regien DA, Nartow WI and Rae DS. The epidemiology of anxiety disorders: the Epidemiologic

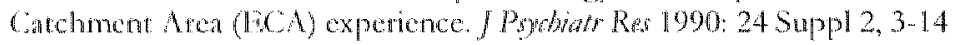

Reger DA, Rae DS, Natrow WI, Kaclber CT and Scharaberg AF. Prevalence of anxict disonders and their comorbiclity with mood and addictive disorders. By / Pswotary 1.908: Suppli, $24-28$

Robins IN, Holzer JL, Croughat J and Ratclif KS. National Institute of Mental Health Diagnostic Intervicw Schedule: Its history, chanacteristics, and validigy. Awh Gey Poydsiatr 1981: $38,381-389$

Robins I.N, Wing J, Wirthen HU, Hetzer JE, Babor TF, Burke JD, Farmer A, JablenskyA, Pickens R, Regier DA. Sartorius $N$ and Towle LH. The Composite Inremational Diagnostic lnterviow: an epidemologic insmument sutable for use in conjunction with difetent diagnostic sysems and in different cultures. Ard Gen Pyowing $1988: 45$, $1069-1077$ 
Rotondo A, Mazanti C, Del'Osso L, Rucci P, Sulliwa P, Bounam S, Gomelli C, Godman D, Cassano GB. Catechol omethyteransterase, seroconin trasporter, and mppophan hydroxylase gene polymorphisms in bipolat disorder paticnts with and without comorbid panic disonder. Am I Py dhatry 2002: 159,23-29

Sanderson WC, Beck AT and Beck J. Syndrome comorbidiry in patients with major depression or dysthyma: prevalence and temporal whanships. Am Podbiato 1990: 147, 10251028

Satotius $N$, Ustun TB, Lecrubier $Y$ and Witchen HU. Depression comorbid with anxicy" resules from the WHO study on psychological disorders in primary health care $\mathrm{Br}$. Psychioty Supp/ 1996: $38-43$

Seligman MEP. Heplesmesr. 1975, San Francisco. WH Freman

Shcehan DV, Lecrubier Y, Shechan KH, Amorim P. Janavs J, Weiler I, Hergucta T, Baker $R$ and Dumbar GC. The Mini-International Neuropsychatric Interview (M.I.N.1.): the development and validation of st structured diagnostic psychiatric intervicw for DSMTV and ICD-10. J Clim Pyoliain 1998: 59 Suppl 20, 22-33

Snath P. What do depression rating scales measure? Br / Psybaty $1993: 163,293.298$

Snath RP, Baugh SI, Clayden AD, Husin A and Sipple MA. The Clinical Anxien Scalc: an instrument derived from the Hamilton Anxieg Scale, Br/P.jobidoy 1982: 141,518-523

Snaith RP and Taylor CM. Rating scales for depression and anxicty: a current perspective. BrJ Clin Phamalol 1985: 19 Suppl 1, 17-20

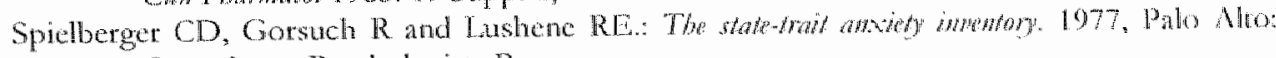
Consultants Pychologists Press

Spinoza B. Eibocs. 1677. Translated from the Iatin by RHM Elwes, 1883, Middk Tennessee State University Philosophy Webworks, Hypertext Edition

Spitzer RI, Williams JB, Gibbon M and First MB. The Structured Conicat Interview for DSM-

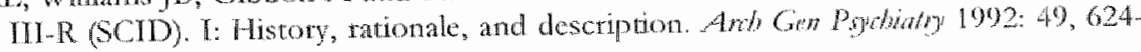
629

Statcevic $V$, Uhlenhuth $E$, Kellnex $R$ and Pathak D. Paterns of comotbidity in panic disorder and agotaphobia. Pybiaty Rexamb 1992: 42, 171-183

Tellegen A. Structures of mood and personality and their relexance wassessing anxiety, with an emphasis on self-repott. In: Tuma AH, Maser JD (cds) Awrol and the Amaty Disorders. 1985, Hillsdale NJ, Eribaum

Trotsi A and McGuite M. Darwinian psychiatry and the concept of mencal disonder, Nerrowdormology heter 2002: special issuc, suppl 4: 23, 31-37

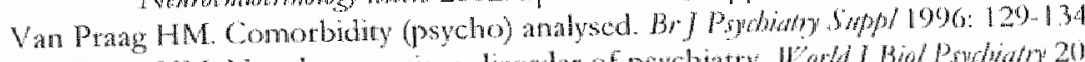

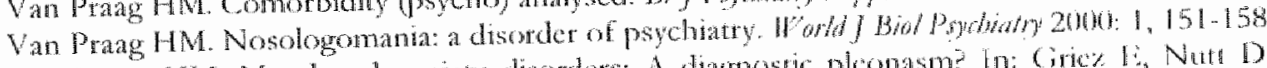

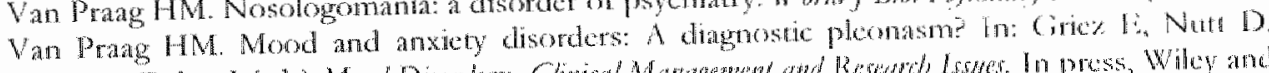

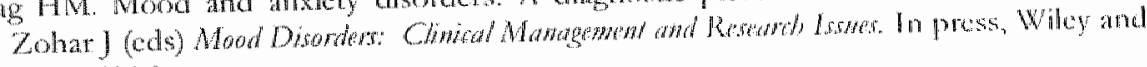
Sons, Chichester

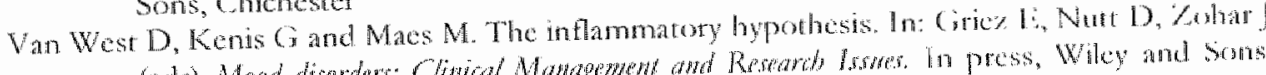

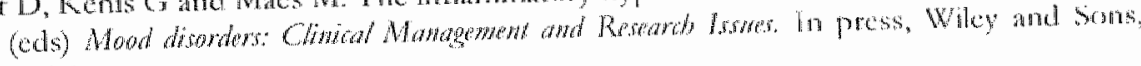
Chichester

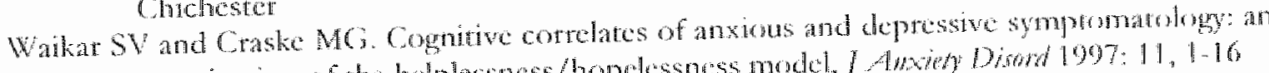

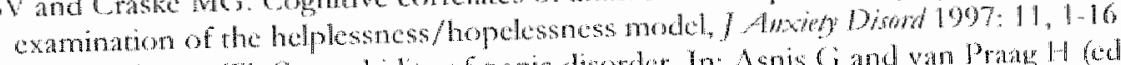

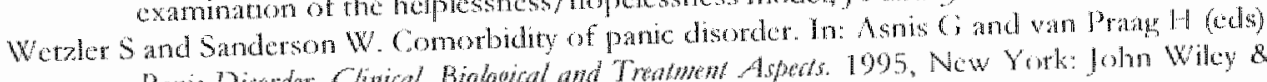

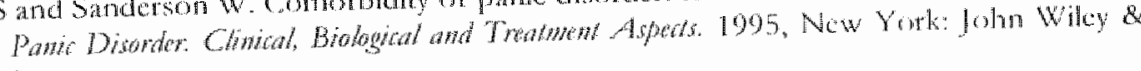
Sons

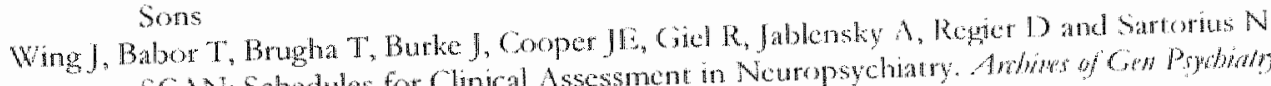
SCAN: Schedules tor Clinical Assessment in Neuropsychatry. Awhiw of Cen Psydiath 1990: $47,589-593$ 
Witchen HU, thao S, Kesser RC and Eaton WW. DSM-JTI-R generalized anxiety disorder in

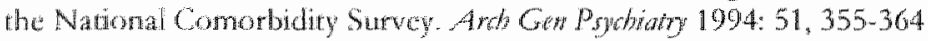

Witthen HU. Critical issues in the evaluation of comorbidity of psychiatric disorders. Br $J$ Psydialoy 1906: Suppl, 9-16

Witteten HU, lieb R, Wunderlich $U$ and Schuster $P$. Comorbidity in primary care: presentation and consequences. Chin Psybiany 1999:60 Suppl 7,29-36

Wirthen HU, Schuster $\mathrm{P}$, Lieb R. Comorbidicy and mixed anxicy-depressive disonder clinical

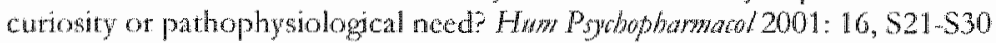

World Mcatth Organization The ICD-10 Classification of Mental and Behavioural Diseases. 1992: Gineva, WHO

Yerevanian BI, Koek RJ and Ramdev S. Anxicy disoders comorbidiry in mood disorder sulbgroups: data from a mood disonders clinic. / Afed Disord 2001, 67: 167-173

Zigmond AS and Snath RP. The hospital anxiety and depression scale. Acta Pothatr Sedrd 1983 : $67,361-370$

Zimmeman M, Chelminski I and McDermut W. Major depressive disorder and axis I diagnostic comorbidity. J Clin Psydiaty $2002.63,187-193$

Zinbarg RE, Barlow DH, Liebowitz M, Stree L, Broadhead E, Katon W, Roy-Byme P, Lepine JP, Teherani M, Richards J, Brantey PJ and Kracmer H. The DSM rV field trial for mixed anxiery-depression. Am/ Psychiaty 1994: 151, 1153-1162

Zung WW. Selfating depression scale. Arb Gen Pshiaty 1965: 12, 63.70 


\section{SUMMARY AND CONCLUDING REMARKS}

The frequent co-occurrence of anxiety disonders with depression in clinical practice provided the foundation for this thesis. Several studies wore performed at the intorface between anxiety disorders and depressive disorders, and related features like suicidality and sleep complaints.

After a formond 1 in the Introductorn Section, datpter 2 provides an overview of large population based surveys conceming prevalence, demographics, risk factors, natural course, and comorbidity of the DSM-IV anxiety disorders. The estimated lifetime prevalence of all anxiety disorders is $25 \%$, compared to major depression which occurs in about $17 \%$ of the population. Among anxiery disorders, social phobia and specific phobias are the most prevalent (11-12\%). The prevalence figures for the other anxicty disorders are: paric disorder (PD) $2 \%$, obsessive-compulsive disorder (OCD) $2-3 \%$, gencralized anxiety disorder (GAD) 5\%, and $7 \%$ of the population may develop posttraumatic stress disorder (PTSD). Various factors such as selection bias, severity of symptoms, diagnostic criteria, and instruments used in these studies wartant great caution in interpretating these epidemiological data.

Section I statts the description of the empirical studies with data on comorbidity and treatment aspects of comorbid disorders on the index anxicty disordet. Chapter 3 reviews the literature on comorbidity of PD and depression. In addition, it reported on a retrospective study in PD patients. Although PD is not the most prevalent anxicty disorder, it is frequenty encountered in clinical practice because of its usually disabling conscquences. In order to study the cinical characteristics and impact of comotbid depression on treament outcome, we assessed comorbid depressive fearures in PD. In a sample of 160 patients with panic disorder, $30 \%$ met criteria for concurrent major depression or dysthymia. The group of depressed PD patients were significantly older $(p<0.05)$, and reported more severe anxiety symproms than the nondepressed PD patients. Both groups benefited equally from combined pharmacological and behaviotal treatment, as illustrated by a comparable decreasc on the assessment scales used. These findings are consistent with a theorctical model that conceives anxiety disorders (i.e. PD) as predisposing to depression.

Chapter 4 reports on the comorbidity of OCD and depression, and the impact of the comorbid depression on treatment outcome for OCD. $A$ retrospective 
study was performed on baselne tatings of 120 OCD patients and postreatmont ratings of 72 patiens. One third $(37 \%$ of the OCD patients also met DSM-IV criteria for major depression of dysthymia at baseline. Symptom severity of OCD symptoms at baseline did not differ between depressed and nondepressed OCD patients; on genetal anxiety symptoms the comorbid group was more severely affected. Borh deptessed and nondepressed OCD paticnts responded well to treament, as reflected in assessments for depressive, obsessive-compulsive, and general anxiety symptoms. However, comorbid depression appeated to have a negative effect on treatment: depressed OCD parients showed less improvement than nondepressed OCD patients on most scales. In addition, although both groups were equally affected at baseline, postreament scores on OCD measures were significantly higher for the depressed OCD patients than for the nondepressed group. These results underscore the importance of assessing comorbid disonders in OCD, since this may have an impact on treatment outcome.

Serrom II contains the reports on associated features of panic disotder. Chapter 5 assesses suicidal ideation and risk for PD patients. In order to assess to what extent a reported rate of higher suicidality in PD could be attributed to PD alone, we excluded all comorbid DSM-TII-R axis I or axis Tl pathology in this study. Fifty patients with pure PD (but with or without agoraphobia) were compated with fifty age- and gendet- matched controls. We found that pare PD parients were more preoccupied with death in general than controls; PD patients also expressed a passive wish to be dead more frequently. However, PD patients did not think about committing suicide more frequently, nor reported more suicide attempts than controls. We concluded that PD alone was not associated with higher suicide risk. By meticulously cxcluding comorbid disonders in PD, we showed that it is likely that the previously reported higher suicide risk in PD can be accounted for by prevalent comorbid disotedetis.

Chaph 6 focuses on the association between sleep complaints and PD. The study assossed the prevalence of slecp complaims in PD in comparison with secp complaints in a nomal population, and assessed whether nocturnal panic attacks and comorbid depression could account fot sleep complaints in PD. Seventy PD pationts and 70 healthy controls were asked about their subjective scop chancteristics by ment of tho Sleep-Wake Expertence list, which asscsess slep/atousal complants over a 24 -hour period, in the past three months. Sixty-seren percent of the PD patients repotted sleep complaints, compared to $20 \%$ of the controls. Seventy-seven percent of the PD parients with comorbid depression and/or nocturnal panic artacks reported sleep 
complaints versus $53 \%$ of the prye PD patients. We conchuded that both noctumal panic attacks and comorbid deptession only pattally accounted for the higher prevalence of sleep complaints in PD: also prry PD patients without noctumal panic and without depression suffered mone frequently from slep disturbances than healthy controls.

Cbater 7 describes a study on the predictive value of a specific subscale (BloodInjury phobia) of the Fear Questionnaire (FQ) for reament ourcome in PD. In 1995 an intriguing finding was reported by Slape et al. They found that blood-injury phobia scores on the $\mathbb{F Q}$ were negatively correlated with drug treatmentoutcome in PD. We assessed 61 PD patients by means of a trectospective chart analysis at baseline and after 12 weeks of SSRL-treatment. Response was defined as absence of panic attacks and/or a reduction of at least $50 \%$ on the FQ Agoraphobia subscale. Nonresponse was defined as the continued presence of panic attacks. Twenty (32\%) pationts were found to be nonresponders. Fifty-five percent of the nontesponders had a high score (cutof: $=20$ ) on the FQ Blood-Injury subscale. "This was only the case for $19.5 \%$ of the responders group $(\mathrm{p}=.008)$. like Slaxp et al., we conchuded that the presence of comorbid blood-injury related phobic symptoms ncgatively affects treatment for $P D$ and agoraphobia.

Section III concludes a series of clinical studies. Chapher 8 describes an experimental study using the $\mathrm{CO}_{2}$ paradigm. To date, $\mathrm{CO}_{2}$ challenge tests in PD patients focused on anxiety as the sole outcome measure. The aim of this study was to assess affectiwe symptoms in addition to anxiety in a sample of PD patients with and without depression. A gas mixture of $35 \%$ CO and $65 \%$ O2, known to provoke panic in PD patients, was administeted to $25 \mathrm{PD}$ patients. Nine of these had a comorbid (current or lifetime) depression and 16 patients did not meet criteria for dopression. At bascline, and immediately after the challenge, subjects were assessed on a list of panic symptoms, an adapted Profile of Mood States regatding aggtessive and depressive feelings, and visual analogue scales of aggression and depression. All patients reported an increase in anxiety symptoms. PD patients with comorbid depression showed a significantly highet increase on both aggression and dapression than did nondepressed PD patients. These findings suggest that a comorbio depression in $\mathrm{PD}$ is related to both anxicty and other affective symproms in response ro a $\mathrm{CO}_{2}$ challenge. Besides its known panicogenic effects, this $\mathrm{CO}_{2}$ challenge also demonstrates depressogenic and aggressogenic affects, dependent on the comorbid disonder present.

Secton IV goes beyond the empirics and attempts to retlect on the interface between anxiety and depression from a diferent perspective. Cowter 9 provides a conceptual approach to the relationship berween anxiety and depressive 
disorders, without questioning the validity of nosological diagnoses. It starts with an overvicw of current assessment procedures and instruments for anxiety and depression, and reviews the prevalence of comorbidity between anxiety disorders and depressive disorders. The remainder of this final chapter reflects on the concepts of anxicty and depression themselves, and the logical relationships that may follow from their meaning. Our conceptual inquiry into the nature of emotions, focused on fear and sadness as supposed nomal counterparts of patbolagical anxiety and depression. This followed the conceptualization of Spinoza, as described in 1677 in his book "Ethics". We provide a perspective in which it is assumed that anxiety and depression are features on a continuous affective spectrum, with no clear overlap. Another framework shortly hinted at in this chapter is the field of evolutionary affective neuroscience, where emotions are conceived of as adaptive functions that have emerged from brain processes because emotions maximized chances for survival.

In the introduction of this thesis, reference was made to multiple meanings of the term 'interface'. Among its meanings were a boundary between two things, but also an overlap, and interaction between two things. An example of the 'boundary' interpretation was seen in the study on suicidal ideation in panic disorder patients. It was shown that pure panic disorder patients without comorbid disorders did not report making suicide plans more frequently, nor did they report more suicide attenpts than controls. It is known that depression predisposes to suicide. Supposedly, only after 'crossing the boundary" with depression, PD patients would also have a higher risk for suicide. But without comorbid depression, there is no increased risk for suicide in PD patients. An example of the 'overlap' interpretation could be inferred from the study on sleep complaints in PD patients. It was shown that the complaints of sleep disturbances in PD parients could not only be attributed to nocturnal panic attacks or a comorbid depression. Sleep complaints can be supposed to be a symptom that overlaps PD and depression. The meaning of interface, being 'interaction", seems appropriate to reflect the results of the other studies discussed here. For example, the chapters on depression in PD and OCD, both showed an impact of comorbid depressive disorder on symprom severity, and treatment outcome for the index anxiety disorder. This meaning of interface, however, does not rule out a 'boundary' or 'overlap' interpretarion, since two separate disorders might just as well influence one another. Aso, overlapping disorders may interact in several ways, eg. on treatment outcome.

In conclusion, anxiety and depressive disorders share a number of clinical feanures, they may even belong to the same spectrum. Assessing comorbidity is 
important, in disentangling core feantes from confounders, and in predicting

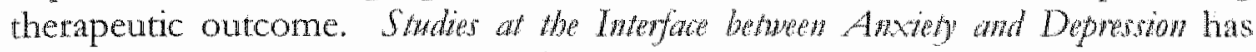
demonstrated that in order to evaluate comorbidity it is essential to empirically assess both 'boundary' and 'overlapping" phenomena of symproms of anxiety and depression. 



\section{SAMENVATTING EN CONCLUSIE}

Het veelvuldig gelijktijdig voorkomen van angst en depressie in de klinische praktijk vormde de aanleiding voor dit proefschrift. Verschillende studies werden uitgevoerd in het grensgebied tussen angststoomissen en depressieve stoornissen, en rond aanverwante onderwerpen als suicidaliteit en slaapklachten.

Na cen voonword $I$ in de Inteddude Sutie geeft boofdrtuk 2 cen overzicht van bevolkingsstudies met betrekking tot prevalentie, demografische kenmerken, risicofactoren, natuurijk beloop en comorbiditeit van de DSM-IV angststoomissen. De geschatte lifetime prevalentic van alle angststoomissen is $25 \%$, vergeleken met ongeveer $17 \%$ voor depressieve stoomissen in de populatie. Van alle angststoomissen komen de sociale fobic en de specifieke fobie het meest voot (11-12\%). De prevalenties van de andere angststoomissen zijn: panielstoomis met of zonder agotafobie $2 \%$, obsessief-compulsieve stoornis (dwangstoornis) 2-3\%, gegeneraliseerde angststoornis $5 \%$, cn ongeveer $7 \%$ van de populatic zou een posttraumatische stress stoomis kunnen ontwikkelen. Vanwege diverse factoren zoals selectiebias, emst van de symptomen, gebruikte diagnostische criteria, en gebrukte meecinstrumenten in de verschillende studies is terughoudendheid gebolen bij interptetatic van deze epidemiologische data.

Sectie I begint de beschrijving van de empirische studies met gegevens over comorbiditeit en behandelaspecten van comorbide depressic cu angststoomissen. Hoofdste 3 bicdt cen literatuuroverzicht van de comorbiditeitsgegevens van paniekstoomis en depressic. Daamast wordt cen retrospectieve studie bij patiènten mer ecn panielstoornis beschreven. Hocwel de panickstoomis niet de meest voorkomende angststoomis is, wotd de\%e in de klinische praktijk wel veelvuldig gezicn, met nane vanwege de forse beperkingen in het dagelijlss leven waarmee patienten mot deze stoornis to maken krijgen. Het voorkomen van comorbide depressic bij patiënten met een paniekstoomis werd onderzocht, teneinde zicht te krijgen op kinisehe kenmerken en invloed van de comorbiditeit op de behandeling. Van 160 patiënten met een paniekstoornis bleek $30 \%$ eveneens te voldoen ana de criteria voor cen gelijktijdige depressieve stootnis of dysthyme. De groep paniekpatiënten met een depressie was significant ouder dan de nictdepressieve groep, en meldden enstiger angst symptomen. Beide groepen verbeterden in dezelfde mate met een gecombinecte farmacologische en 
gedragstherapeutische behandeling, zoals bleek uit een afname op gebruikte psychomerrische schalen. Deze uitkomsten zijn consistent met een theoretisch model waarin angststoomissen (in dit geval paniekstoornis) predisponeren tot depressie.

Howfstuk 4 handelt over de comorbiditeit van de dwangstoomis met depressie, en de betekenis van een comorbide depressie voor het behandelresultaat van de dwangstoonis. Et werd een retrospectief onderzoek gedaan naar de baseline gegevens van 120 pariènten met dwangstoornis en gegevens van 72 patienten na behandeling. Ruim ecn derde $(37 \%)$ van de dwangstoomis patiënten bleek tevens depressief bij aanmelding. De ernst van de dwangsymptomen verschilde bij annvang niet tussen depressieve en niet-depressieve patienten, op de algemene angst maten waren de depressieve patiënten wel ernstiger aangedaan dan de niet-depressieve. Zowel depressieve als niet-depressieve dwangpatiërnten reageerden goed op de behandeling, zoals bleek uit de metingen van depressieve-, dwang- en algemene angstklachten. Echter, een comorbide depressie bleek toch een negatief effect te hebben op de behandeling, de verbetering bij deze groep was minder groot dan bij de niet- depressieve patiëntengroep, op de meeste onderzoeksparameters. Bovendien, tenwil beide groepen OCD patiënten bij aanvang een gelijke etnst van de dwang lieten zien, na behandeling bleek het eindresultaat voor de depressieve patiënten minder gunstig dan voor de niet-depressieven. Deze bevindingen benadnikken het belang van het herkennen en diagnostiseren wan comorbide aandoeningen bij OCD, vanwege hun invloed op de behandeling.

Sectie II bevat verslagen van gerelateerde fenomenen bij de paniekstoomis. Hoofdsthk 5 gaat in op suicidaliteit in patiënten met paniekstoomis. In deze studie werd alle DSM-IV as I en as II parhologie zorgvuldig geëxcludeerd, om een goed beeld te kunnen krijgen van de mate waarin 'pwre' paniekstoornis vermonootdelijk zou zijn voor de in cerdere studies gemelde verhoogde kans op suicide in deze groep. Viffrig prre paniekstoomis patiënten (met of zonder agotafobic) werden vergeleken met 50 gezonde, op leeftijd en geslacht gematchte vrijwilligers. Het bleek dat pure paniekstoomis parienten vaker dan do gezonde controlegroep gepreoccupeerd waren met de dood in het algemeen, en bovendien vaker een passicve doodswens te kennen gaven. Echter, panickpatiënten hadden niet vaker dan de controles zelfmoordgedachten, zelfmoordplannen of meer zelfmoordpogingen ondernomen. Wij concludeerden hieruit dat de paniekstoomis alleen geen aanleiding geeft tot een hoger suicide risico. Door het zorgvuldig uitsluiten van comorbide stoornissen, werd angetoond dat het voorheen gerapporteerde verhoogd suicide risico vermoedelijk te wijten is an (in de praktijk vaak vootkomende) comorbicle stoomissen. 
Hoofistate 6 bespreekt het verband tussen shapklachten en paniekstoomys. In dit onderzoek werd nagegaan hoe vaak slaapklachton vootkomen bij patienten met een paniekstoornis in vergelijking met een gezonde controlegtocp. Aan 70 paniekpatiënten en 70 gezonden werd gevragd nat hun subjectieve slaapbeleving, met behulp van een vragenlijst, de Slap-Wak Ervaringen Lijst (SWEL), die de slaap-wak beleving over een vol etmaal bestrijkt, in de afgelopen 3 maanden. Zevenenzestig procent van de paniek patiënten tegenover $20 \%$ van de gezonden rapporteerden slapklachten. In de groep paniek patiënten had $77 \%$ van de patiënten met comorbide depressic en/of nachtelijke paniekanvallen slaapklachten, tegenover $53 \%$ van de pmo paniek patiënten. Deze verschillen waten significant. Hieruit werd geconcludeerd dat comorbide depressie en nachtelije panichaanvallen slechts gedeeltelijk verantwoordelijk zijn voor de verhoogde prevalentic van slaapklachten bij patiënten met paniekstoomis: ook pure paniek patiënten, dus zonder nachtelijke paniek en zonder depressie, hebben vaker en meer last van slaapklachten dan controle personen.

Hoofdstuk 7 is een verslag van een teplicatiestudie natr de voorspellende waarde van een hoge 'bloed-letsel-fobie' score op de Fear Qucstionnaire (FQ) voor behandelresultaat van paniekstoornis. In 1995 werd een opmerkelijke studie gepubliceerd door Slaap et al. Dexe onderzockers meldden dat scotes op de FQ bloed-letsel fobie sublijst negatief correleerden met het medicamenteuze behandelingsresultat van een paniekstoomis. In onze studie werden de gegevens van 61 paniek patiënten geanalyseerd, ten tijde van anmolding en na 12 weken behandeling met cen SSRI. Response was gedefinicerd als een afwezigheid van paniekaanvallen en/of een afname van tenminste $50 \%$ op de agorafobische vermijding, gemeten met de FQ agorafobie subschaal. Nonresponse werd gedefinieerd door het persisteren van paniekanvallen. Twintig (32\%) patiënten waren nonresponders. Viffenviffug procent van deze nonresponders had een hoge score (boven de cutoff van 20) op de Ii(2) bloedletsel subschaal, tegenover $19,5 \%$ van de responders $(p=.008)$. In navolging van Slaap et al. concludecrden wij dat comorbide bloed-letsel fobische sympromen de behandeling van paniekstoornis negatief beinvloeden.

Sectie III beshit de serie klinische studies. Hoofdstuk 8 beschrift ect experimenteel onderzoek dat gebruik maakt van de $\mathrm{CO}_{2}$ provocatic methode. "Tot nu toe hebben studies die gebruik maken van deze methode rich voornamelijk gericht op het meten van angst als uitkomstmat. Het docl van dit onderzoek was om naast angst ook andere affectieve symptomen te meten, in een groep paniekpatienten met en zonder comorbide depressic. Fien gasmengsel van $35 \% \quad \mathrm{CO}_{2}$ en $65 \% \quad \mathrm{O}$, warvan bekend is dat het panieksymptomen kan oproepen in patiënten met ceri paniekstoomis, werd toegediend aan 25 panick patiënten. Negen van deze groep panick patiënten 
hadden een comorbide depressie (geliktijdig of in de voorgeschiedenis), 16 paticnten hadden geen depressie (gehad). Zowel voor, als vlak na de provocatie test, vulden de patienten een vragenlijst met panieksymptomen in, cen lijst met stemmings-items, en visuecl-analoge schalen met betrekking tot angst, depressicve en agressieve gevoelens. Alle patienten meldden verhoogde angstsymptomen na de $\mathrm{CO}_{2}$ test, paniekpatiënten met een depressie vertoonden een significant hogere stijging op depressieve en agressieve symptomen na de test dan niet-deptessieve paniek patiënten. Deze uitkomsten suggereren dat en comorbide depressie in paniekpatiënten gerelateerd is aan zowel angst- als agressicve en depressieve reacties op een $\mathrm{CO}_{2}$ test. Deze provocatie methode bijkt naast paniek-uitlokkende effecten tevens depressieve en agressieve gevoelens te kunnen uitlokken bij paniek patiënten in afhankelijkheid van de comorbide stoornis.

Secki IV gaat voorbij de empirie en probeert het grensgebied tussen angst en depressic vanuit een ander perspectief te benaderen. Hooflstuk 9 biedt een conceptuele benadering van de relatie tussen angststoomissen en depressie, de validiteit van de nosologie buiten beschouwing latend. Dit hoofdstuk begint. met een overzicht van enkele veel gebruikte dimensionale en categoriale meetinstrumenten voor angst en depressie, en geeft een overzicht van de comorbiditeits cijfers van angst en depressie. Vervolgens wordt nader ingegaan op de betekenis van de concepten angst en depressie zelf, en de logische verbanden die daaruit zouden kunnen voortvloeien. Onze conceptuele zoektocht naar de aard van emoties, richt zich op vrees en droetheid, als veronderstelde nomale tegenhangers van patbologisobe angst en depressic. Wij volgen de conceptualisatie volgens Spinoza, zoals beschreven in zijn "Exhica" uit 1677 . Wij schetsen een perspectief waarin wordt aangenomen dat angst en depressic uitingen zijn op een continu affectief spectrum, zonder duidelijke overlap. Fen ander kader waaran zijdelings gerefereerd wordt in dit hoofdstuk is het terrein van de evolutionaire affectieve neurowetenschappen, watrin emotics beschouwd worden als adaptieve functies die zich hebben onrwikkeld uit hersenprocessen en waar gesteld wordt dat emoties uiteindelijk overlevingskansen vergrootten.

In het voorwoord van dit proefschrift werd gerefereerd aan de meervoudige betekenissen van het begrip 'interface' zoals gebruikt in de titel. Onder andere, betckende 'interface' een 'grenswlak', en ook kon een 'overlap' of 'interactie' worden bedoeld. In dit proesschrift zagen we een voorbeeld van de 'gtensvlak" betekenis in de studie naar suicidaliteit bij paniek patiënten. Hier werd angetoond dat pure paniek patiënten zonder comorbide stoomissen niet vaker dan gezonde controle personen melding makten van suicideplannen of suicidepogingen. Het is bekend dat depressie tot suicicle kan leiden. Blijkbaar is 
het zo dat panickpatienten pas na het 'oversteken van de grens' met depressic een verhoogd suiciderisico hebben. Maar zonder deze comorbiditeir, is er geen verhoogd suiciderisico.

Een voorbeeld van de 'overlap' interpretatie van 'interface" werd gezien in de studie naar slaapklachten bij patiënten met een paniekstoomis. Dit onderzock wees uit dat comorbide depressie en nachtelijke panickaanvallen bijdragen tor het voorkomen wan slaapklachten, maar onvoldoende zijn on alle slaapklachten bij pantek patienten te verklaten. Slaapklachten kunnen beschouwd worden als een overlappend symptoom bij zowel paniek als depressie. De latste betekenis ran 'interface, zijnde 'interactie', is tocpasbar: op de overige beschreven studies. Bijvoorbeeld, de hoofdstukken over comorbide depressie in paniekstoomis en OCD lieten zien dat de aanwerigheid van de depressie een duidelijke invloed had op de ernst van de angstsymptomen, en op het behandelingstesultat wan de betreffende angststoomis. Maat dit wil niet zeggen dat deze lantste betekenis van 'interface' de beide anderen uit sluit. Twee onathankelijke stoomissen kunnen immers evengoed interactie geven, en zo kunnen ook twee elkaar overlappende aandoeningen op verschillende manieren wederzijdse invloed uitoefenen.

Concluderend, angststoomissen en depressieve stoornissen hebben cen aantal klinische kenmerken gemeenschappelijk. Ze zouden zels tor een zelfde spectrum kunnen behoren. Het beoordelen en diagnostiseren van comorbiditeit is van wezenlijk belang om kernsymptomen van ruis te onderscheiden, en om goede vootspellingen mogelijk te maken van behandel effecten. Sindies at the interface betwen anxiety and depression heeft aangetoond dat het essentieel is om zowel de grensgebieden als de overtappende terrcinen empirisch te toetsen, teneinde zo het gehele spectrum te kunnen beoordelen van angst en depressic. 



\section{DANKWOORD}

Uiteraard wil ik als eerste mijn promotor professor Eric Griez bedanken. Ik heb veel van u geleetd, en veel aan u te danken. Al vanaf ons eerste contact in het sollicitatiegesprek in 1995 hebt u me gestimuleerd on nast het klinisch werk op de afdeling, vooral ook ondetzoek te doen en gewoon door te zerten. Onderzoek met de nadruk op haalbaarheid, naast relevantie en uitroerbaatheid. Dat u erin bleef geloven heeft mij uiteindelijk tot hier gebracht, hiervoor mijn oprechte dank. Overigens, het feit dat ik niet tutoyeer en u nog steeds als professor aanspreek is slechts een uiting van respect. Dank voor de uren gezamenlijke arbeid die geleid hebben tot het volbrengen van dere tak.

Ook mijn copromotor, Koen Schruers, wil ik hartelijk danken voor zijn steun en praktische begeleiding bij de diverse onderdelen van dit proefschrift, de studies en artikelen. Beste Koen, je was altijd beschikbaar voor hulp en advies, geduldig en motiverend. Mede dankzij jou is dit proefschtift er gekomen, en moet ik dan toch maar de 'ultieme exposure' ondergaan.

Op vele onderdelen heb ik ook grote hulp ervaren wan Nicolette Bongacts en Inge Leclaire, research-verpleegkundigen, die uitgebreid assistentic hebben verleend bij het verzamelen van data en waar nodig het achterhalen van ontbrekende gegevens. Mark Ahsmann, documentalist, heel veel dank voor je hulp bij het opvragen van zovele artikelen. Medewerkers wan de zorgadministratie van Vijverdal, ook jullie wil ik bedanken voor het diverse malen verzamelen van stapels reeds gearchiveerde dossiers waaruit nog aanvullencle patientengegevens nodig waren.

Ook andere co-auteurs bij de verschillende onderzocken wil ik bedanken, Hagen Büchold, voor de grondlegging wan de studic nat predictoren, Tineke KJassen voot haar bijdrage aan de challenge studie, Rob van Diest voor zijn statistische adviezen en zijn inhoudelijke bijdrage aan de slapp-studic.

Ook de diverse studenten/stagiaites die mee hebben geholpen met het uitvoeren van verschillende onderzoeken wil ik hicr hatelijk bedanken, zoals Femmie Kruizinga, Janneke Rikken en Ine Docters van Leeurwen. Jullie hebben me veel 'veldwerk' wit handen genomen.

Uiteraard gat ook mijn dank naar alle patienten, wicns 'gegevens', klinisch gezegd, wiens subjectief ervaren 'ellende' ik mocht gebruiken voor deze onderzocken, en ook dank aan alle gezonde vrijwilligers dic declgenomen hebben aan verschillende onderzocken wat referenticwatden van cen 'controlegroep' waren vereist. 
Ale andere medewerkers van onze afdeling het Academisch Angst Centrum hebben ook bijgednagen aan de totstandkoming van dit proefschrift. Julien Pecters, als coördinator van het AAC heb je op diverse fronten geholpen, door het aandragen van de benodigde administratieve gegevens die dankzij jouw systeem alrijd traceerbaar waren, door adviezen, of tijdelijke herverdeling van klinische taken in de periode dat ik dat echt even nodig had.

Van alle klinische medewerkers van het $A \Lambda C$, onze therapeuten, heb ik ook in alle periodes van voor en tegenspoed steur mogen ervaren. Ik heb veel bewondering voor jullie werk als gedragstherapeut, het resultaat dat ook bij gecompliceerde (comorbicle) patiënten behaald kan worden dankzij jullie professioncle en persoonlijke kwaliteiten, werd ook beschreven in enkele studies. Ik wil jullie bijzonder bedanken voot de fijne samenwerking, Marjan Böhm, Louis Kersten, Rudy Nijssen en François Wilms.

De recentere aanwinsten wan het AAC Marlies van Duinen, Lies Goossens, Klara de Cort, Jaimic Luermans, Nicole Theunissen, Femmie Kruizinga, Cindy Debie, Mayke Jilderda, Rob Wertz en Henri Smeets, ook jullie bedank ik voor jullie bijdrage aan de prettige sfeer op het AAC.

Dan zijn er in die lange periode dat ik op het $A A C$ verblijf natuurlijk ook diverse mensen vertrokken, die ik hicr toch wil bedanken. Kees Verburg, in mijn beginperiode bezig met zijn promoticonderzock, Nicole van Beek, recent gepromoveerd, Annet Hofman, Henk Pols, arts-onderzoeker die ik zeer waatdeer, Jaap Meijer, afdelingspsychiater uit mijn beginuren, helaas heb ik met jou maar kort samengewerkt, ik had vecl van je kunnen leren.

Ook onze secretaresses ben ik dankbar voor hun steun, Mariette Ubaghs en Manuela Walraeven, onmisbare krachten van het AAC, mijn dank dat jullie me in de periodes dat ik aan het schrijven was waar nodig en mogelijk wat uit de wind hielden, en in goed overleg mijn intake-agenda planden.

Ook de secretaresses 'van bowen', Leni Noteborn als mijn eerste a anspreckpunt, bedankt voor al je hulp en goede zorgen, je werk als sccretaresse van professor Gricz is van onschatbare waarde, ook voor de promovendi! Jolanda Koch, Ine Kusters, Lea Esten en Danielle Vanderschuren, bedankt roor jullie hulp.

lederen van het $\triangle A C$, dic me bij tijden met rust liet als ik me achter mijn po verschanste en de deut sloot, en me bij tijden verplichtte om toch even koffie te komen drinken, bedankt: vanaf nu stat mijn deur open en zal ik me wat socialer gann gedngen, ik ben er weer.

Ook mijn werkgever, Vijwerdal, wil ik hier bijzonder bedanken. Enkele personen die ik hier wil noemen zijn onze directeur Chris Breemer ter Stege, Marten Verkerk, Geert de Booij en zijn roorganger Olga Sollet. Hoewel ik een klinische aanstelling heb, was ik in de gelegenheid om naast de patiëntenzorg 
ook wetenschappelijk onderzoek te doen bij onze patiëntenpopulatie. $\mathrm{Al}$ is het geen gemakkelijke combinatie, ik heb het als een verrijking etvaten voor het klinisch werk om patiëntenzorg met onderzock te verweven. En hoewel deze constructie niet was geformaliseerd, heb il mij impliciet wel gesteund gevoeld door mijn werkgever Vijverdal. Ook de onderwijstak wa het Teaching Hospital had hierin zijn plaats, derdejaars studenten Geneeskunde, Geneeskunde studenten die roor een wetenschaps-stage het AAC uitkozen, stagiaires Geestelijke Gezondheidskunde die zowel hun klinische als onderzoeksstage op onze afdeling deden, en de vele co-assistenten die ik ontmoette, ook hun aanwezigheid was stimulerend.

Eindelijk kom ik bij mijn paranimfen, Marie-Jeanne Haack en Ann Goorts, mijn zeer gewaardeerde en lieve collega's. Jullie hebben een heel belangrijk andeel gehad, jullie wil ik in het bijzonder bedanken voor alles wat jullie hebben gedaan, met name het afgelopen voor mij nogal stresserend half jaat, hebben jullie een deel van mijn klinische taken overgenomen zodat ik dit proefschrift kon afronden, bedankt! En Abdul Dandachi, als extra kracht op het $A A C$, ook jij hebt een deel van mijn patiëntenzorg verlicht, bedankt voot de samenwerking!

Tot slot, mijn dierbaren, familie en gezin, zonder jullie zou niets zin hebben. Mijn moeder, jij hebr me altijd gesteund in de keuzes die ik makte, altijd betrokken, optimistisch en motiverend. Mijn vader, ook van jou kreeg ik alle ruimte, dank voor alles. De laatste jaren ben je zick, maar ik weet dat je altijd achter me staat.

Harm en Anke, Bert en Els, en jullie kinderen, ik ben jullie dankbaar voor jullie steun. Al zien we elkaar weing, het is alrijd goed, jullie zijn mijn altijd trouwe achterban.

Schoonmoeder, ook u bedankt voor alle hulp!

Lieve Eric, jouw andeel is moeilijk te beschrijven. Je hebt me altrijd gesteund en gestimuleerd, zij het langere rijd van op grote afstand, goed dat je tentig bent. Je onuitputtelike energie, optimisme en ambitic bewonder ik, je rust en geduld eveneens. Wat verschillen we, wat heb ik je nodig.

Lieve kinderen, Diederick, Henrieke en Johanne, ik ben klat met het boekje. Jasjes aan, we gan fietsen! 



\section{CURRICULUM VITAE}

Thea Overbeek werd geboren op 11 maart 1959 te Gendringen. Zij volgde her Atheneum-A an de Protestants-Christelijke Scholengemeenschap te Doetinchem van 1971 tot 1977. Van 1977 tot 1981 studeerde zij Psychologic aan de Katholieke Universiteit van Nijmegen en sloot dit af met het kandidaatsexamen. Na een colloquium doctum voor natuur-en scheikunde re hebben behaald werd zij in 1981 toegelaten tor de studie Genceskunde, eveneens aan de Katholieke Universiteit van Nijmegen en behaalde in 1988 het arts-examen. Hierna heeft zij in verschillende ziekenhuizen (Nieuwegein, Delft, Utrecht) gewerkt als arts-assistent pathologie, tot zij in 1993 overstapte naar de psychiatrie. Zij werkte als arts-assistent psychiarric in een ambulante setting to Weert en als afdelingsarts in de Bernard Lievegoed Kliniek te Bilthoven. Sinds 1995 is zij werkzaam als afdelingsarts op het Academisch Angst Centrum (AAC) te Maastricht, een geacademiseerde afdeling van het Psycho-Medisch Strcekcentrum Vijverdal, tevens Teaching Hospital. Zij combinecrde haar klinische werkzaamheden met de wetenschappelijke studies die in dit proefschrift resulteerden. 



\section{Publications}

Griez E and Overbeek T. Comorbidity of Depression and Anxiety. In: Hong A, Anseau M and van Praag HM (Eds). Depresion: Neurobrobogiah, P.jchopathalogial and Therapentic Adrawes. Wiley \& Sons, Chichester, 1997. pp $41-57$

Overbeek T, Rikken J, Schruets $K$ and Griez E. Sucidal idcation in panic disorder patients. J Nem Ment Dis 1998: 186, 577-580

Schruers K, Pols H, Overbeck $T$ and Griez E. 10 Microg C.K-4 premedication and $35 \%$ CO2 challenge in healthy volunteers. Prog Nernopsychophamacol Bio/ Psydiatry 2000; 24, 409-418

Schruers K, Klaassen T, Pols H, Overbeek T, Deutz N and Griez E. Effects of tryptophan depletion on carbon dioxide provoked panic in panic disorder patients. Psybratuy Res 2000: 93, 179-187

Schruers K, Caycedo N, Overbeek T Buchold H, Bourin M and Griez. E. Effects of low-dose cholecystokinin on respiratory function in healthy volunteers. Eur Newropsychopharmace/2000: 10, 419-421

Overbeek T, Vermetten E and Griez E. Epidemiology of Anxiety Disorders. In: Griez EJL, Faravelli C. Nutt D and Zohar I (Eds). Amiety Disorders: $A n$ Inimadution to Clanical Management and Resedm. 2001. Wiley \& Sons, Chichester, Pp $3-23$

Overbeck T and Griez E. The Interface between Depression and Anxiety: Comorbidiry and Concepts. To appear in: Gricz Efll, Garavell C, Nutt D and ZoharJ (Eds). Mood Disorders: An Introdwition to Chimol Manowemont and Researb. Wiley \& Sons, Chichester. In press

Schruers $K$, wan Diest $R$, Overbeck $T$ and Griez Li. Acute 1,-5hydroxytryptophan administration inhibits carbon dioxide-induced panic in panic disorder patients. Psychiaty Res. 2002: 113,237-243

Overbeek T, Schruers K, Vermetten $\mathrm{E}$ and Cricz $\mathbb{1}$. Comorbicity of obsessive-compulsive disorder and clepression: prevalence, symptom severtity, and treatment effect. J Clin Psychiany 2002: 63, 1106-1112 
Overbeek T, Buchold H, Schners K and Griez E. Blood-injury related phobic avoidance as predictor of nonresponse to pharmacotherapy in panic disonder with agoraphobia. / Affect Disond 2004: 78, 227-233 